\title{
Can Fitts' Throughput Be A Predictor Of Muscle Fatigue - A Study Based On Metacarpal Gloves?
}

\author{
Sachin Sah \\ ss0191@mix.wvu.edu
}

Follow this and additional works at: https://researchrepository.wvu.edu/etd

Part of the Ergonomics Commons, and the Industrial Engineering Commons

\section{Recommended Citation}

Sah, Sachin, "Can Fitts' Throughput Be A Predictor Of Muscle Fatigue - A Study Based On Metacarpal Gloves?" (2019). Graduate Theses, Dissertations, and Problem Reports. 7409.

https://researchrepository.wvu.edu/etd/7409

This Thesis is protected by copyright and/or related rights. It has been brought to you by the The Research Repository @ WVU with permission from the rights-holder(s). You are free to use this Thesis in any way that is permitted by the copyright and related rights legislation that applies to your use. For other uses you must obtain permission from the rights-holder(s) directly, unless additional rights are indicated by a Creative Commons license in the record and/ or on the work itself. This Thesis has been accepted for inclusion in WVU Graduate Theses, Dissertations, and Problem Reports collection by an authorized administrator of The Research Repository @ WVU. For more information, please contact researchrepository@mail.wvu.edu. 
Can Fitts' Throughput Be A Predictor Of Muscle Fatigue - A Study Based On Metacarpal Gloves?

\title{
Sachin Sah
}

Thesis submitted to the Benjamin M. Statler College of Engineering and Mineral Resources at West Virginia University in partial fulfillment of the requirement for the degree of

$$
\text { Master of Science }
$$

in

Industrial Engineering

Ashish D. Nimbarte, Ph.D., Chair

Eduardo Sosa, Ph.D.

Leily Farrokhvar, Ph.D.

Department of Industrial and Management Systems Engineering

\author{
Morgantown, West Virginia
}

December 2019

Keywords: Metacarpal Gloves; Fitt's Law; Throughput; Muscle Activity Copyright 2019 Sachin Sah 


\section{Abstract \\ Can Fitts' Throughput Be A Predictor Of Muscle Fatigue - A Study Based On Metacarpal Gloves?}

\section{Sachin Sah}

In this study, Fitts' throughput was used to estimate throughput for metacarpal gloves. Fitts' throughput combines speed and accuracy during target transfer/movement tasks into a single performance index. It was hypothesized that the throughput will be affected by the glove condition and it will exhibit a relationship with the physiological response of hand muscles and perceived exertions. Fifteen healthy participants (10 males, 5 females) were recruited for data collection. Each participant performed a series of target transfer tasks using four glove conditions: (1) a pigskin leather (glove 1); (2) a synthetic fiber glove (glove 2); (3) a goat-grain leather glove (glove 3); (4) bare hand. The physiological response of hand muscles was recorded during a separate gripping study. The participants performed 60second static gripping tasks using each glove condition at force levels of $35 \%$ of their maximum gripping strength. Surface electromyography (SEMG) was used to record activation levels of four-hand muscles: (i) Flexor Digitorum Superficialis, (ii) Flexor Carpi Radialis, (iii) Extensor Carpi Radialis Longus, and (iv) Extensor Digitorum. Glove condition had a significant effect on throughput $(p<0.05)$. The highest throughput was observed for bare hand ( $3.17 \mathrm{bits} / \mathrm{s})$, followed by Glove 3 (2.44 bits/s). High throughput signifies high accuracy and low task completion time. Glove 2 and Glove 1 had a similar throughput of 2.34 bits/s. The lowest muscle activation was observed for bare hand (51\%), followed by glove 1 (59\%), glove 2 (60\%) and glove 3 (64\%). A drop in the median frequency of SEMG data, which is an indication of muscle fatigue was significantly affected by the glove condition $(p<0.05)$. The lowest drop was observed for bare hand (9\%), followed by glove $2(17 \%)$, glove $1(18 \%)$ and glove $3(23 \%)$. A similar trend was also observed for perceived exertions. Overall, the results of this study indicate that during gloved exertions, a direct relationship exists between throughput and the physiological response of hand muscles. The Fitts' throughput holds the potential to be used as a performance measure to evaluate and compare different types of gloves. 


\section{Acknowledgements}

I would like to express my sincerest gratitude to my advisor, Dr. Ashish Nimbarte, for providing me the opportunity to further my education and whose continued support, guidance, and encouragement throughout my studies have been truly appreciated and have allowed me to reach this milestone.

I would also like to thank the members of my committee, Dr. Leily Farrokhvar and Dr. Eduardo Sosa, for their invaluable advice and support.

I also wish to thank my colleagues in the Ergonomics laboratory for their assistance, advice, and friendship, which I will always be grateful for.

Finally, I wish to thank my parent, siblings and friends for their constant support and encouragement throughout the years and in my many endeavors. 


\section{Table of Contents}

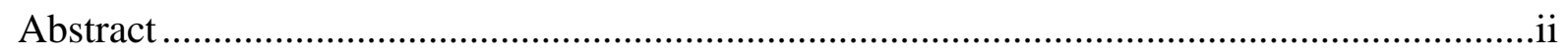

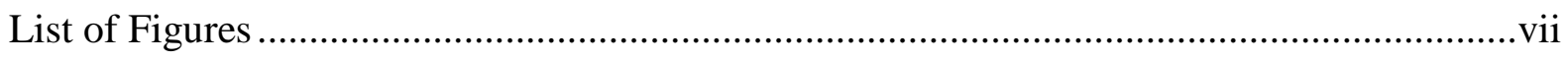

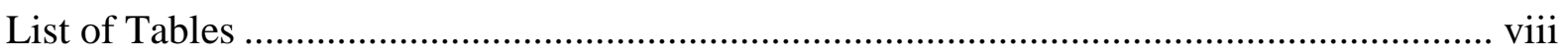

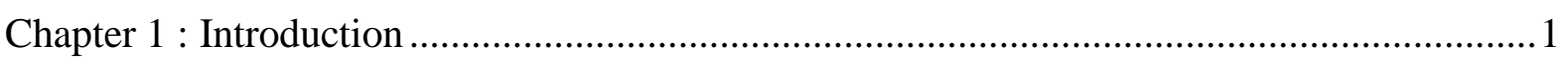

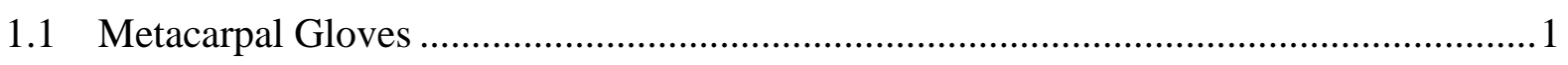

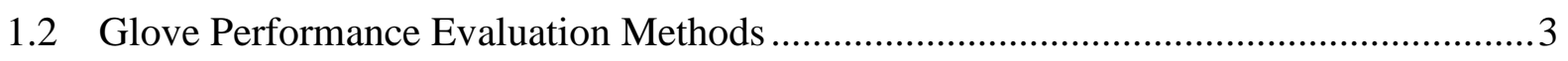

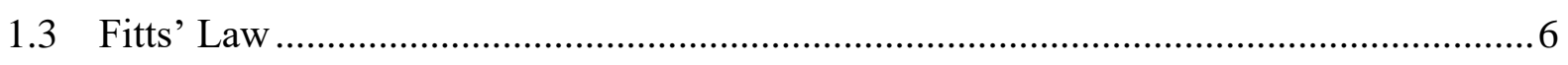

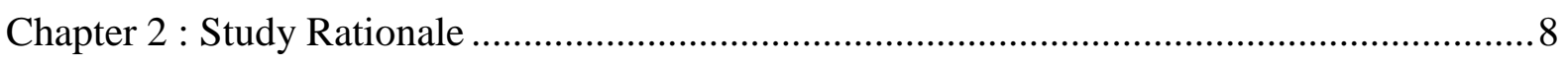

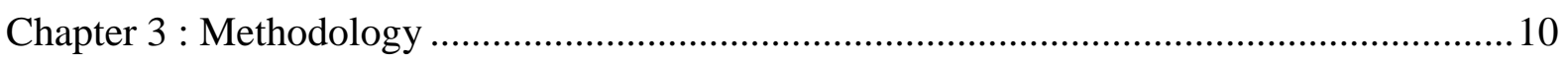



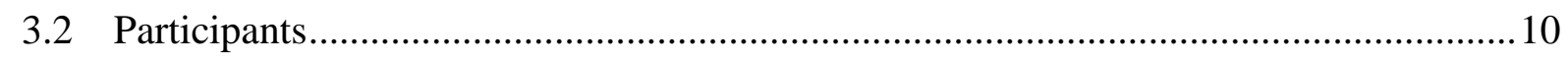

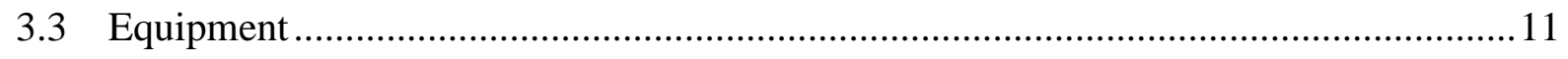

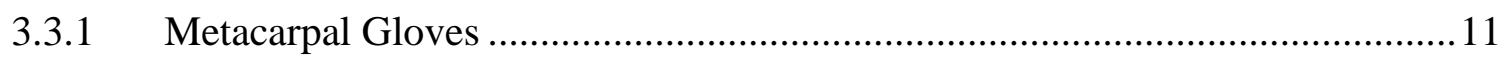

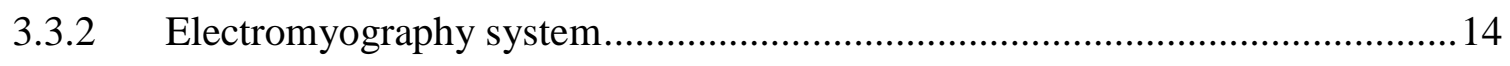

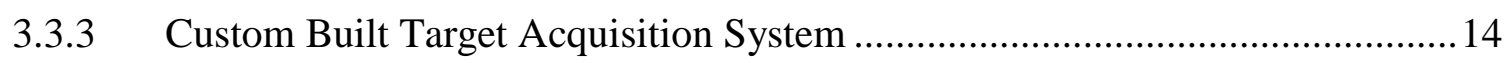

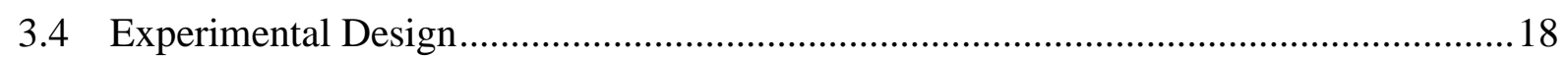

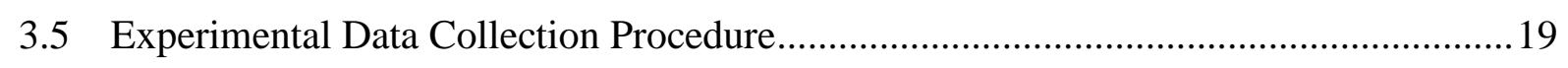

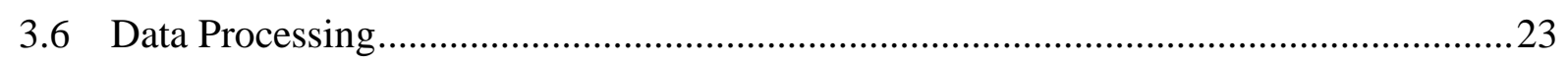

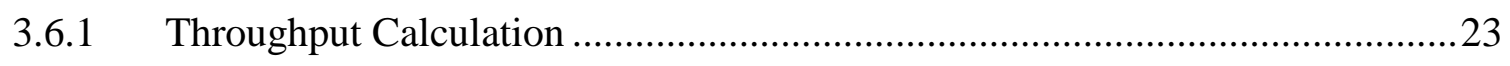

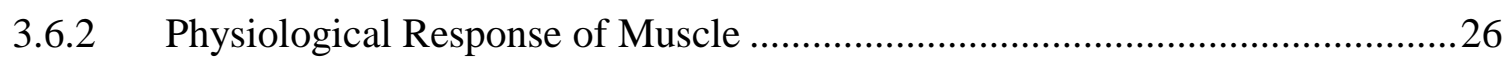

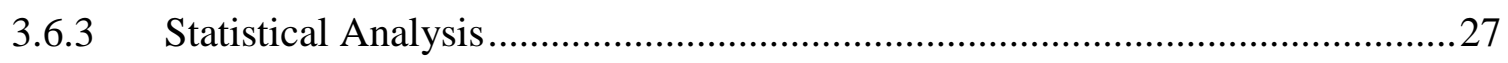

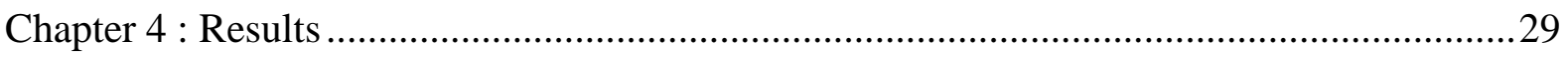




4.2 Throughput

4.3 Effect of Glove Condition on Muscle Activation ......................................................... 30

4.3.1 Muscle activation on Individual Muscle ...................................................... 30

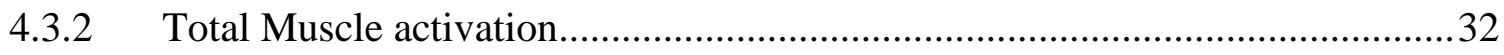



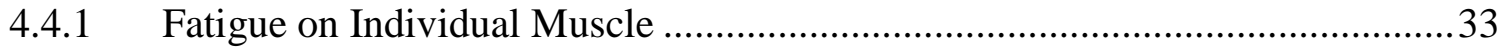

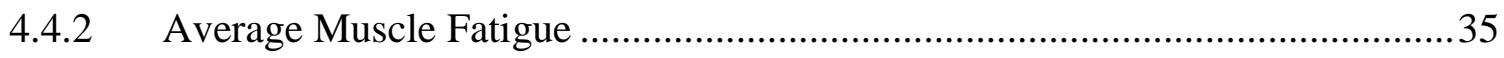

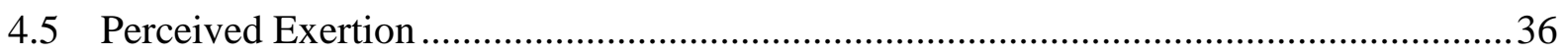

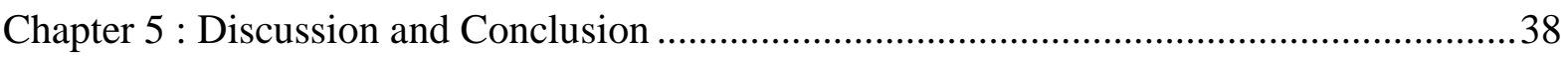

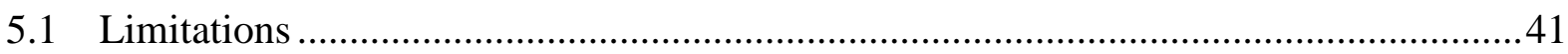

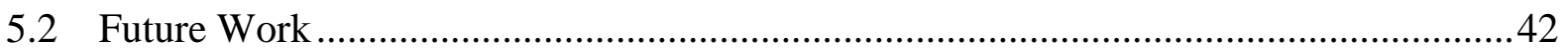

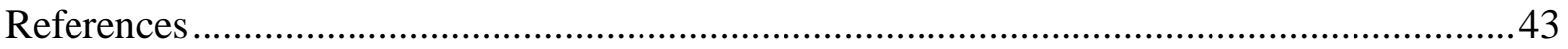

Appendix I: Anthropometric Measurement of Participant ................................................ A

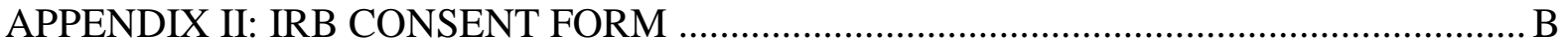

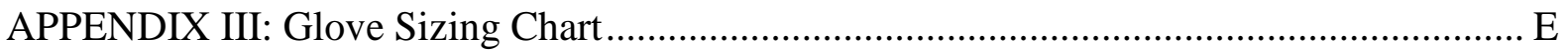

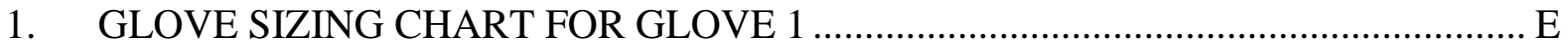

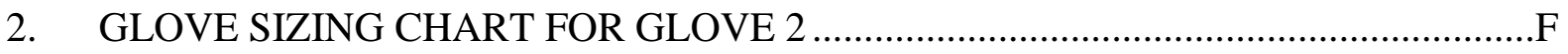

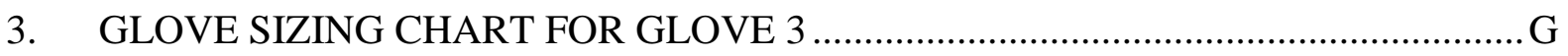

APPENDIX IV: MATLAB Code for Image Processing ....................................................

APPENDIX V: MATLAB Code for MF Calculation.............................................................. J

APPENDIX VI: JMP Result for Normal Quantile Plot of Throughput.................................. L

APPENDIX VII: JMP Result for Normal Quantile Plot of Total NMAV Normality ............. M

APPENDIX VIII: JMP Result for Normal Quantile Plot of Average \% drop in MF.............. N

APPENDIX IX: JMP Result for Normal Quantile Plot Perceived Exertions...........................

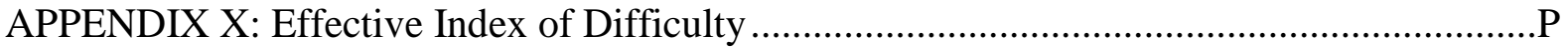

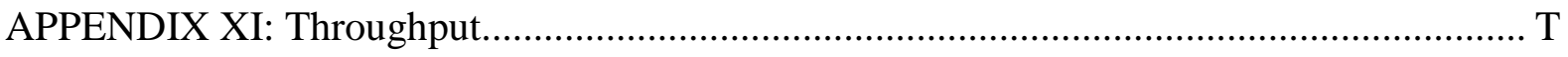

APPENDIX XII: Normalized Mean Absolute Value ........................................................... 
APPENDIX XIII: Percentage Drop in Median Frequency .................................................

APPENDIX XIV: Subjective Assessment of Perceived exertion....................................... CC 


\section{List of Figures}

Figure 1.1: Impact Protection provided by TPR ..........................................................

Figure 1.2: Currently Available Metacarpal Gloves...............................................................2

Figure 1.3: Physical Layout of Fitts' Model ....................................................................... 6

Figure 3.1: Dorsal and Palmar Side of Gloves Tested in This Study .................................... 13

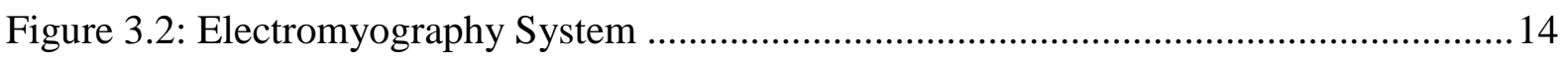

Figure 3.3: Custom Built Target Acquisition Task System ................................................. 16

Figure 3.4: Physical Layout of Target Transfer Task Plate .................................................. 16

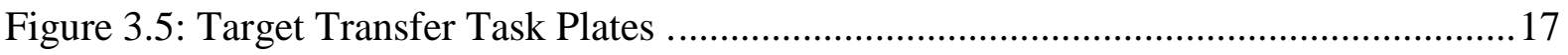

Figure 3.6: Posture and Fingers Used For Throughput Study ............................................... 19

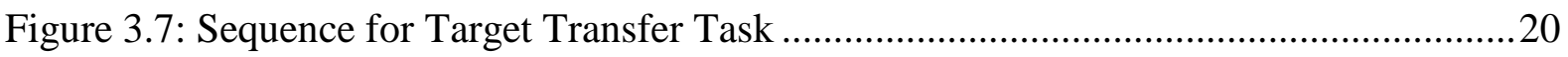

Figure 3.8: Posture and Electrode Placement for Muscle Response Study ............................22

Figure 3.9: Borg's CR-scale of Perceived Exertion .............................................................23

Figure 3.10: Geometry for a Target Transfer Task ...........................................................24



Figure 4.1: Mean and Confidence Interval of Throughput....................................................... 30

Figure 4.2: Mean and Confidence Interval of NMAV for Hand Muscles...............................31

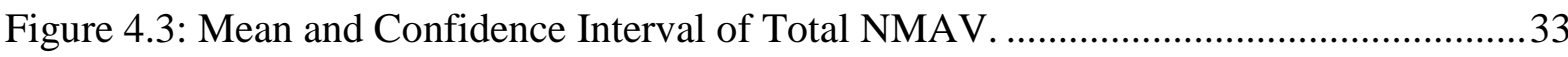

Figure 4.4: Mean and Confidence Interval of \% drop in MF for Hand Muscles...................... 34

Figure 4.5: Mean and Confidence Interval of Average \% drop in MF................................... 36

Figure 4.6: Mean and Confidence Interval of Perceived Exertion....................................... 37 


\section{List of Tables}

Table 3.1: Anthropometric Measurement of Participant ........................................................ 10

Table 3.2: Impact Protection Index of Semi-flexible Hand for Selected Gloves .................... 12

Table 3.3: Series of Layout Design and Their Corresponding ID ........................................ 15

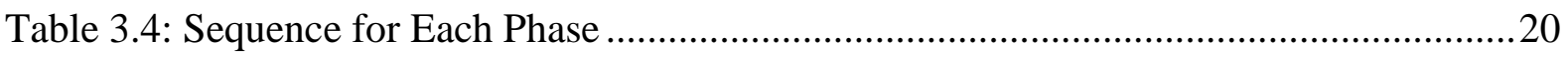

Table 3.5: Lead Position for Electrode Placement .............................................................. 21

Table 4.1: ANOVA and Mean Pairwise Comparison Result of Effective Index of Difficulty29

Table 4.2: ANOVA and Mean Pairwise Comparison Result of Throughput ...........................30

Table 4.3: ANOVA and Mean Pairwise Comparison Result of NMAV for Hand Muscles ... 32

Table 4.4: ANOVA and Mean Pairwise Comparison Result of Total NMAV ......................33

Table 4.5: ANOVA and Mean Pairwise Comparison Result of \% drop in MF for Hand

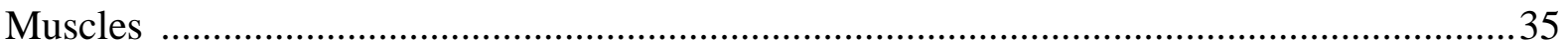

Table 4.6: ANOVA and Mean Pairwise Comparison Result of Average \% drop in MF .......36

Table 4.7: ANOVA and Mean Pairwise Comparison Result of Perceived Exertion ...............37 


\section{Chapter 1: Introduction}

Human hands are the most used body part in the work sector, and they are highly prone to varieties of injuries ranging from small scratches or cuts to major fractures and broken bones. Hand injuries have always been daunting in various occupations including farming, construction, installation and maintenance, and transportation. Data from Occupation Safety and Health Association (OSHA) statistics estimated that the cost of one hand injury varied from $\$ 540$ to $\$ 26,000$ per patient [1]. A US Department of Labor study reported that more than 140,000 workers suffered from hand injuries in 2017, accounting for almost eight percent of all nonfatal workplace injury [2]. According to U.S. Bureau of Labor Statistics report, median lost work days due to hand injuries ranged from 5 to 15 , accumulating to be around 110,000 days annually, and ranked second compared to all injuries reported [3]. The figures from the Department of Labor study also claimed that the risk of hand injury has increased more than two and a half times in 2017.

\subsection{Metacarpal Gloves}

The causes of hand injuries are mainly due to negligence and inappropriate selection of glove. Applying the Hierarchy of Hazard Control system, most of the hand injuries including cut, puncture, abrasion, and fracture can be minimized or eliminated using a proper set of gloves. Therefore, to reduce relatively high number of incidents, workers in many industries are required to wear impact resistant hand protection gloves (also called metacarpal protective gloves) as personal protective equipment. According to a recent OSHA study, the concern of hand injuries could be lowered by $70.9 \%$ with the usage of metacarpal protective gloves [4]. Metacarpal gloves are usually stiffer and bulkier than a conventional glove, which are not provided with any protection. Metacarpal gloves provide more protection to the different types of hand injuries caused by contusion/bruise, crushing, cut/laceration, dislocation, and fracture.

Metacarpal gloves are manufactured with protective panels and ridges of Thermoplastic Rubber (TPR) Adhesion. The hardness of protective molded materials provide coverage to the hand and disperse energy away from the bone under the impact as shown in 
Figure 1.1. Moreover, the elasticity of protective layer offers flexibility and range of motion. The protective panels and ridges of metacarpal gloves are kept down on the fingers, thumbs and back of the hand, while, some of the other models have thick pad [5]. Typically, the material and style of the glove are chosen based on task type and safety requirements. Currently, there are 45 manufacturers in North America producing different metacarpal gloves design that can vary based on protective layer, durability, stiffness, cut resistance, puncture-resistance, abrasion-resistance, and many more. Some of the currently available metacarpal gloves are shown in Figure 1.2.
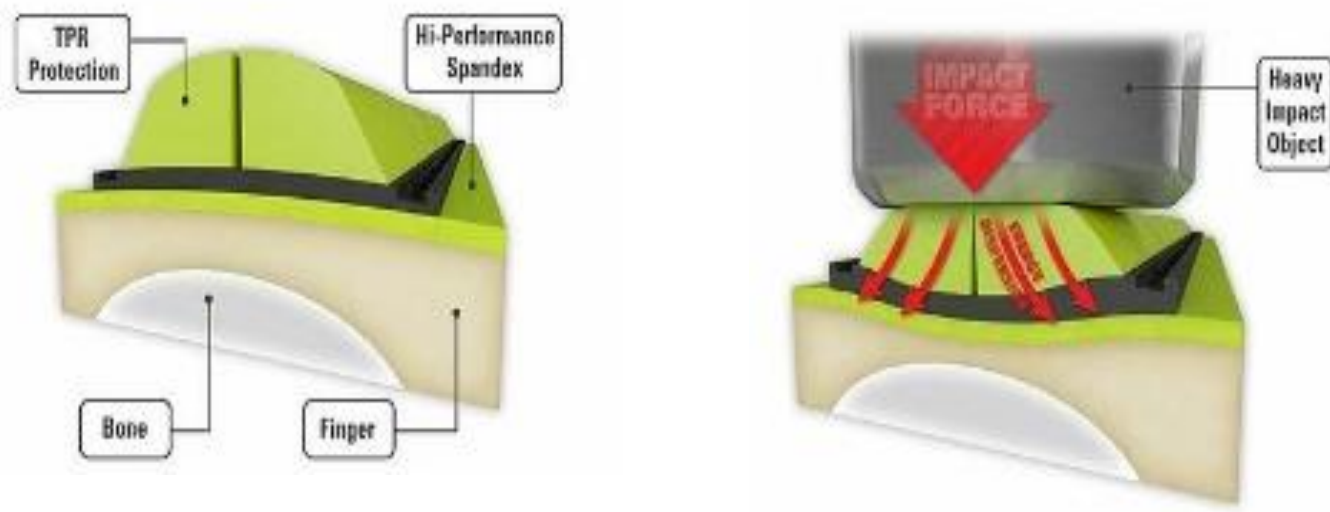

Figure 1.1: Impact Protection provided by TPR .

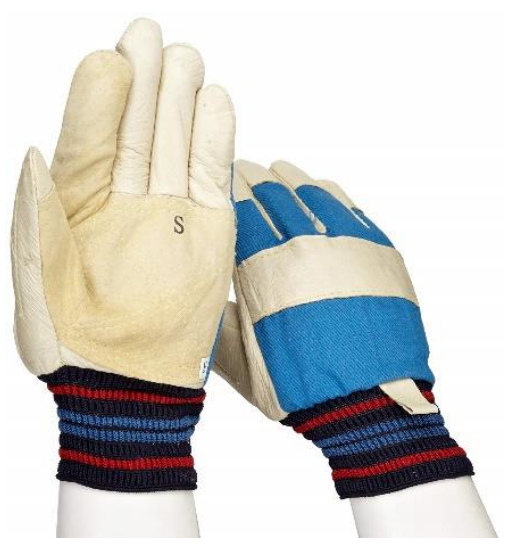

(a)

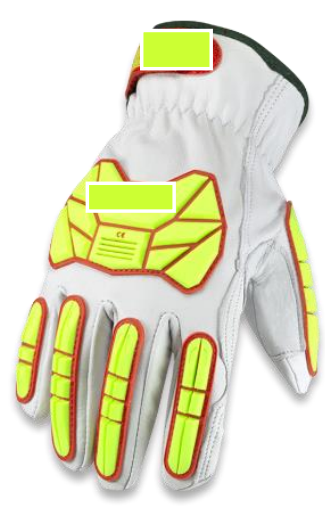

(b)

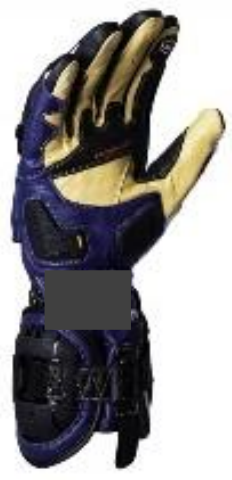

(c)

Figure 1.2: Currently Available Metacarpal Gloves. (a) Pigskin leather glove with thick pads put down on knuckles ${ }^{6}$. (b) Synthetic leather with TPR impact protection on top of metacarpals and full length of fingers ${ }^{7}$. (c) Leather glove with TPR on top of finger, knuckles and back of hand $^{8}$.

The amount of protection provided by the metacarpal gloves make these gloves a popular choice of safety managers. In industrial operations, workers use metacarpal gloves 
under various settings including: assembly, sheet metal handling, material handling, small part handling such as nut/bolts, steel/metal rolling, wiring, heavy metal fabrication, welding/cutting and many more. Due to a widespread use of metacarpal gloves, it is expected that these gloves should provide significant protection along with adequate sensitivity and flexibility.

The use of metacarpal gloves, although useful and common in the workplace to prevent hand injuries, have some disadvantages. The protective ridges and panels on metacarpal gloves are thicker than the conventional gloves. Such structure can reduce the movement to the fingers and curtail the hand movement capabilities to a narrow range. In another words, there is a compromise between safety and hand performance. This trait of the gloves can sometimes force the workers to take off their gloves thus making them vulnerable to hand injuries. U.S. Bureau of Labor statistics study also claimed that almost $70 \%$ of the hand injuries were the ramification of not wearing the gloves and the remaining $30 \%$ were the consequences of not wearing appropriate gloves [2]. Therefore, it is necessary to study the performance capabilities before selecting the proper set of gloves.

\subsection{Glove Performance Evaluation Methods}

Existing glove performance evaluation methods are based on the measurement of physical characteristics such as strength, dexterity, tactile sensitivity, range of finger and wrist movements, and muscle fatigue. In the study conducted by Fonner (2019), the author examined the impact of four metacarpal gloves on the subject's gripping and pinching strength [9]. The participants were advised to exert maximum strength on Jamar Pinch Meter and Jamar Hydraulic Hand Dynamometer under two different postures. The researcher found that the mean grip strength for the different gloves ranged from 83.95 to 92.65 pounds (decrement of $10 \%-23 \%$ compared to ungloved condition) and the pinch strength ranged from 22.3 to 22.5 pounds (slightly higher pinch strength for gloved condition). In another study, Dianat et al. (2012) investigated the effect of wearing industrial gloves (cotton, nylon and nitrile gloves) on hand performance attributes for a two-hour assembly task [10]. The task consisted of tying wire with pliers, which involved several hand abilities such as grip, strength exertions, tactile sensitivity and movement of the hand/wrist. The researcher discovered that gloves significantly reduced the mean hand and forearm strength $(15 \%$ $20 \%$ ), and sensitivity (15\% - 200\%), while it increased the muscle activity (10\%-25\%), wrist deviation $(15 \%-30 \%)$, and discomfort against the ungloved condition. The same authors, 
Dianat et al. (2010), also examined the effect of glove condition (same glove as tested in the previous study by Dianat et al. [10]) for a short and long duration simulated screw-driving task [11]. The authors also investigated the dexterity and figure pinch along with the other performance parameters. There was a decrease in the dexterity by $5 \%-10 \%$, whereas a slight increase in the pinch strength (5\% - 20\%). Furthermore, Dianat et al. (2014), also compared the effects of barehand with two new design of cotton gloves, single- and double-layered cotton gloves (thickness varying between $0.8 \mathrm{~mm}$ and $1.6 \mathrm{~mm}$ ) while working with hand tools (screwdrivers and pliers) [12]. Wearing two new design of cotton glove required higher completion time than the bare hand. In all the three studies by Dianat et al., the authors concluded the bare hand condition had better performance with respect to the gloved condition.

Willms et al. (2009) examined the hypothesis that wearing gloves increase the manual tasks performance of a worker [13]. The author measured the grip force, perceived exertion, tactile sensitivity, grip size, and glove thickness to compare the manual performance under three different rubber glove type and bare hand condition. The gloves were classified as Class $0(0.8 \mathrm{~mm})$, Class $2(1.8 \mathrm{~mm})$ and Class $4(3.1 \mathrm{~mm})$ based on their thickness. Compared to bare hand, the authors discovered a decrease in average grip force (10\% - 37\%), increased effort to maintain the perceived exertion $(30 \%-150 \%)$, and reduction in tactical sensitivity $(30 \%-250 \%)$. Hence, the author claimed that the performance of hand with gloves decreases rapidly with increased thickness. Unlike previous studies, Mital et al. (1994) observed a positive effect with gloves on hand performance [14]. The authors studied the torque exertion of workers on a simulated task using seven different hand tool (three screwdrivers and four wrenches) and nine types of commercial gloves. The subjects were instructed to exert peak torque at least $20 \mathrm{~N}$ minutes for each condition. The findings of the study showed a slight overall increase of torque exertions by $5 \%$ to $10 \%$ for the gloved condition compared to the bare hand.

The literature shows that in general, gloves significantly decrease the performance of hand compared to the bare hand. Besides, glove promotes the risk of developing fatigue. Many studies have used Surface Electromyography (SEMG) for the evaluation of fatigue [1519]. SEMG is a safe, easy, reliable, and non-invasive procedure in which electrodes are placed on the skin to detect, record and interpret the electric activity of the group of muscles. 
The electrical signal can then be processed in the time and frequency domain to gain information regarding muscle activation and fatigue.

Willms et al. (2009) recorded SEMG for seven forearm muscles where the participants had to maintain a 75-N grip force on the dynamometer for $5 \mathrm{sec}$ [13]. The seven forearm muscles were: Flexor Digitorum Superficialis, Extensor Digitorum, Flexor Pollicis Longus, Flexor Carpi Radialis, Flexor Carpi Ulnaris, Extensor Carpi Radialis, and Extensor Carpi Ulnaris. Compared to bare hand, the authors found that the increase in the glove thickness of rubber gloves had an accelerated increase in muscle activity of wrist and fingers.

Another study by Rybczynski \& Fathallah (2002) investigated the effect of gloves of varying thickness and materials on muscle activation, during a coating removal task [20]. The main objective of this study was to investigate muscle fatigue activation for a common industrial operation setting. The force exertions were monitored using SEMG readings from the finger flexors, finger extensors, biceps, and triceps. The results presented that the glove caused a significant increase in force outputs and muscle activation compared to bared hands. The increment in the muscle activities implied a worker's musculoskeletal disorder risk in industrial operations and hence implying the requirement of proper glove selection guidelines in the industry.

Larivière et al. (2010) used the SEMG test to estimate the effect of glove stiffness on forearm muscle (two flexors and two extensors) during a standardized grip test [21]. In total, twenty-seven glove and bare hand were selected. The assessment of Normalized Root Mean Square amplitude of SEMG signal indicated an increase in muscle activity from $16 \%$ to $21 \%$ (depending on muscle type) against the ungloved condition. Similarly, Dianat et al. examined four-glove condition (three industrial gloves- cotton, nylon, and nitrile- and bare hand) on the muscle activation of flexor and extensor hand muscle [10-12]. The result of ANOVA revealed a significant increase in muscle activity while wearing a glove $(p<0.05)$. They exhibited Extensor Digitorum and Flexor Digitorum Superficialis exerted high muscle activity. Further, Furr et al. (1989) measured Median Frequency (MF) slope to determine the effect of glove condition on muscle fatigue. Associated glove conditions were bare hand, glove-hand/0 psid and glove-hand/4.3 psid [22], where psid is pounds per square inch differential. SEMG data from three muscles- Flexor Digitorum Superficialis (finger flexor), Extensor Carpi Ulnaris (wrist extensor) and Flexor Policis Brevis (thumb flexor)- were collected. The finger flexor and thumb flexor exhibited low fatigue for bare hand condition, 
whereas, the glove-hand/4.3 psid condition displayed the greatest amount of fatigue. For wrist extensor, there was no significant difference between gloved conditions.

\subsection{Fitts' Law}

Fitts' Law has been developed in analogous to with the physical communication system to investigate the human performance using information theory. In a typical Fitts' law study, the user drives displacement over varying distance, also termed as amplitude (A), to a target of different widths (W) [23]. Fitts' suggested that the act of performing human movements over a distance A to acquire a target of certain $\mathrm{W}$ is similar to transmitting information through a channel- human channel. Hence, the movement amplitude A was referred as signals and W was referred as noise. Further, the corresponding difficulty while performing human movements was quantified as Index of Difficulty (ID) using the information metric bits. Based on Shannon's Theorem [24], the corresponding difficulty ID for human movement/target selection task was estimated using log-term as follows:

ID $=\log _{2}\left(\frac{A}{W}+1\right)$

Equation 1-1

With the log-term in Equation 1-1, the units for ID are bits because the unit the ration within parameter are dimensionless and the log is taken to the base 2. Finally, Fitts' termed the rate of transmission of information as throughput and mathematically expressed as the ratio of ID and movement time for a sequence of a task and expressed as bits/s.

The two-basic model of Fitts' Law are illustrated in the Figure 1.3. The participant taps backand-forth between combination of $\mathrm{D}$ and $\mathrm{W}$ for the first model. While in the second model, the participant performs multidirectional tapping task based on ISO9241-9 standard [25]. The path the participant follows starts and ends in the top target. The arrows in Fig 1.3.b indicate the path participants should follow between alternating targets.

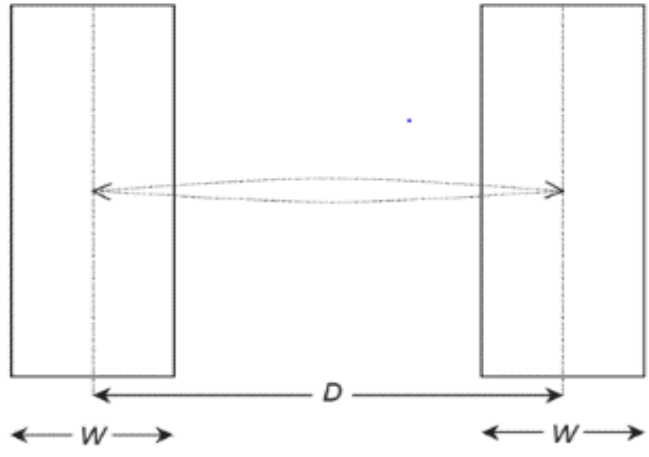

(a)

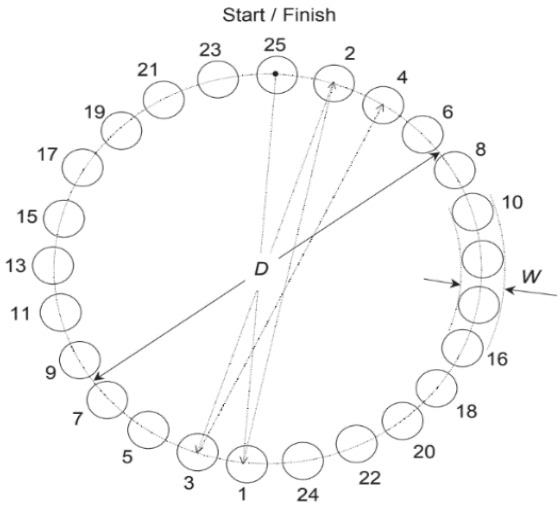

(b)

Figure 1.3: Physical Layout of Fitts' Model [20]: (a) Back-and-forth tapping task, and (b) Multidirectional tapping task. 
The application of Fitts' Law in Human-Computer Interface includes the prediction of the throughput in a pointing device such as cursor area, eye-tracker, and trajectory-based movement [26-29]. As a predictive model, Fitts' law projected the time required for the user of the graphical interface to move the device and click on it [30-32]. Additionally, Fitts' model in Human Computer Interface has been extended to compare the throughput of a cursor control device. Six cursor control devices were measured on a target acquisition task by Epps (1986) [33]. In this study, device types comprised two touchpads, a trackball, two joysticks, and a mouse. Analysis of task data indicated that the throughput was highest for trackball and lowest for displacement joystick (Trackball- 2.6 bits/s, Mouse- 2.6 bits/s, Touchpad- 2.3-1.6 bits/s, Joystick- 1.2-1.1 bits/s). Hence, for a given set of devices, the performance of trackball was the best with a total movement of 2.5 seconds.

Similarly, MacKenzie et al. (2001) evaluated the throughput of a joystick, touchpad, trackball, and mouse- based on Fitts' throughput ISO standard 9241-9 [34]. The resultant observed throughput was $4.9 \mathrm{bits} / \mathrm{s}$ for the mouse, $3.0 \mathrm{bits} / \mathrm{s}$ for the trackball, $1.8 \mathrm{bits} / \mathrm{s}$ for the joystick and $2.9 \mathrm{bits} / \mathrm{s}$ for the touchpad. Between the throughput of the devices, the author claimed that performance for mouse was the best compared to other devices. In another study by Johnsgard (1994), the author compared the movement of the Virtual Mattle PowerGlove with the mouse [35]. The task included a simple pointing and dragging from the starting point to the designated target. The researcher observed a lower movement time and throughput of the glove compared to the mouse. The researched perceived the advantage to rest one's arm on the mouse than using glove.

In the functional domain, Fitts' law has served to study human movements tasks including targeted foot movements under desk [36], movement of chin stylus for data entry job for disable people [37], foot- pedal design for various width and movement directions [38] and sorting of two items and ' $n$ ' tasks [39]. In all these studies, the dependent variables were displacement and target width. The one with the highest value of throughput was selected as the best performing model or design. 


\section{Chapter 2: Study Rationale}

Hand injuries are very common in many industries. As one of the safety measures to protect against hand injuries, workers are required to wear metacarpal gloves. Metacarpal gloves are claimed to provide protection against a wide range of hazards that include mechanical, chemical, thermal, biological, electrical and electrostatic, vibration, radiation. Among other gloves, the metacarpal gloves are typically thicker, stiffer and bulkier. These characteristics of metacarpal gloves may hinder the worker's performance. To our knowledge, no study has evaluated the effect of different metacarpal gloves on the performance. Therefore, there is a critical need to evaluate the performance of the workers while wearing metacarpal gloves. Protective gloves that improve safety without compromising accuracy may have tremendous potential for reducing hand injuries.

Existing glove evaluation studies focus on factors such as dexterity, tactile sensitivity, strength capabilities, range of finger and wrist movements, and muscle activity. Most of these factors do not provide a direct measurement of performance. A performance matrix that can account for speed-accuracy trade-off would be ideal for evaluation and comparison of different types of metacarpal gloves. Throughput based on Fitts' Law combines time and accuracy into one number and holds the potential to measure the performance of gloves. However, the Fitts' Law and the associated matrices were predominantly used in various human-computer interaction studies. The majority of these studies were performed in a virtual environment to either evaluate or compare interface or interaction (hand) devices. Application of Fitts' Law in the physical world has been limited. This study attempts to develop and compare new measure of Fitts' throughput for metacarpal gloves. Hence, the objectives of this study were:

(i) To develop a new glove evaluation method based on Fitts' Throughput using ISO 9241-9 standard.

(ii) To develop a relation and find a trend between the measurements obtained from the new method and physiological response of hand muscles.

The following hypothesis were examined in this study:

(i) Null Hypothesis $H_{01}$ : glove condition will have no effect on the throughput. 
(ii) Alternative Hypothesis $H_{A l}$ : glove condition will have an effect on the throughput.

(iii) Null Hypothesis $H_{02}$ : glove condition will have no effect on physiological response of hand muscles.

(iv) Alternative Hypothesis $H_{A 2}$ : glove condition will have an effect on physiological response and subjective assessment of hand muscles.

It is also hypothesized that the throughput will follow a trend with the physiological response of hand muscles and the subjective assessment of glove. 


\section{Chapter 3: Methodology}

\subsection{Approach}

Experimental method was used to measure the throughput and physiological response of hand muscle for the different gloved conditions. The study comprised of two parts. In the first part, the participants performed a series of multi-tapping target transfer on task plates. The task plates were designed according to ISO9241-9 standard. The participant performed the experimental task using four glove conditions (three types of metacarpal gloves and bare hand). Fitts' Law was used to quantify the throughput. In the second part, the participants performed gripping tasks for a duration of 60 seconds and the activity of four hand muscles was recorded using SEMG. The gripping task was performed under the same glove condition and the participants exerted force at $35 \%$ of their maximum gripping strength.

\subsection{Participants}

A total of 15 participants between the ages of 22 and 34 were recruited for the current research. A summary of mean and standard deviation (S.D.) participant's age, weight, height, knuckle width and palm size is shown in Table 3.1. Data for individual participants is presented in Appendix I. Participants were included from the research if they did not suffer from any type of musculoskeletal, degenerative, or neurological disorder or if they had not a history of hand or fingertip pain or any pain at the time of the measurements. Participants were then asked to read and sign the consent form approved by the local Institutional Review Board (attached on Appendix II).

Table 3.1: Anthropometric Measurement of Participant

\begin{tabular}{|l|r|r|}
\hline \multicolumn{1}{|c|}{ Variable } & \multicolumn{1}{|c|}{ Mean } & \multicolumn{1}{c|}{ S.D. } \\
\hline Age (years) & 26.9 & 3.8 \\
\hline Weight (pounds) & 144.6 & 32.0 \\
\hline Height (feet) & 5.5 & 0.3 \\
\hline Knuckles Width (inches) & 3.4 & 0.2 \\
\hline Palm Size (inches) & 7.0 & 0.5 \\
\hline
\end{tabular}




\subsection{Equipment}

\subsubsection{Metacarpal Gloves}

Three different metacarpal gloves were tested in this study are illustrated in Figure 3.1. Glove 1 is a double split glove pigskin leather sewed with Kevlar thread and has a thick pad for protection on palm, thumb and index finger [40]. Glove 2 is a synthetic fiber glove. Glove 2 is commonly used in the mining industry. It has an extra-thick smooth palm and TPR on back of fingers and thumb [41]. Glove 3 is a brown goat-grain leather glove with TPR impact protection strips on fingers, thumb and metacarpal region of the hand. The goatskin provides the high tensile strength and is a reinforced with vibration dampening gel padding inside the palm for protection and absorption of industrial vibrations [42]. The sizing chart for three gloves in this study is included in APPENDIX II. These three types of gloves were selected based on physical and mechanical properties as listed below.

1. Impact Protection Index (IPI): Findings from a prior study by Sosa et al. (2019) on IPI were considered in this study [5]. High IPI indicates that the gloves provide more protection against impacts. The three gloves used in this study have low, medium and high IPI values as summarized in Table 3.1, where the maximum in the IPI scale is $100 \%$.

2. Impact Resistance: ANSI/ISEA 138-2019 is a standard to measure and accurately classify different level of gloves based on the ability to absorb the impact under collision [43]. Among the three gloves used in the study, Glove 3 was ANSI/ISEA 138 certified with a performance level of 2 [41]. High performance level indicates that less amount of force can be transmitted under impact (Performance level 1- Transmitted force $\leq 9 \mathrm{kN}$, Performance Level 2- transmitted force $\leq 6.5 \mathrm{kN}$ and Performance level $3 \leq 4 \mathrm{kN}$. Glove 2 was ASTM: D2632 certified, however, performance level and the transmitted force on the hand under impact are not published. There was lack of information or study on the impact resistance standard for Glove 1.

3. Cost: Glove 1 was the cheapest one among the three gloves used in the study. Each pair of Glove 1 cost around \$4. The cost of Glove 2 was in between Glove 1 and Glove 3 . Each pair of Glove 2 cost around \$18. Whereas, the Glove 3 was the most expensive among all the gloves. The cost of each pair of Glove 3 was around $\$ 32$. 
4. Other properties: Glove 1 was reported to have a cut resistance, abrasion and puncture resistance, however, no studies regarding these measures were reported in the manufacturer's specifications. Glove 2 complies with ASTM D3884-92 for abrasion resistance and also with ASTM 1790-97 for cutting resistance [41]. Glove 3 was reported to have abrasion resistance and a cut resistant level of A5 according to the ANSI standard [42]. It is important to note that no information on the performance level were published.

Table 3.2: Impact Protection Index of Semi-flexible Hand for Selected Gloves [5].

\begin{tabular}{|c|c|}
\hline Gloves Type & Impact Protection Index (IPI) \\
\hline 1 & $37 \%$ \\
\hline 2 & $40 \%$ \\
\hline 3 & $51 \%$ \\
\hline
\end{tabular}



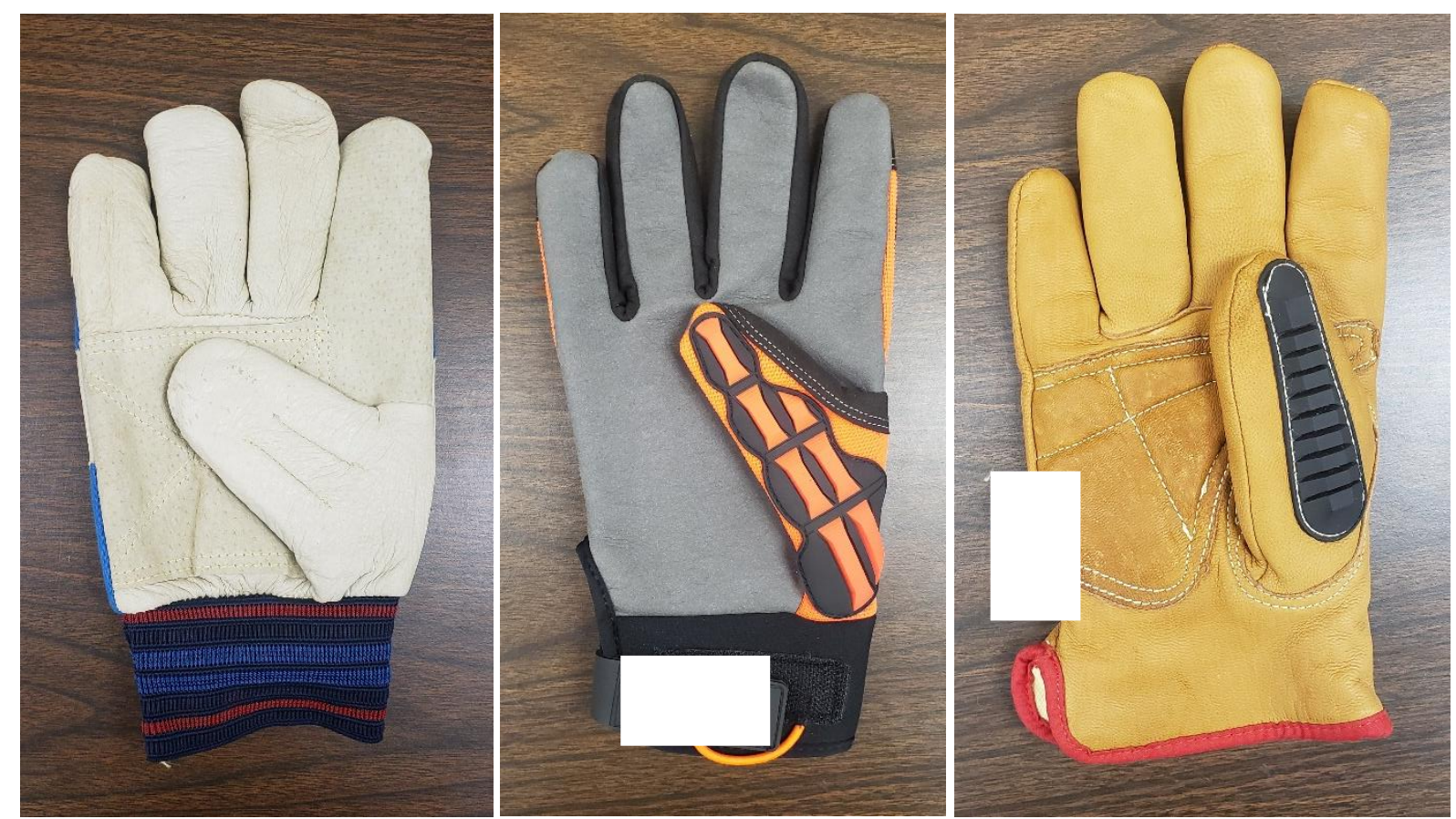

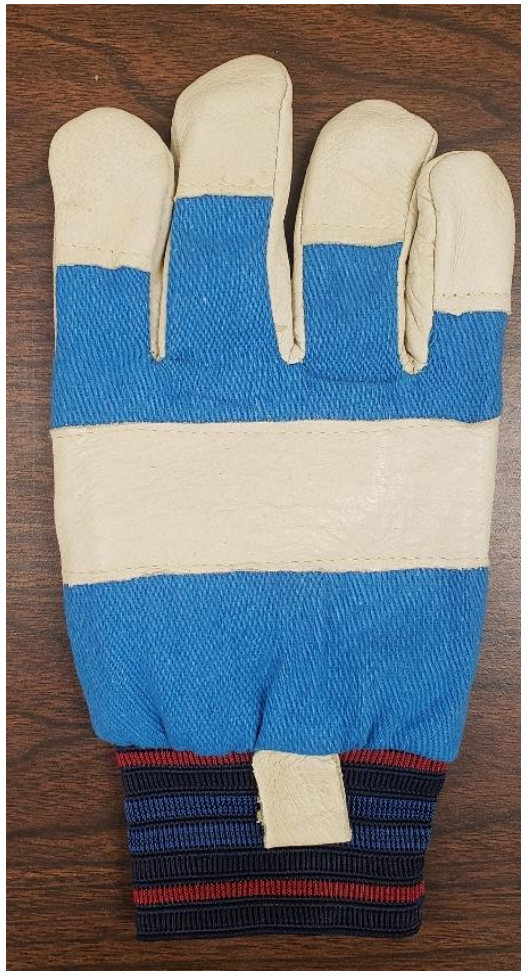

(a)

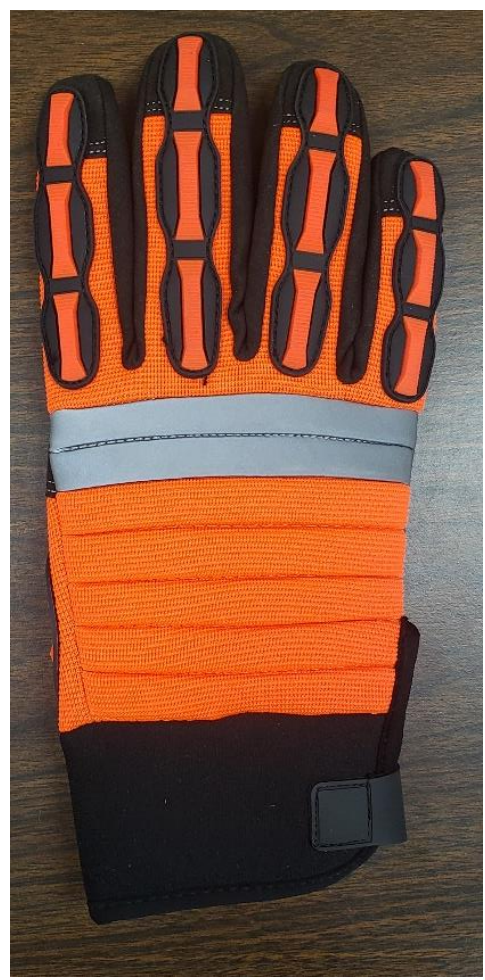

(b)

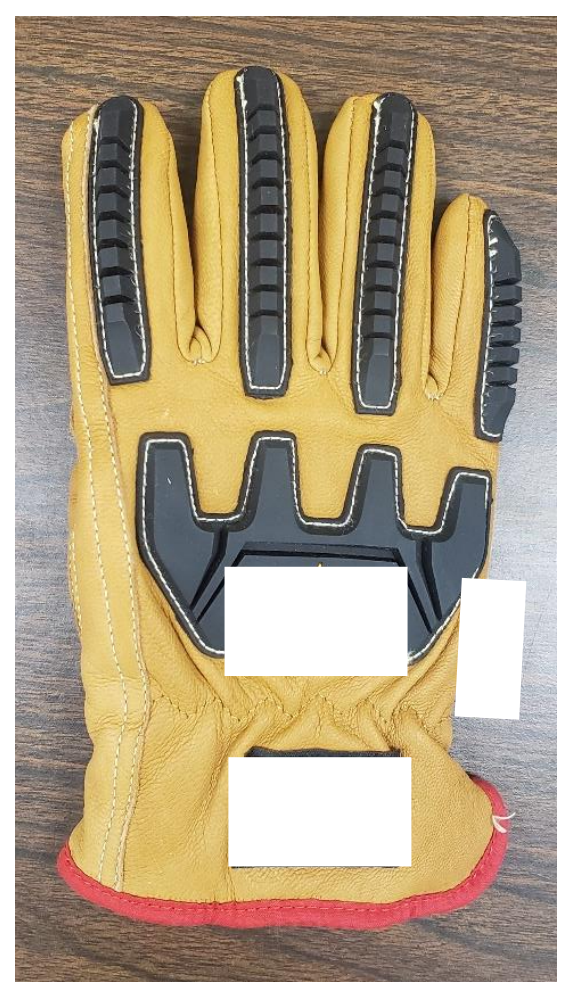

(c)

Figure 3.1: Dorsal and Palmar Side of Gloves Tested in This Study: (a) Glove $\mathbf{1}^{40}$; (b) Glove $2^{41}$; (c) Glove $3^{42}$. 


\subsubsection{Electromyography system}

A Bangoli Desktop EMG system (Delsys Inc., Boston, US) was used to record the muscle activity (Figure 3.2). The system mainly consist of a SEMG electrode $(3 \mathrm{~cm} \times 1.5$ $\mathrm{cm}$ ), a main amplifier unit, input cables, input modules, power supply, and other peripheral cables. The muscle activity was directly recorded into the lab computer via Delsys EMGworks 4 Acquisition and raw EMG data was analyzed in MATLAB R2019a (The MathWorks Inc., US). The muscle activity data was recorded at a frequency of $1000 \mathrm{~Hz}$.

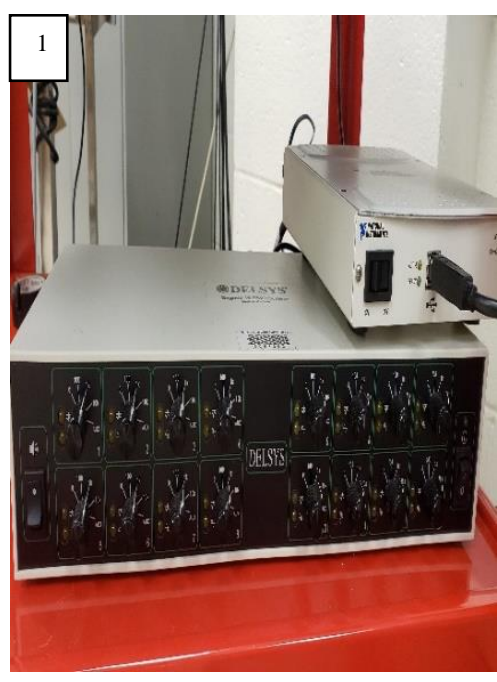

(a)

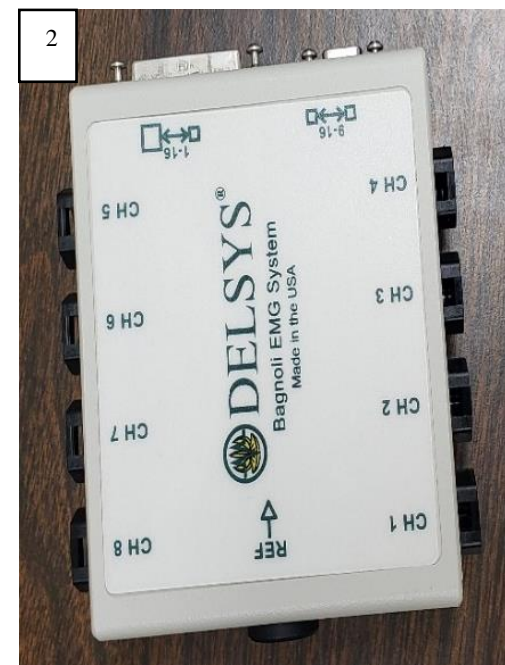

(b)

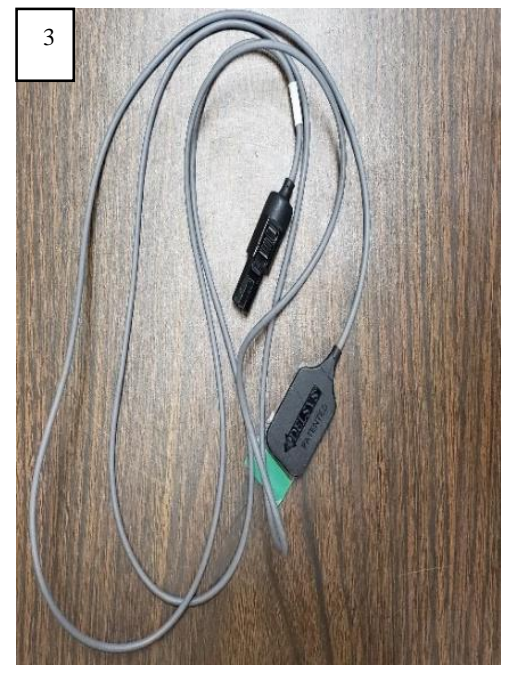

(c)

Figure 3.2: Electromyography System: (1) Power Supply, (2) input modules, and (3) Electrode.

\subsubsection{Custom Built Target Acquisition System}

The custom-built target acquisition system consisted of horizontal task plates and an image recording hardware, as shown in Figure 3.3. The task plates were made out of $0.25 \mathrm{~cm}$ thick steel sheets of different dimensions. The steel sheets were affixed with opaque vinyl adhesive mats. Each mat included a pattern consisting of 12 small circles placed along a big circle. The patterns were different from each other in terms of size of small and big circles. The diameter of the small circle was referred as a Target Width $(W)$ and the diameter of the big circle was referred as Amplitude $(A)$. A general physical layout of task plate is shown in Figure 3.4. Based on Shannon's theorem [24], the Index of Difficulty (ID) for the plate was estimated using the following equation:

$\mathrm{ID}=\log _{2}\left(\frac{A}{W}+1\right)$

Equation 3-1 
The IDs are a measure of task difficulty where low ID is associated with an easy task and a high ID is associated with a difficult task. Different IDs for plates were constructed, as calculated in Table 3.3, to represent different levels of difficulty while performing a task and the selection of it was motivated from the findings of Soukoreff \& MacKenzie (2004) [44]. A series of task plate layout design and their corresponding ID used in the study is shown in Table 3.3 and Figure 3.5. Furthermore, amplitudes $(A)$ were selected such that they are within the reachable distance of the human participants.

Table 3.3: Series of Layout Design and Their Corresponding ID.

\begin{tabular}{|l|l|l|l|}
\hline $\begin{array}{c}\text { Target Acquisition } \\
\text { Plate number }\end{array}$ & \multicolumn{1}{|c|}{$\begin{array}{c}\text { Amplitude (inches) } \\
(A)\end{array}$} & $\begin{array}{c}\text { Target Width (inches) } \\
(W)\end{array}$ & $\begin{array}{l}\text { Index of Difficulty } \\
(I D)\end{array}$ \\
\hline 1 & 7 & 1.5 & 2.5 \\
\hline 2 & 6 & 0.75 & 3.09 \\
\hline 3 & 18 & 1.5 & 3.68 \\
\hline 4 & 27 & 1.5 & 4.27 \\
\hline 5 & 21 & 0.5 & 4.86 \\
\hline 6 & 32 & 0.5 & 5.45 \\
\hline
\end{tabular}



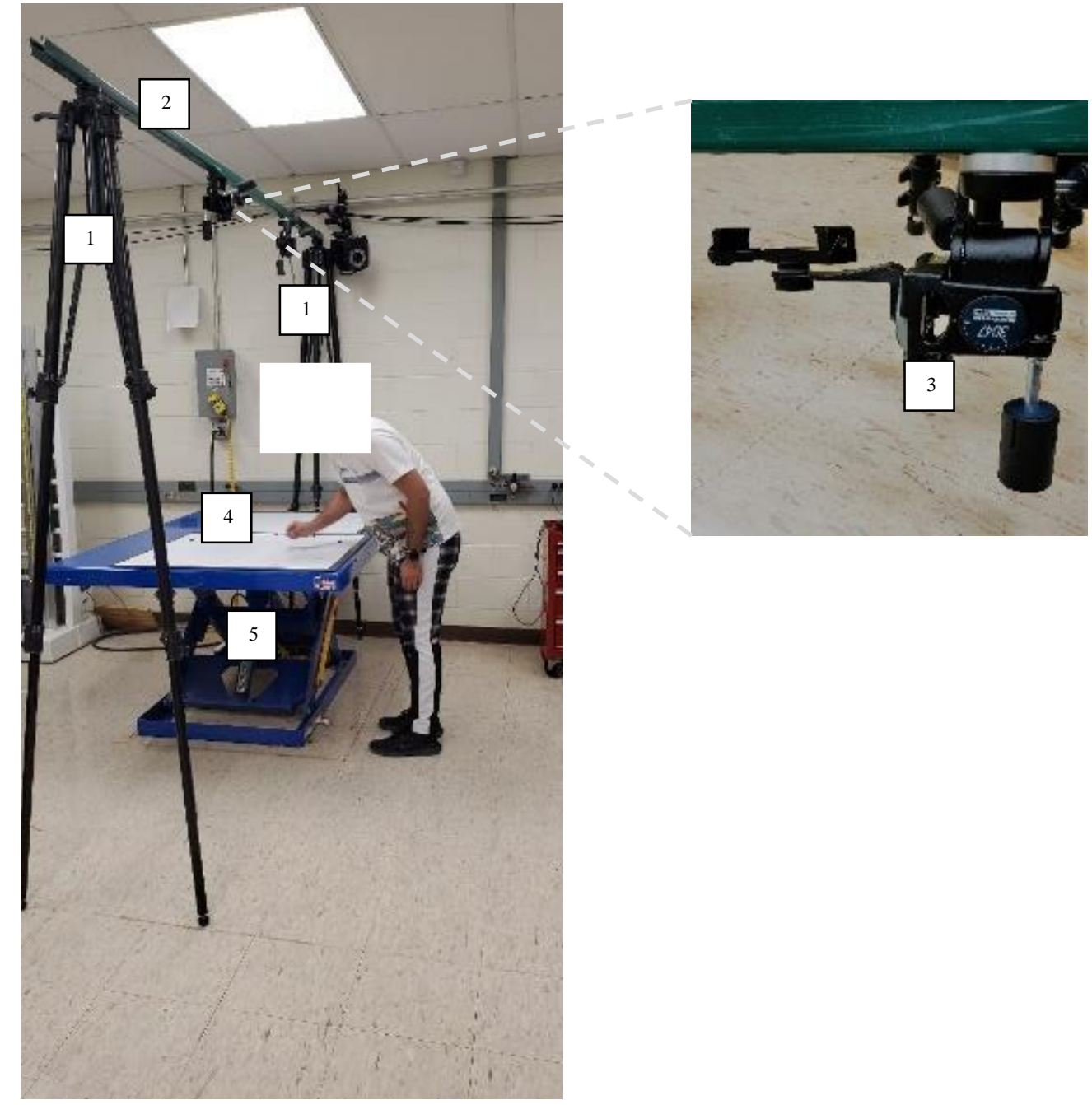

Figure 3.3: Custom Built Target Acquisition Task System: (1) Tripods; (2) U-shaped Bar; (3) Pan-and-tilt Mount for Camera; (4) Task Plate; (5) Scissor Lift.

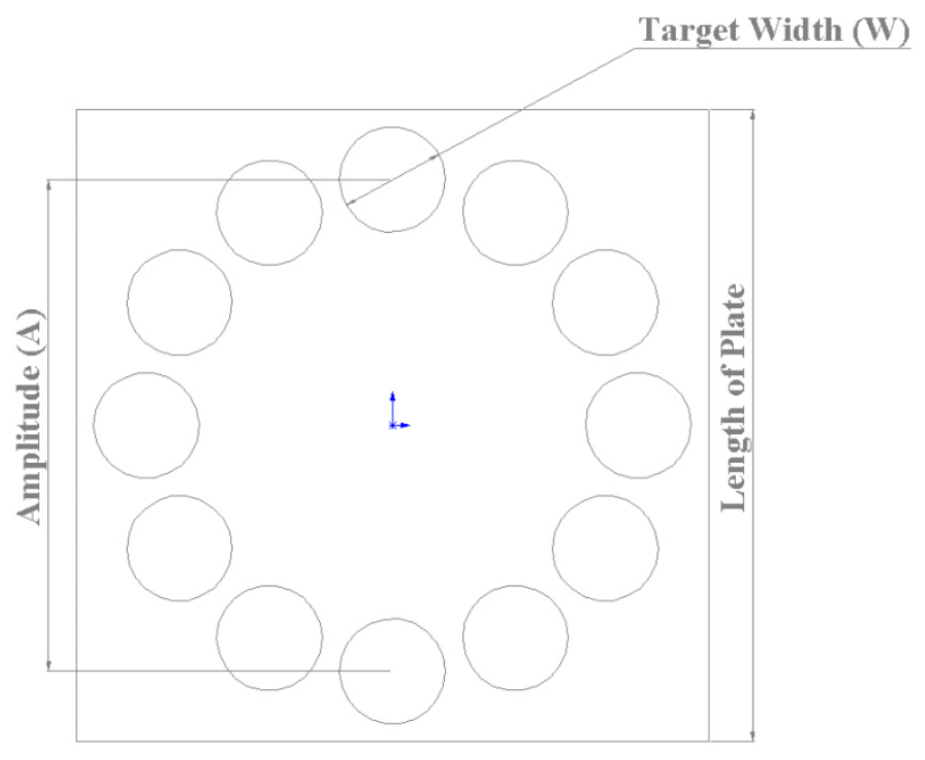

Figure 3.4: Physical Layout of Target Transfer Task Plate 
$\mathrm{ID}=5.45$

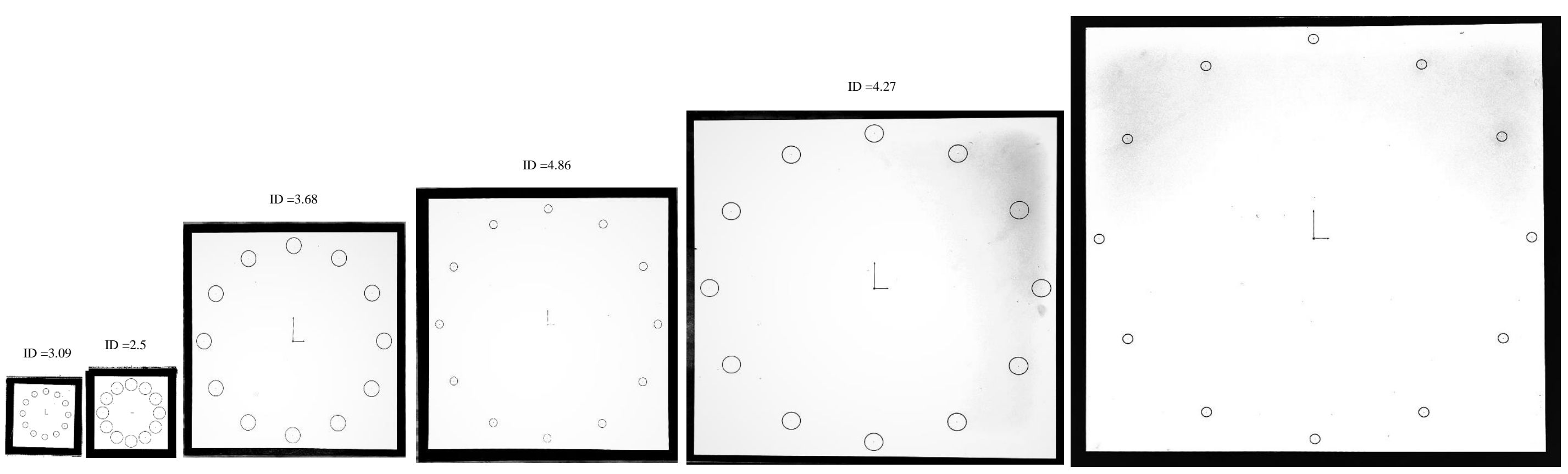

Figure 3.5: Target Transfer Task Plates (Plates are arranged on the basis of their increasing amplitude from left to right). Values of Amplitude $(A)$ and target Width $(W)$ are summarized in Table 3.3. 
The image recording hardware consisted of two tripods (Lino Manfrotto \& Co., UK), a U-shaped bar, a pan-and-tilt mount for a camera and a scissor lift as shown in Figure 3.3. The scissor lift provided a height adjustable surface to place the task plate. Images of task plates were captured with the camera pointing towards the scissor lift, and held by a pan and tilt mount which was placed on the U-shaped bar supported by two tripods as shown in the detail of Figure 3.3. Pan-and-tilt mount included a hexagonal quick release plate with $1 / 4$ "-20 mount screws, and the head could be rotated 360 degrees horizontal, tilted 90 degrees forward or 25 degrees backward, as well as 30 degrees sideways for portrait orientation. The pan-and-tilt mount also included a scale to measure its rotational and sideway tilt movements. This feature allowed fast, repeatable, and accurate device positioning. The scissor lift and tripods provided height adjustability to precisely control the height of the task plates and the distance between task plates and camera. The distance between task plate and camera was adjusted to make sure the camera lens covered a full image of the task plate. The camera was operated using Airdroid (Sand Studio Inc., US) - a remote network control app.

\subsection{Experimental Design}

In this study glove conditions were the independent variable and it was treated at 4 levels: (1) bare hand (2) Glove 1, (3) Glove 2, and (4) Glove 3. For throughput study, each participant performed 24 trials (6 IDs/task plate $\times 4$ Gloves condition). The selection of the IDs were randomized and for a given ID, the glove conditions were randomized again. Each trial lasted approximately for a minute. A rest period of 60 secs was provided between each plate to mitigate fatigue. The dependent measures for throughput study were the task completion time and $\mathrm{ID}_{\mathrm{e}}$. The term $\mathrm{ID}_{\mathrm{e}}$ is an effective index of difficulty and is in computed data processing section. For the study of physiological response of muscle, each participant performed 4 trials, one per glove condition. The dependent measure for this study was the SEMG activity of hand muscles. Likewise, for subjective assessment of perceived exertion, the dependent measure was the subjective rating of participants, which is measured based on Borg's CR-10 scale [45]. Each trial lasted approximately for 60 secs with a rest period of 5 minutes between the trials. The approximate data collection time for an individual participant was around 2 to 2.75 hours, which include about 60-75 minutes for task execution, about 4065 minutes of rest period and about 20-25 minutes of preparation time). 


\subsection{Experimental Data Collection Procedure}

Upon arriving at the laboratory, the participants were given a thorough explanation of purpose of the study, the equipment, data collection procedures, and experimental tasks. The participants' signature was then obtained on an IRB consent form. A set of anthropometric measures such as height, body weight, age, and hand measurements were recorded for each participant. Based on their knuckle width and glove size chart, participants were assigned with their matching glove size. If the assigned glove size was not fit, participants were given the option to select the glove size most comfortable to them. The size charts for gloves are presented in Appendix III.

For the throughput study, the participants were instructed to stand in the midway at the edge of the plate and their shoulders were aligned parallel to the body as illustrated in Figure 3.6.a. Participants placed their foot on the top of the drawn line on the floor as shown in Figure 3.6.b. Then the participants were advised to grasp the target using their thumb, index and middle finger of dominant hand, as illustrated in Figure 3.6.c. Height of the plate was adjusted to the hip height of the participant. Each participant was allowed for a practice session until they were comfortable with the nature of task. Once the participant reported their acquaintance with the task and target, the participant was requested to perform the experiment.

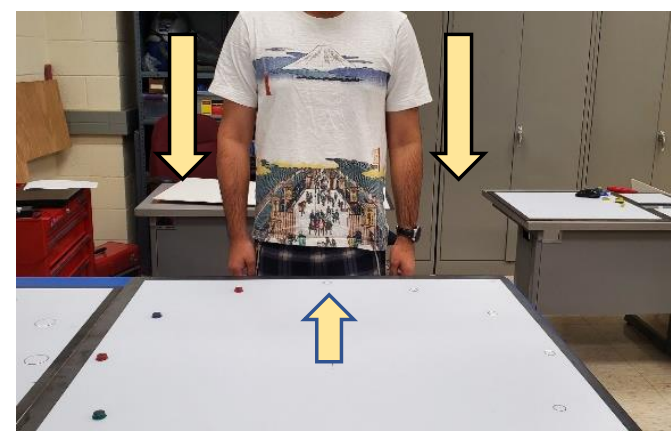

(a)

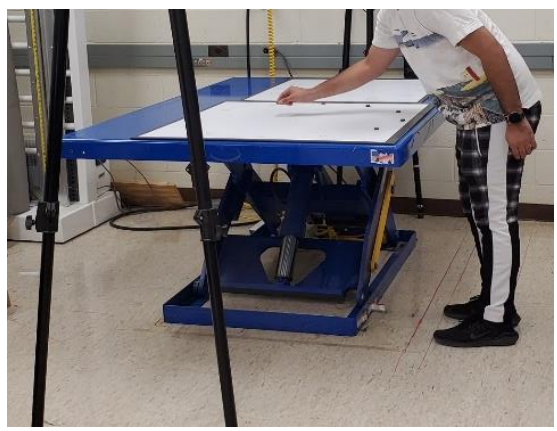

(b)

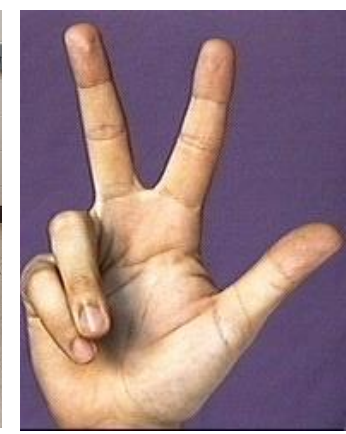

(c)

Figure 3.6: Posture and Fingers Used For Throughput Study.

The participants performed target transfer tasks while wearing metacarpal gloves and bare hand. Each task involved 12 rapid movements - between the starting "from" position to the target "to" position. Circular magnets were used as the targets. Each target transfer task was completed in two phases. The trial for first phase started as the participant moved the targets (magnets) "from" (1-6) positions to "to" (7-12) positions. The trials for second phase started by placing the target back to its original position. The sequence for each phase is 
further detailed in Figure 3.7 and Table 3.4. The targets were centered at small circles ("from" positions) at the beginning of first phase and the selected position for the first phase was the starting position of second phase. The participants were instructed to complete the tasks as quickly and accurately as possible by conducting a transfer along a straight path, i.e., along the diameter of the big circle. The positions of the targets were recorded by taking pre and post images of the task plates for each succession. Additionally, the movement time to complete the target transfer task was video recorded.
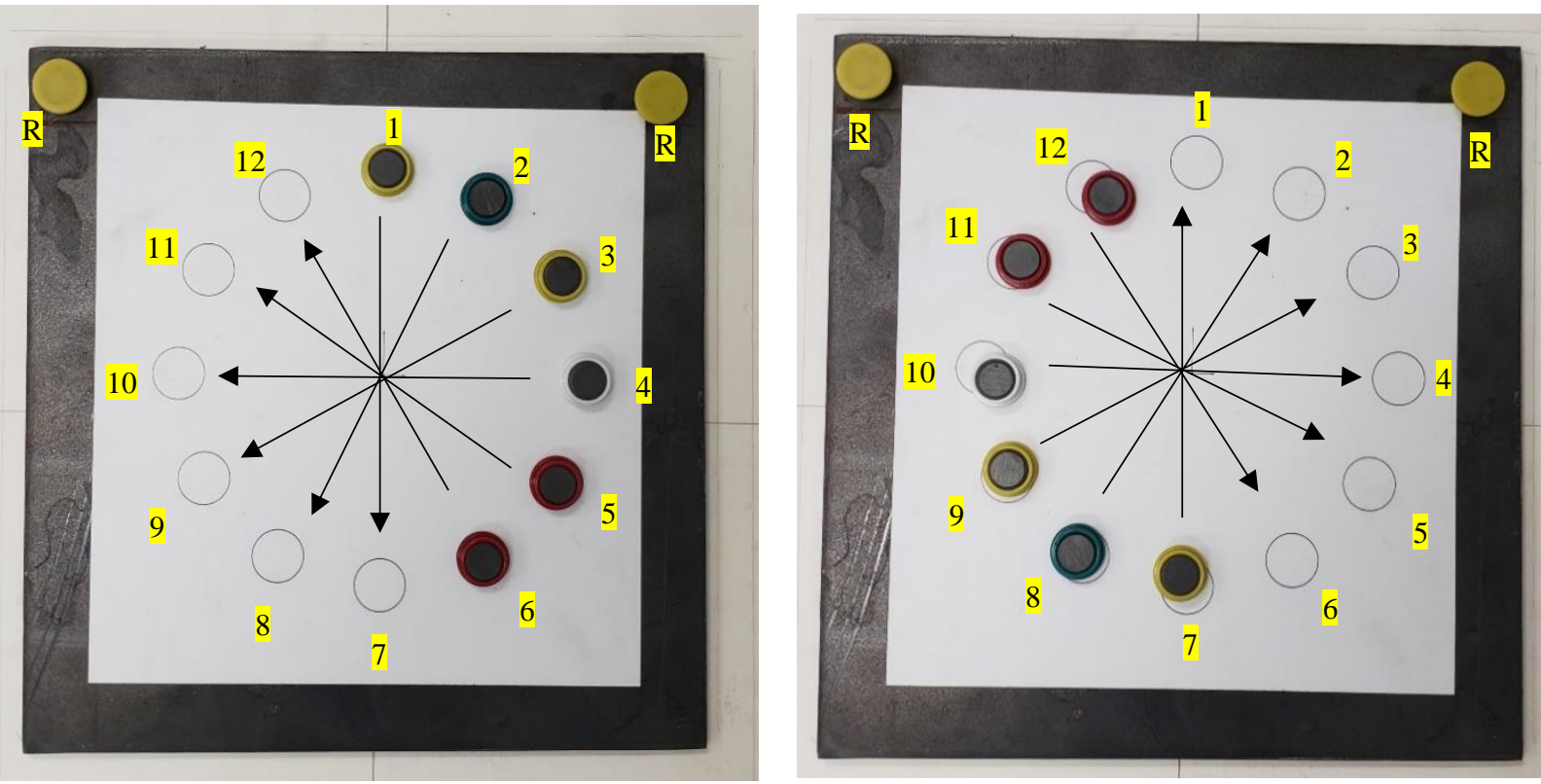

Figure 3.7: Sequence for Target Transfer Task. (Left Figure) The "From and "to" position for the first Succession. (Right Figure) The "from" and "to" for the second succession. The circles " $R$ " on the plates refers to Reference Points.

Table 3.4: Sequence for Each Phase.

\begin{tabular}{|l|c|c|c|c|}
\hline \multirow{2}{*}{ Order Number } & \multicolumn{2}{|c|}{ Trial Position for First Phase } & \multicolumn{2}{c|}{ Trial Position for Second Phase } \\
\cline { 2 - 5 } & "From" & "To" & "From" & "To" \\
\hline 1 & 1 & 7 & 7 & 2 \\
\hline 2 & 2 & 8 & 8 & 3 \\
\hline 3 & 3 & 9 & 9 & 4 \\
\hline 4 & 4 & 10 & 10 & 5 \\
\hline 5 & 5 & 11 & 11 & 6 \\
\hline 6 & 6 & 12 & 12 & \\
\hline
\end{tabular}


For the physiological response of muscle, the participants were prepared for SEMG data collection. The SEMG data was recorded from four hand muscles: (i) Flexor Digitorum Superficialis (FDS), (ii) Flexor Carpi Radialis (FCR), (iii) Extensor Carpi Radialis Longus (ECR), and (iv) Extensor Digitorum (ED). The actions and locations of SEMG electrode for these muscles are illustrated in Table 3.5 and Figure 3.8. To place the SEMG electrode, muscles were palpitated according to their actions and the skin underneath the electrodes was cleaned and shaved. The quality of SEMG signal was checked by applying muscle-specific exertions.

Next, maximum grip strength was measured using a testing protocol by the American Society of Hand Therapist [45]. The participants were seated on a chair with the shoulder adducted and neutrally rotated, the elbow flexed at 90 degrees and forearm in neutral and the wrist between 0 - and 30-degree extension and between 0 - and 15-degree ulnar deviations. The maximum grip strength was measured using three to five trials such that three values within $10 \%$ of each other are obtained [46]. Each trial lasted for 5-7 sec, 2 to $3 \mathrm{sec}$ to build up the force, $3 \mathrm{sec}$ of maximum force exertion followed by the 1-2 sec to return to normal. Two minutes of rest was allowed between the maximum grip strength measurement trials.

Table 3.5: Lead Position for Electrode Placement [47-48].

\begin{tabular}{|l|l|l|l|}
\hline S.N. & \multicolumn{1}{|c|}{ Muscle } & \multicolumn{1}{|c|}{ Action } & \multicolumn{1}{c|}{ Lead Line } \\
\hline 1 & Extensor Digitorum (ED) & Finger Extension & $\begin{array}{l}\text { 1.Lateral epicondyle of the } \\
\text { humerus } \\
2 . \text { Midpoint between the } \\
\text { styloid process of radius and } \\
\text { ulna }\end{array}$ \\
\hline 2 & $\begin{array}{l}\text { Extensor Carpi Radialis } \\
\text { ECR) }\end{array}$ & $\begin{array}{l}\text { Wrist Extension, } \\
\text { abduction }\end{array}$ & $\begin{array}{l}\text { 1.Midpoint between the lateral } \\
\text { epicondyle of the humerus and the } \\
\text { olecranon } \\
\text { 2.Styloid process of the ulna }\end{array}$ \\
\hline 3 & $\begin{array}{l}\text { Flexor Digitorum } \\
\text { Superficialis (FDS) }\end{array}$ & $\begin{array}{l}\text { Flexor of the wrist and } \\
\text { the second through fifth } \\
\text { fingers }\end{array}$ & $\begin{array}{l}\text { 1.Medial epicondyle of the humerus } \\
\text { 2.Skin fold at the wrist }\end{array}$ \\
\hline 4 & Flexor Carpi Radialis (FCR) & $\begin{array}{l}\text { Wrist flexion and radial } \\
\text { deviation }\end{array}$ & $\begin{array}{l}\text { 1.Medial epicondyle of the humerus } \\
\text { 2.Base of the second Metacarpal }\end{array}$ \\
\hline
\end{tabular}



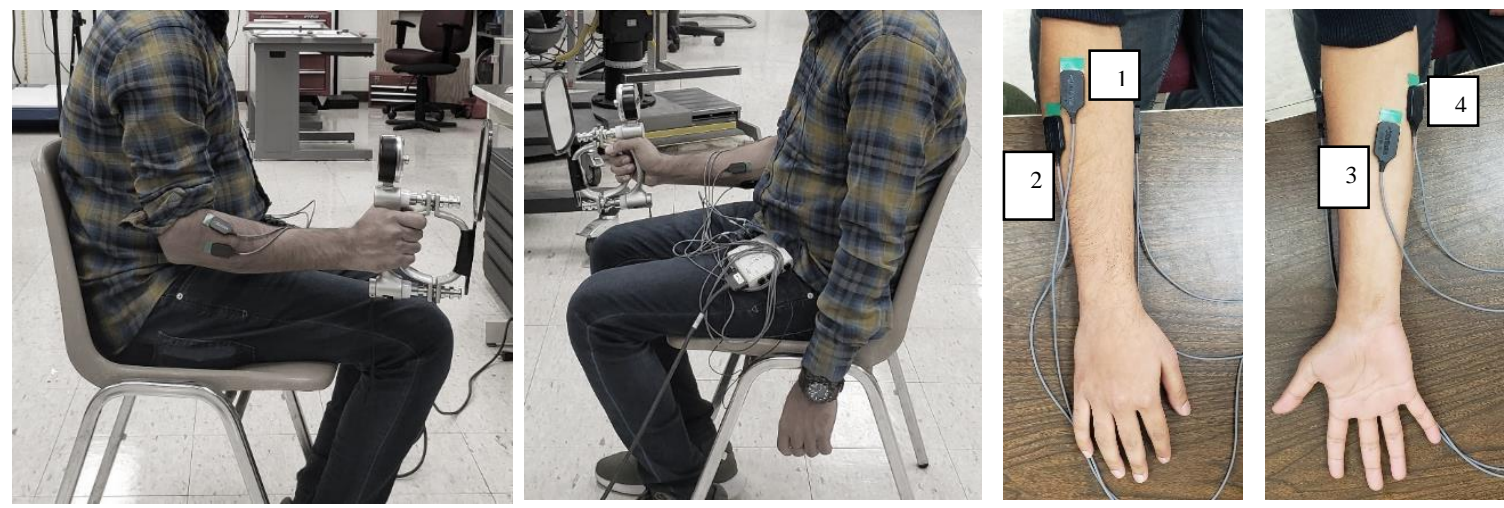

Figure 3.8: Posture and Electrode Placement for Muscle Response Study.

The test consisted of a 60 -sec of static handgrip effort at $35 \%$ of maximum strength. The participant performed static hand gripping task by applying a force equivalent to $35 \%$ of their maximum strength. The muscle activity was continuously recorded during the fatigue test. Each test was completely randomized and separated by a 5 min rest period to mitigate the fatigue. The design for physiological response of hand muscles study has been adapted from a previous study by Larivière et al. (2010) [21].

Immediately following the completion of each exertion, the participants were asked to numerically rate their perceived exertion using Borg's CR-10 scale [49] (Figure 3.9). The rating of Borg CR-10 scale ranges on a scale of 0 to 10 and were associated with the different categories. Here the scale 0 signifies a perceived exertion of "Nothing at all" and scale 10 signifies "Extremely strong" perceived exertion. Participants were given instruction on how to interpret the scale prior to actual data collection with a rating of zero corresponding to the participant feeling no noticeable effort required for the exertion and 10 corresponding to the exertion requiring the participant's full effort. 


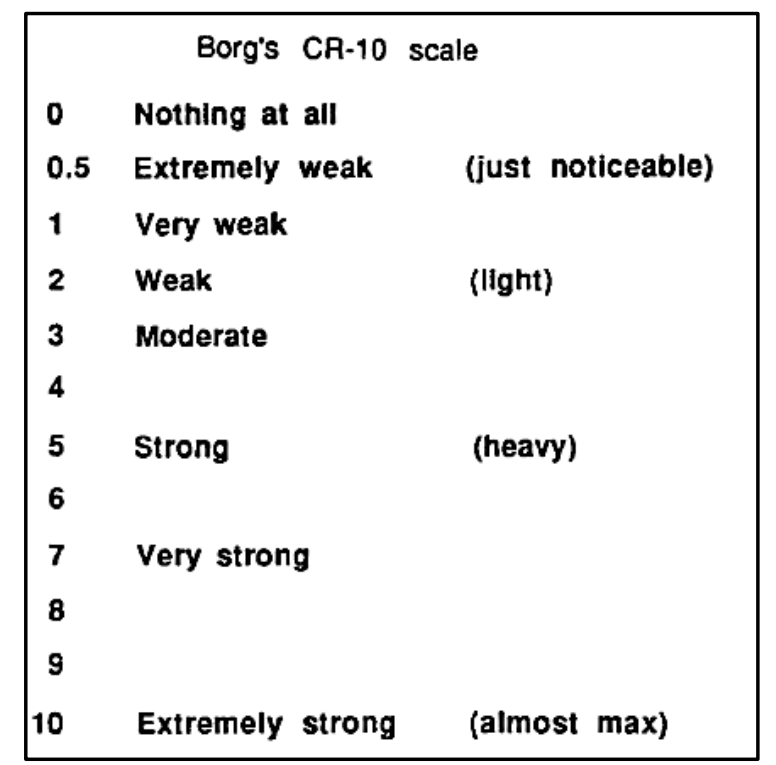

Figure 3.9: Borg's CR-scale of Perceived Exertion ${ }^{49}$.

\subsection{Data Processing}

\subsubsection{Throughput Calculation}

The throughput, which is a measure of speed and accuracy for a target acquisition task, was calculated based on ISO 9241-9 standard, "Ergonomics of human-system interaction". The equation for the throughput is based on Shannon's Formulation of ID [24] and MacKenzie et al. (2001) [34]. The throughput for a glove condition was calculated using the following equation:

$$
\mathbf{T P}=\frac{1}{n} \sum_{\mathrm{i}=1}^{\mathrm{n}} \frac{\mathrm{ID}_{\mathrm{ei}}}{\mathrm{MT}_{\mathrm{i}}}
$$

Where,

$\mathrm{TP}=$ Throughput for a glove condition.

$\mathrm{n}=$ number of participants $\times$ sequence combinations.

$\mathrm{ID}_{\mathrm{ei}}=\mathrm{ID}_{\mathrm{e}}$ for $\mathrm{i}^{\text {th }}$ task plate.

$\mathrm{MT}_{\mathrm{i}}=$ movement time for the $\mathrm{i}^{\text {th }}$ plate.

$=$ total movement time for a plate / number of movements $(=12$, in the study)

The $\mathrm{ID}_{\mathrm{e}}$ is computed from the effective amplitude $\left(\mathrm{A}_{\mathrm{e}}\right)$, defined as the mean of the movement distance "from" to "select", and effective target width $\left(\mathrm{W}_{\mathrm{e}}\right)$. Mathematically, it is represented as:

$\mathrm{ID}_{\mathrm{e}}=\log _{2}\left(\frac{A_{e}}{W_{e}}+1\right)$

Equation 3-3 
To further illustrate $\mathrm{ID}_{\mathrm{e}}$ calculation for our target transfer tasks, we refer to the guidance provided in a study by MacKenzie (2018) [50]. The process is depicted in Figure 3.10 .

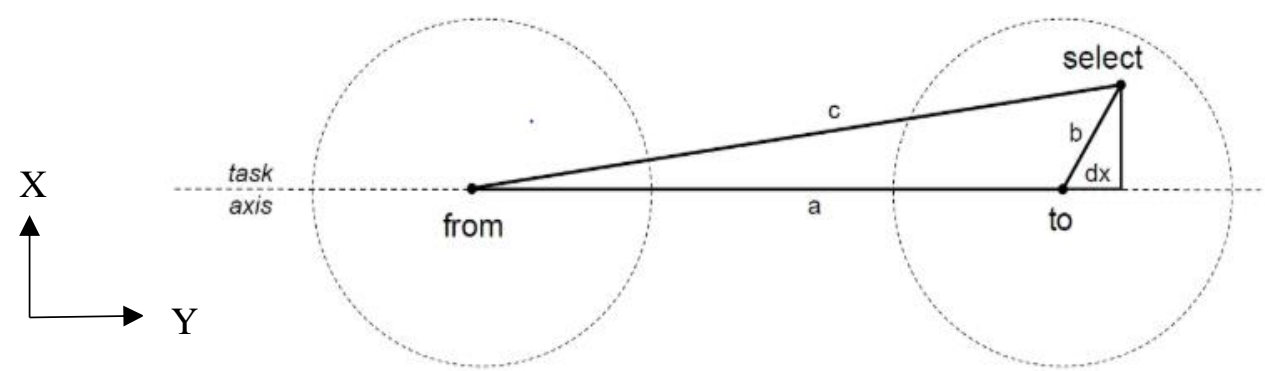

Figure 3.10: Geometry for a Target Transfer Task.

Let $\left(\mathrm{x}_{1}, \mathrm{y}_{1}\right),\left(\mathrm{x}_{2}, \mathrm{y}_{2}\right)$, and $(\mathrm{x}, \mathrm{y})$ be the coordinate positions of the "from", "to", and "select" point respectively. Here, the "from" point represents starting position (original/starting position of a magnet), and "to" point represents target position (position where a magnet is expected to be placed) and "select" point represents the final position (position where a magnet is actually placed). Using the coordinate data, distances $a, b$, and $c$ were estimated using the following equations:

$\mathrm{a}=\left(\mathrm{x}_{1}-\mathrm{x}_{2}\right)^{2}+\left(\mathrm{y}_{1}-\mathrm{y}_{2}\right)^{2}$ Equation 3-4

$b=\left(x-x_{2}\right)^{2}+\left(y-y_{2}\right)^{2}$ Equation 3-5

$c=\left(x_{1}-x\right)^{2}+\left(y_{1}-y\right)^{2}$ Equation 3-6

Given the length of sides, $d_{x}$ is calculated to determine $a_{e}$ as:

$d_{x}=\left(c^{2}-b^{2}-a^{2}\right) / 2 a$

Equation 3-7

$a_{e}=\mathbf{a}+\mathbf{d}_{\mathbf{x}}$

Equation 3-8

Here, $\mathrm{a}_{\mathrm{e}}$ is effective target amplitude for a single movement. The effective target amplitude $\left(\mathrm{A}_{\mathrm{e}}\right)$ for a task plate is the average of all $\mathrm{a}_{\mathrm{e}}$ values. Likewise, the effective target width, $\mathrm{W}_{\mathrm{e}}$, can be computed over a task plate using the following equation: $\mathrm{W}_{\mathrm{e}}=4.133 \times \mathrm{SD}_{\mathrm{x}}$

Equation 3-9

In the above equation, $\mathrm{SD}_{\mathrm{x}}$ is the standard deviation of all $\mathrm{d}_{\mathrm{x}}$ values obtained for a plate and 4.133 represents a condition that indicates that $96 \%$ of the hits fall within the target and $4 \%$ of the hits miss the target. There are 12 movements for a plate.

For each plate, images were acquired before and after the completion of the target transfer task. The Image Processing Toolbox available in MATLAB R2019a was used to process the images and obtain the Cartesian coordinates for these points using Hough 
principle as illustrated in Figure 3.11. The reference coordinate of pre image was kept recorded and the coordinate of post images were transformed with respect to the reference point of pre image to allow same position and direction in both images. The MATLAB code for extracting the coordinate is shown in Appendix IV.


(a)
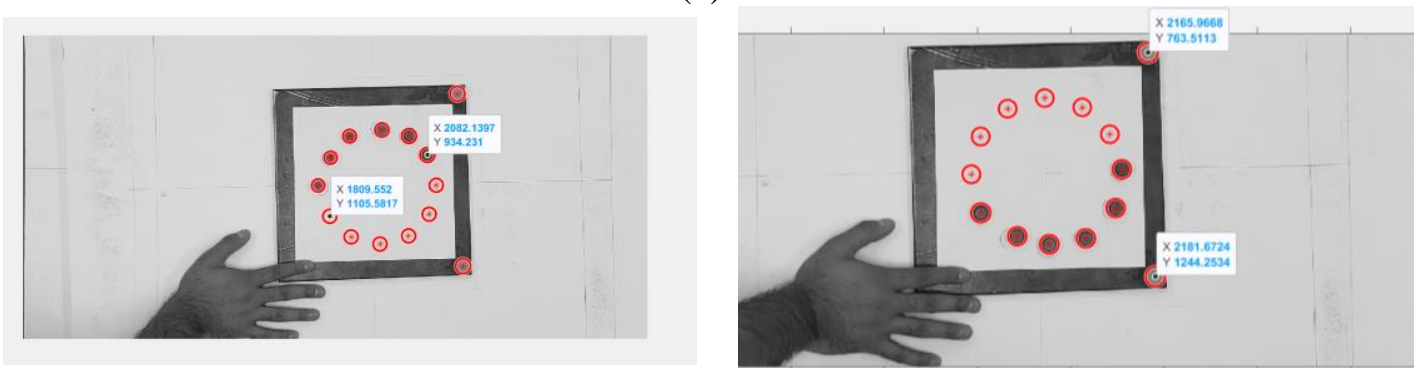

(b)

Figure 3.11: Image Processing: (a) Pre and Post of First Phase and (b) Pre and Post Image of Second Phase.

Upon comparison of the experimental setup used in this study with the setup used by MacKenzie et al. (2018) [50], it was recognized that the concept of effective target width is not applicable to this study. The effective target width proposed by MacKenzie et al. (2018) [50] is applicable to experimental setups used for virtual environments, in which the participants are required to tap/click within circular targets using handheld devices. Based on the accuracy of tapping/clicking the effective target width for a participant could be different (smaller or larger) than the actual target width (diameter of circle). For example, for a participant who is trying to maintain a very high level of accuracy by clicking very close to center of the circle would have effective target width smaller than the actual target width (circle diameter) and vice versa. In this study, circular magnets of fixed diameters were used and therefore the widths of the targets were controlled and independent of the accuracy desired by the participants. Thus, $\mathrm{W}_{\mathrm{e}}$ in the Equation 3.3 was replaced with $\mathrm{W}$, i.e., actual target width. 


\subsubsection{Physiological Response of Muscle}

Two approaches were used to process EMG data. In the first method, amplitude-based approach was applied to determine the Normalized Mean Absolute Value (NMAV). NMAV indicates overall activation of a muscle during an exertion. Secondly, a frequency-based approach was used to determine percentage drop in Median Frequency ( $\%$ drop in MF). The $\%$ drop in $\mathrm{MF}$, measured using a negative slope for a linear regression line, is considered as a sign of muscle fatigue.

\subsubsection{Normalized Mean Absolute Value}

The EMG data collected during maximum grip and submaximal grip tasks were recorded for 5 and 10 seconds, respectively. The raw data was extracted and processed to estimate NMAV. The data for a given trial was full-wave rectified and then averaged to obtain Mean Absolute Value (MAV). Data points over a selected time period of 15 to 25 secs was used to estimate MAV for submaximal grip tasks. This time window was selected based on the assumptions that the muscle activation is stable once initial adjustment ( $\sim 15$ to $25 \mathrm{~s}$ ) to task is complete and muscle may undergo fatigue related amplitude changes towards the end of the task (after 25 to 30 s). The NMAV for a submaximal grip task can be estimated using the following equation:

NMAV $=\frac{\text { MAV }_{\text {submaximal grip task }}}{M_{\text {maximum grip task }}}$

Equation 3-10

\subsubsection{Percentage Drop in Median Frequency (MF)}

To estimate the percentage drop in MF (\% drop in MF), raw EMG data for a given trial was demeaned i.e. raw data was subtracted with its' average and it was transformed to frequency domain using fast Fourier transformation (FFT) available in MATLAB R2019a. The resulting data points were divided into 10 equal divisions and the MF for each time interval was calculated. The MATLAB code for estimating MF is shown in Appendix V. The 10-data points were fitted using a liner regression model. The model derived slope and intercept values were used to estimate \% drop in MF using the following equation:

Percentage drop in $\mathrm{MF}=\frac{\mathrm{MF}_{\mathrm{t}=1}-\mathrm{MF}_{\mathrm{t}=60}}{\mathrm{MF}_{\mathrm{t}=1}}$

Equation 3-11

Where, 
$\mathrm{MF}_{\mathrm{t}=1}$, median frequency at the start of an exertion, i.e., when time $\mathrm{t}=1 \mathrm{~s}$.

$\mathrm{MF}_{\mathrm{t}=60}$ median frequency at the end of an exertion, i.e., when time $\mathrm{t}=60 \mathrm{~s}$.

\subsubsection{Statistical Analysis}

General Linear Analysis of Variance (ANOVA) models were used to investigate the effects of the independent variables on the dependent variables. To test the effect of plate or ID on IDe, ID was treated as a fixed factor with 6 levels $(2.5,3.09,3.68,4.27,4.86$ and 5.45, as shown in Figure 3.5) and participant was treated as a random factor. To test the effect of glove condition on throughput, physiological response of muscle and subjective assessment of perceived exertion, glove condition was treated as a fixed factor with four levels (bare hand, Glove 1, Glove 2 and Glove 3) and the participant was treated as a random factor. The data were tested for normality and equality of variance prior to performing the ANOVA. The normality and equality of variance for throughput, NMAV, \% drop in MF and perceived exertion are presented in Appendix VI, VII, VIII and IX respectively. Statistical significance was set as $\alpha=0.05$. Significant effects were further evaluated by conducting a comparison between means using Tukey's Honestly Significant Difference (HSD) all-pairwise comparison test. JMP Pro 13 (SAS Institute Inc., US) was used to perform the statistical analyses.

\subsubsection{Missing Value}

In this study, two missing values were encountered for SEMG data. The first missing value was for participant number 10 for the FDS muscle under bare hand condition. The second was also for same participant for the same muscle but under glove 3 condition. The missing values were due to the poor connection of the electrode during initial $10 \mathrm{sec}$ of EMG data collection.

There are two approaches to handle the missing values. The first approach is to use approximate analysis in which missing data points are estimated such that they will have a minimum contribution to the error sum of square. In approximate analysis, if observations are missing from the data, their values are estimated by writing the error sum of squares as a function of the missing values, differentiating with respect to each missing value, equating the results to zero, and solving the resulting equations. The second is an exact analysis. The missing data problems are analyzed exactly as a general regression test. Approximate 
analysis has been shown to produce a biased mean square for treatments. Therefore, in this study missing values were handled using the exact analysis approach. 


\section{Chapter 4: Results}

\subsection{Index of Difficulty}

Descriptive statistics for the $\mathrm{ID}_{\mathrm{e}}$ are shown in the Table 4.1. A close similarity was observed between the ID and IDe. The highest difference of 0.15 for observed for plate 4 (ID=4.27 bits), whereas the difference for plate 3 ( $\mathrm{ID}=3.68$ bits) was zero. Statistically, the effect of plate (or ID) on IDe was significant $(p<0.001)$. Tukey-HSD pairwise comparison revealed that all plates were significantly different from each other based on IDe. The measured $\mathrm{ID}_{\mathrm{e}}$ data for each plate is presented in APPENDIX X.

Table 4.1: ANOVA and Mean Pairwise Comparison Result of Effective Index of Difficulty (IDe).

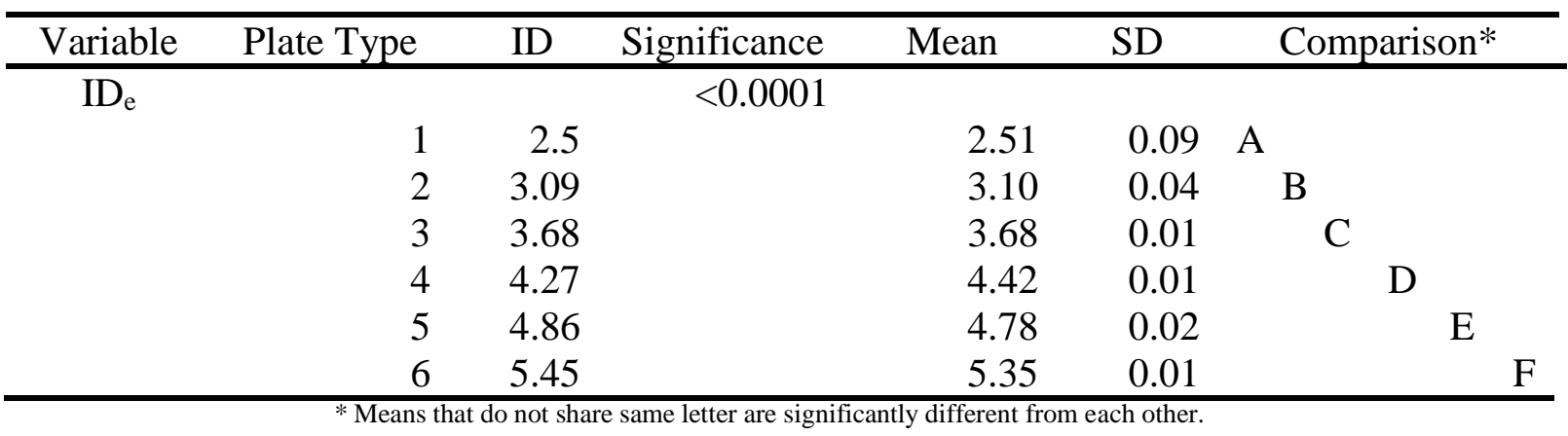

\subsection{Throughput}

Descriptive statistics for the throughput are shown in the Figure 4.1 and Table 4.2. The effect of glove condition was statistically significant on the throughput $(p<0.001)$. Throughput for the bare hand was much higher compared to the three metacarpal gloves. The mean throughput for the bare hand was 3.17 bits/s. Among the metacarpal gloves, Glove 3 had a mean throughput of 2.44 bits/s. While, similar throughput was observed for Glove 2 and Glove 1 with a throughput of 2.34 bits/s.

Tukey-HSD mean pairwise comparison revealed that the throughput for bare hand was significantly different than three metacarpal gloves. No difference in the mean throughput was observed when the gloves were compared with each other. The throughput data for all experimental conditions is presented in APPENDIX XI. 


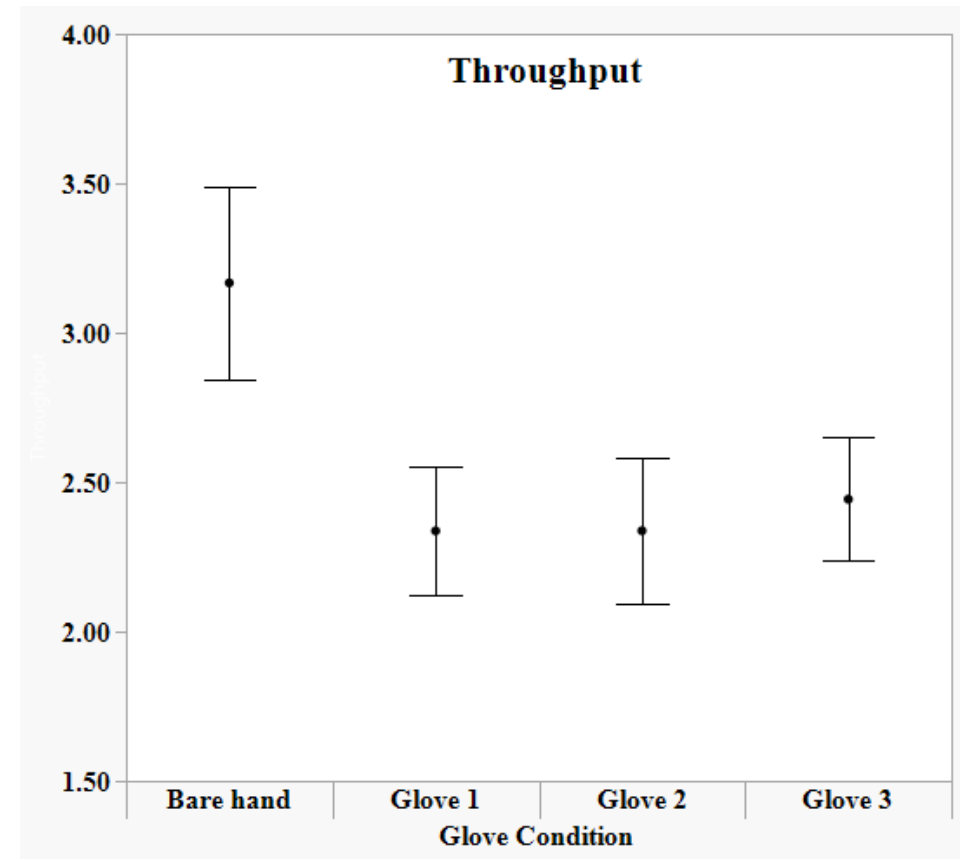

Figure 4.1: Mean and Confidence Interval of Throughput.

*Error bars represent a $95 \%$ confidence interval of the mean.

Table 4.2: ANOVA and Mean Pairwise Comparison Result of Throughput.

\begin{tabular}{rrrrrr}
\hline & Glove Condition & Significance & Mean & SDs & Comparison* \\
\hline Throughput & & $<0.0001$ & & & \\
& Bare hand & 3.17 & 0.58 & A & \\
Glove 1 & 2.34 & 0.39 & & B \\
& Glove 2 & 2.34 & 0.44 & B \\
& Glove 3 & 2.44 & 0.37 & B \\
\hline
\end{tabular}

* Means that do not share same letter are significantly different from each other.

\subsection{Effect of Glove Condition on Muscle Activation}

\subsubsection{Muscle activation on Individual Muscle}

Descriptive statistics for the effect of glove condition on muscle activation (NMAV) are shown in Figure 4.2 and Table 4.3. The effect of glove condition on the NMAV was statistically insignificant. However, a general trend indicated that the mean activation was the lowest when gripping task was performed using bare handed compared to metacarpal gloves. Among the metacarpal gloves, Glove 3 exhibited higher activation compared to Glove 1 and Glove 2. Muscle activation for Glove 1 and Glove 2 was alike. The measured NMAV for each experimental parameter is shown in APPENDIX XII. 
The mean NMAV for ECR muscle ranged between $6 \%$ and $11 \%$, where Glove 3 caused the highest activation (11\%), followed by Glove $1(9.4 \%)$ and Glove $2(9.1 \%)$. Bare hand had the lowest activation $(6.9 \%)$.

For ED muscle, the mean NMAV ranged between $16 \%$ and $19 \%$. Glove 3 had the highest mean NMAV (19\%), followed by Glove 2 (18.6\%), and Glove 1 (17.5\%). The lowest mean NMAV (16.2\%) was detected for bare hand.

For FDS muscle, bare hand had the lowest NMAV (9.7\%). Among the gloves, Glove 1 had lower NMAV (12.1\%), followed by Glove 2 (12.4\%) and Glove 3 (13.4\%). For FCR muscle, the means NMAV were $18.2 \%, 19.9 \%, 19.6 \%$ and $20.6 \%$ for bare hand, Glove 1, Glove 2 and Glove 3, respectively.
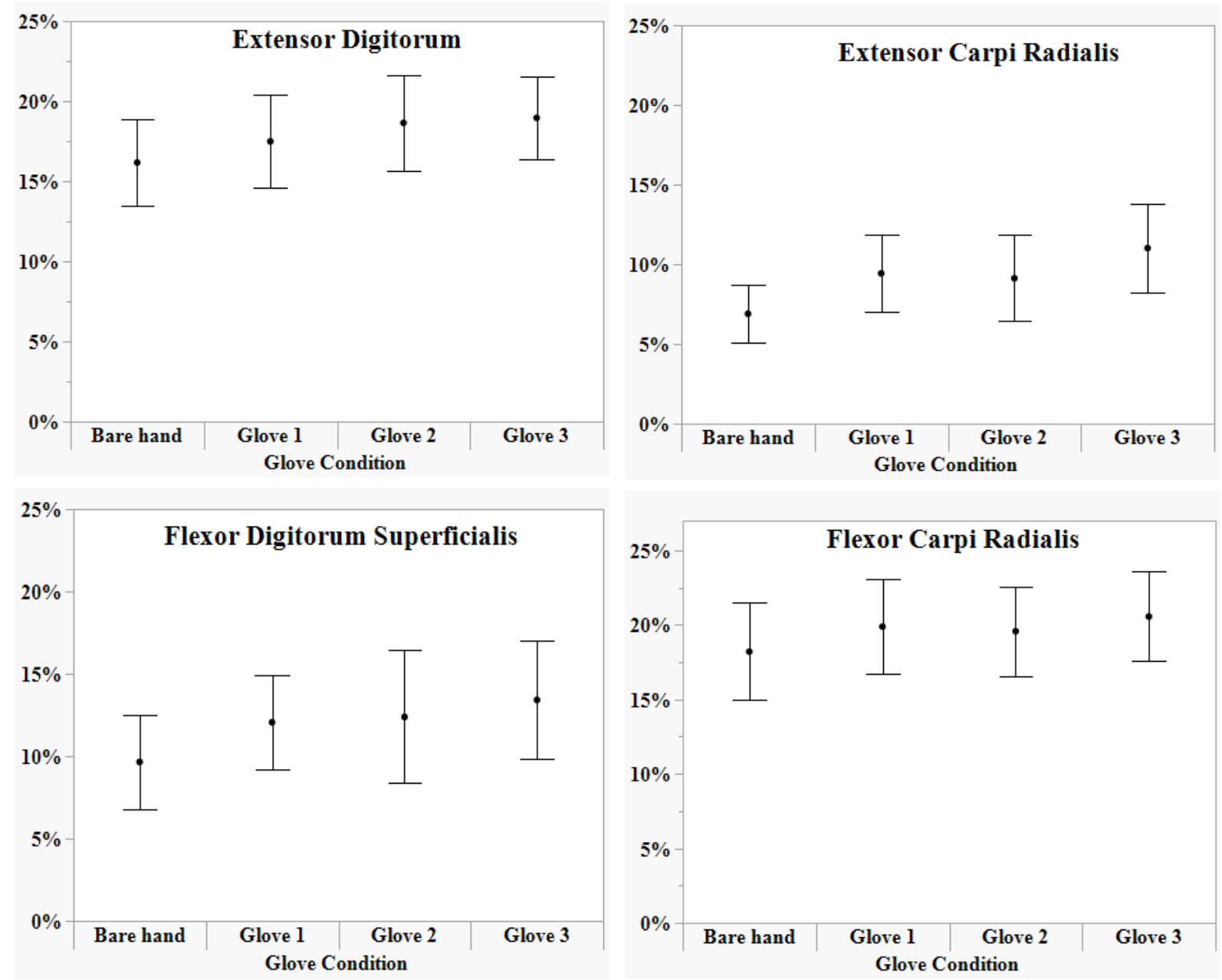

Figure 4.2: Mean and Confidence Interval of NMAV for Hand Muscles.

*Error bars represent a $95 \%$ confidence interval of the mean. 
Table 4.3: ANOVA and Mean Pairwise Comparison Result of NMAV for Hand Muscles.

\begin{tabular}{|c|c|c|c|c|c|}
\hline Muscle & Glove Condition & Mean & SD & Significance & Comparison* \\
\hline \multirow{5}{*}{ ED } & & & \multicolumn{3}{|c|}{0.4219} \\
\hline & Bare hand & $16.2 \%$ & $4.8 \%$ & & $\mathrm{~A}$ \\
\hline & Glove 1 & $17.5 \%$ & $5.2 \%$ & & $\mathrm{~A}$ \\
\hline & Glove 2 & $18.6 \%$ & $5.4 \%$ & & $\mathrm{~A}$ \\
\hline & Glove 3 & $19.0 \%$ & $4.7 \%$ & & A \\
\hline \multirow{5}{*}{ ECR } & & & \multicolumn{3}{|c|}{0.0981} \\
\hline & Bare hand & $6.9 \%$ & $3.2 \%$ & & A \\
\hline & Glove 1 & $9.4 \%$ & $4.4 \%$ & & A \\
\hline & Glove 2 & $9.1 \%$ & $4.9 \%$ & & A \\
\hline & Glove 3 & $11.0 \%$ & $5.0 \%$ & & $\mathrm{~A}$ \\
\hline \multirow{5}{*}{ FDS } & & & \multicolumn{3}{|c|}{0.3907} \\
\hline & Bare hand & $9.7 \%$ & $5.2 \%$ & & A \\
\hline & Glove 1 & $12.1 \%$ & $5.2 \%$ & & A \\
\hline & Glove 2 & $12.4 \%$ & $7.3 \%$ & & A \\
\hline & Glove 3 & $13.4 \%$ & $6.5 \%$ & & $\mathrm{~A}$ \\
\hline \multirow{5}{*}{ FCR } & & & \multicolumn{3}{|c|}{0.7079} \\
\hline & Bare hand & $18.2 \%$ & $5.9 \%$ & & A \\
\hline & Glove 1 & $19.9 \%$ & $5.7 \%$ & & A \\
\hline & Glove 2 & $19.6 \%$ & $5.4 \%$ & & A \\
\hline & Glove 3 & $20.6 \%$ & $5.4 \%$ & & $\mathrm{~A}$ \\
\hline
\end{tabular}

\subsubsection{Total Muscle activation}

Descriptive statistics for the effect of glove condition on total muscle activation $\left(\mathrm{NMAV}_{\text {Total }}\right)$ is shown in the Figure 4.3 and Table 4.4. The total muscle activation was estimated by summing the NMAV values for the individual muscles. The trend in the total muscle activation with respect to the glove condition was very similar to the muscle activation for of hand muscles, where bare hand caused lowest muscle activation and higher activation was induced while wearing Glove 3 . The effect of glove condition on NMAV Total was statistically insignificant. The overall muscle activation for bare hand was the lowest, with a mean $\mathrm{NMAV}_{\text {Total }}$ of $50.9 \%$. Among the three metacarpal gloves, the highest muscle activation was observed for Glove 3, with an NMAV Total of $64.7 \%$. Muscle activations for 
Glove 2 and Glove 1 was approximately equal. The mean $\mathrm{NMAV}_{\text {Total }}$ for Glove 2 and Glove 1 was $59.7 \%$ and $58.9 \%$ respectively. TheNMAV $\mathrm{V}_{\text {Total }}$ is included in APPENDIX XII.

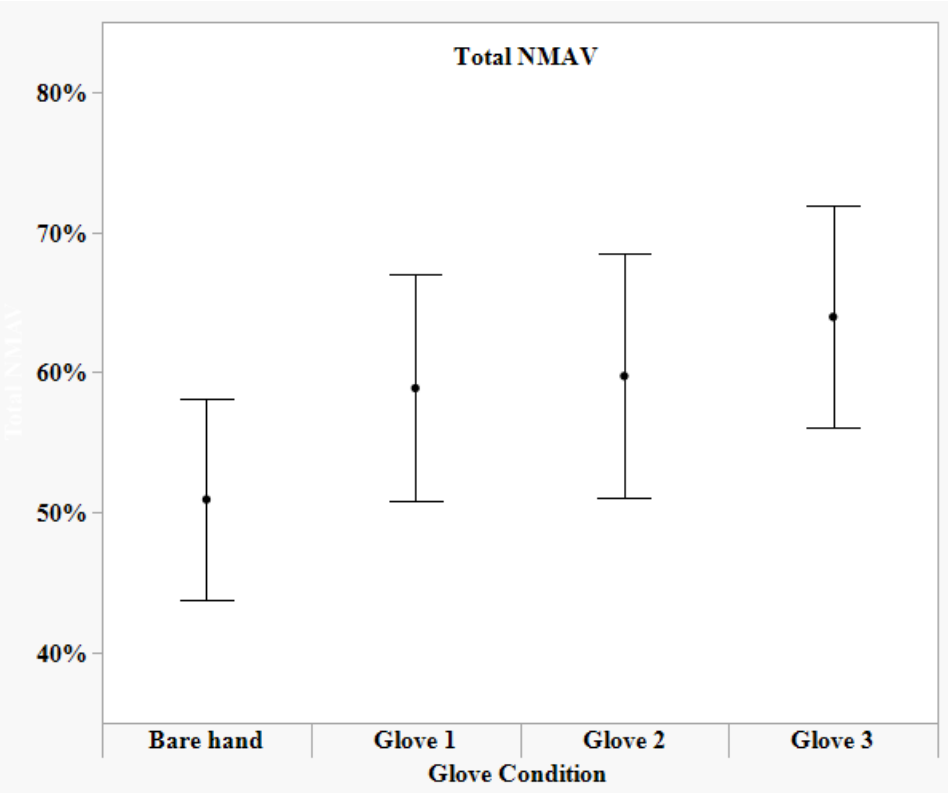

Figure 4.3: Mean and Confidence Interval of Total NMAV. *Error bars represent a $95 \%$ confidence interval of the mean.

Table 4.4: ANOVA and Mean Pairwise Comparison Result of Total NMAV (NMAVTotal).

\begin{tabular}{ccccc}
\hline Glove Condition & Mean & SD & Significance & Comparison* \\
\hline & & & 0.1062 & \\
Bare hand & $50.9 \%$ & $12.9 \%$ & $\mathrm{~A}$ \\
Glove 1 & $58.9 \%$ & $14.6 \%$ & $\mathrm{~A}$ \\
Glove 2 & $59.7 \%$ & $15.7 \%$ & $\mathrm{~A}$ \\
Glove 3 & $64.0 \%$ & $14.3 \%$ & $\mathrm{~A}$ \\
\hline * Means that do not share same letter are significantly different from each other.
\end{tabular}

\subsection{Effect of Glove Condition on Muscle Fatigue}

\subsubsection{Fatigue on Individual Muscle}

Descriptive statistics for the effect of glove condition on muscle fatigue (\% drop in MF) are shown in Figure 4.4 and Table 4.5. A \% drop in MF was observed for all muscles indicating muscle fatigue. The effect of glove condition on muscle fatigue was statistically significant for FDS $(p<0.05)$. Tukey's mean pairwise comparison revealed that wearing Glove 3 yielded a higher fatigue in FDS muscle compared to bare hand. The mean \% drop in MF for FDS muscle was the highest for Glove 3 (24\%), followed by Glove 1 (15\%). The mean \% drop in MF for bare hand and Glove 2 condition was $11 \%$. The effect of glove condition on fatigue for other three muscles i.e. ED, ECR and FCR was statistically 
insignificant as significance value was $>0.05$. Nonetheless, a general trend indicated that the mean fatigue was the lowest when gripping task was performed using bare hand compared to metacarpal gloves. The trend of muscles fatigue for bare hand and metacarpal gloves was analogous to the trend of muscle activation.

For ED muscle, the mean \% drop in MF for bare hand was $7 \%$ and the lowest. Among the metacarpal gloves tested, the mean \% drop in MF for ED muscle was the highest for Glove 3 (19\%), followed by Glove 2 (18\%) and Glove 1 (14\%). Likewise, for ECR muscle, the measured mean \% drop in MF was 9\%, 19\%, 20\% and 23\% for bare hand, Glove 1, Glove 2 and Glove 3 respectively.

For FCR muscle, the mean \% drop in MF for bare hand, Glove 1, Glove 2 and Glove 3 was $13 \%, 24 \%, 20 \%$ and 28\%, respectively. Overall, the \% drop in MF for FCR muscle was higher compared to other three muscles. It ranged from $13 \%$ to $28 \%$. Whereas, the $\%$ drop in MF for ED, ECR and FDS muscles ranged from $7 \%$ to $19 \%, 11 \%$ to $24 \%$ and $11 \%$ to $24 \%$, respectively. The \% drop in MF data is shown in APPENDIX XIII.
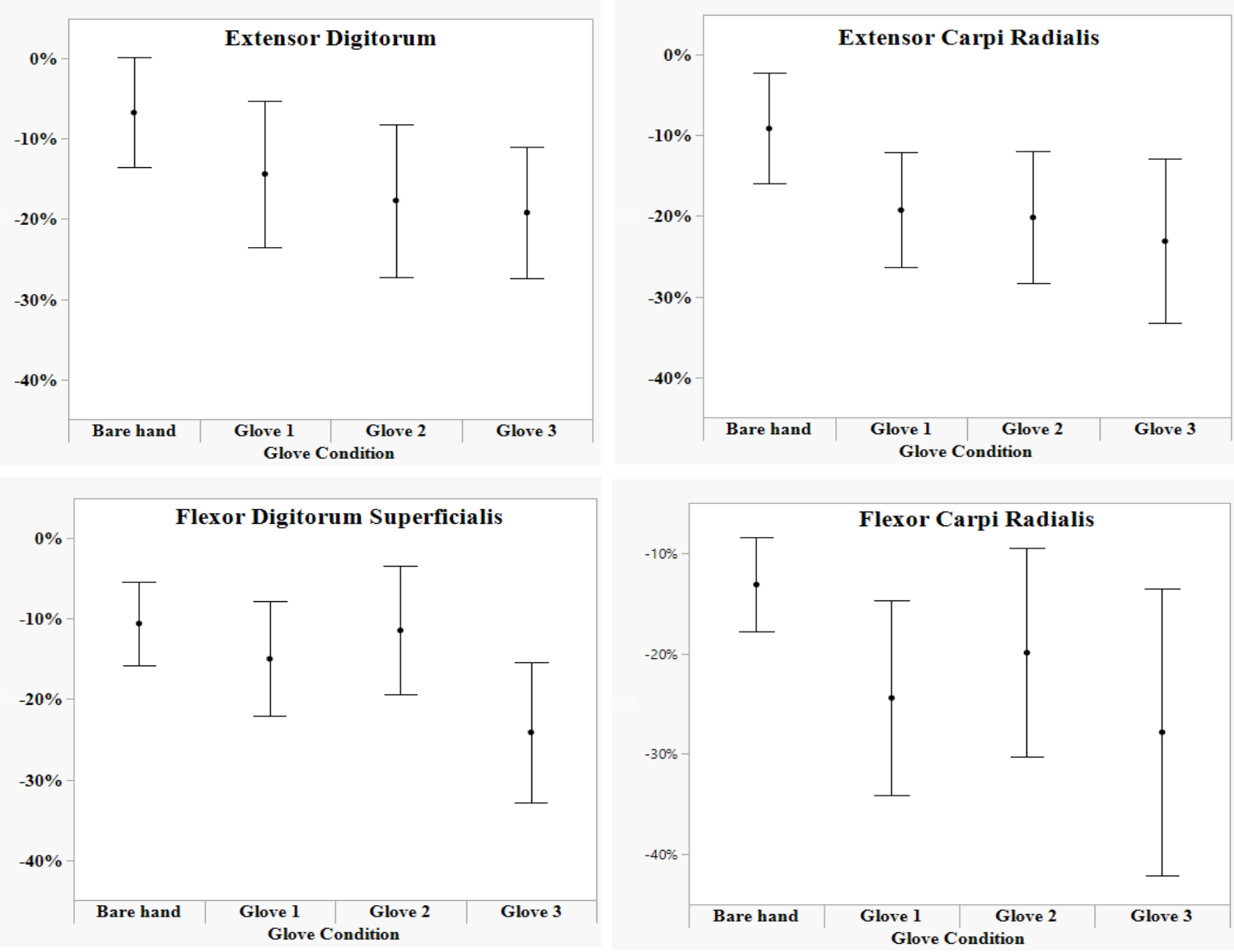

Figure 4.4: Mean and Confidence Interval of \% drop in MF for Hand Muscles. *Error bars represent a $95 \%$ confidence interval of the mean. 
Table 4.5: ANOVA and Mean Pairwise Comparison Result of \% drop in MF for Hand Muscles.

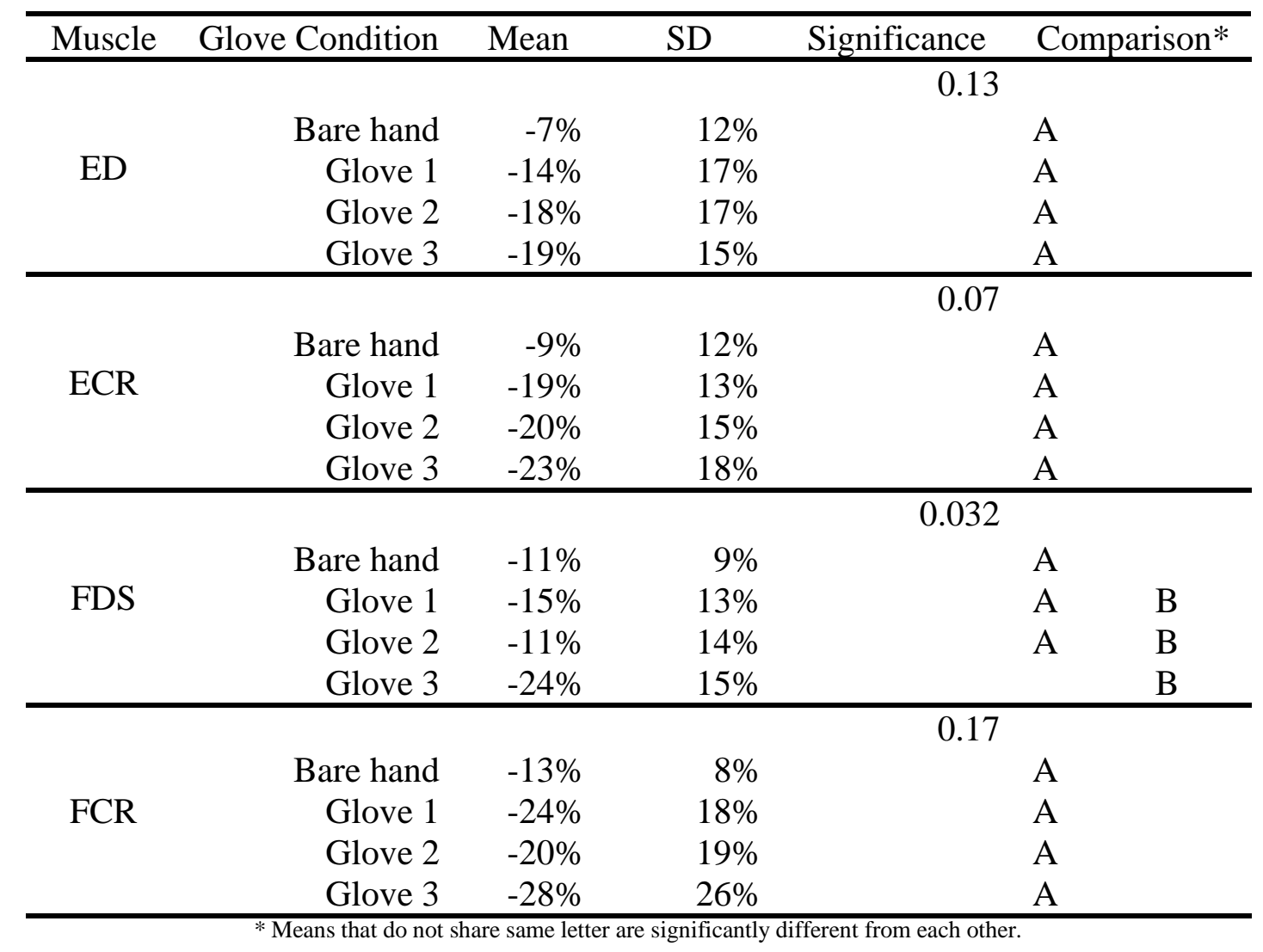

\subsubsection{Average Muscle Fatigue}

Descriptive statistics for the effect of glove condition on average muscles fatigue (average \% drop in MF) is shown in Figure 4.5 and Table 4.6. The average muscle fatigue was estimated by measuring the average of \% drop in MF for the individual muscles. The result of ANOVA revealed a significant effect of glove condition on muscle fatigue $(p<0.05)$. Tukey's mean pairwise comparison also revealed that wearing Glove 3 induced higher muscle fatigue compared to bare hand. The average \% drop in MF for Glove 3 was $23 \%$, while observed average \% drop in MF for bare hand was 9\%. Average \% drop in MF was alike for Glove $1(18 \%)$ and Glove $2(17 \%)$. The measured average \% drop in MF is included in APPENDIX XIII. 


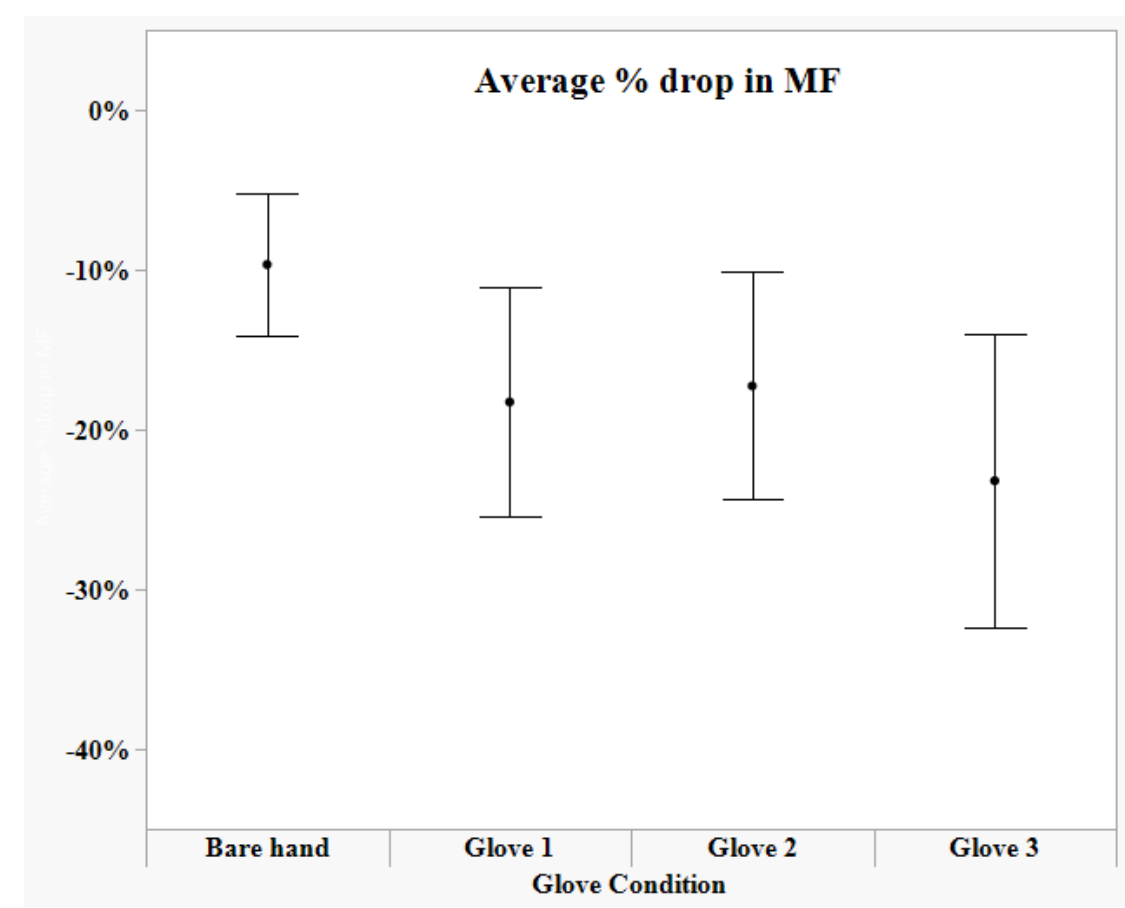

Figure 4.5: Mean and Confidence Interval of Average \% drop in MF.

*Error bars represent a $95 \%$ confidence interval of the mean.

Table 4.6: ANOVA and Mean Pairwise Comparison Result of Average \% drop in MF.

\begin{tabular}{crrlll}
\hline Glove Condition & Mean & SD & Significance & Comparison* \\
\hline & \multicolumn{5}{l}{$0.0490^{*}$} \\
Bare hand & $-9 \%$ & $8 \%$ & $\mathrm{~A}$ & \\
Glove 1 & $-18 \%$ & $13 \%$ & $\mathrm{~A}$ & $\mathrm{~B}$ \\
Glove 2 & $-17 \%$ & $13 \%$ & $\mathrm{~A}$ & $\mathrm{~B}$ \\
Glove 3 & $-23 \%$ & $16 \%$ & $\mathrm{~B}$ \\
\hline * Means that do not share same letter are significantly different from each other.
\end{tabular}

\subsection{Perceived Exertion}

The mean perceived exertion for bare hand and metacarpal gloves is presented in Figure 4.6 and Table 4.7. A significant effect of glove conditions on subjective assessment of perceived exertion could be seen from ANOVA results $(p<0.05)$. Tukey's mean pairwise comparison revealed a significant difference between the perceived exertion of bare hand and Glove 3. The mean perceived exertion for bare hand was between 2 (fairly light) and 3 (moderate). Among the metacarpal gloves, highest perceived exertion was noticed for Glove 3. The mean perceived exertion for Glove 3 was approximately 6 (hard). The participants reported alike perceived exertions for Glove 2 and Glove 1 and rated them as somewhat hard. The mean perceived exertion for Glove 1 and Glove 2 was approximately 4 . The raw perceived exertion data for is presented in APPENDIX XIV. 


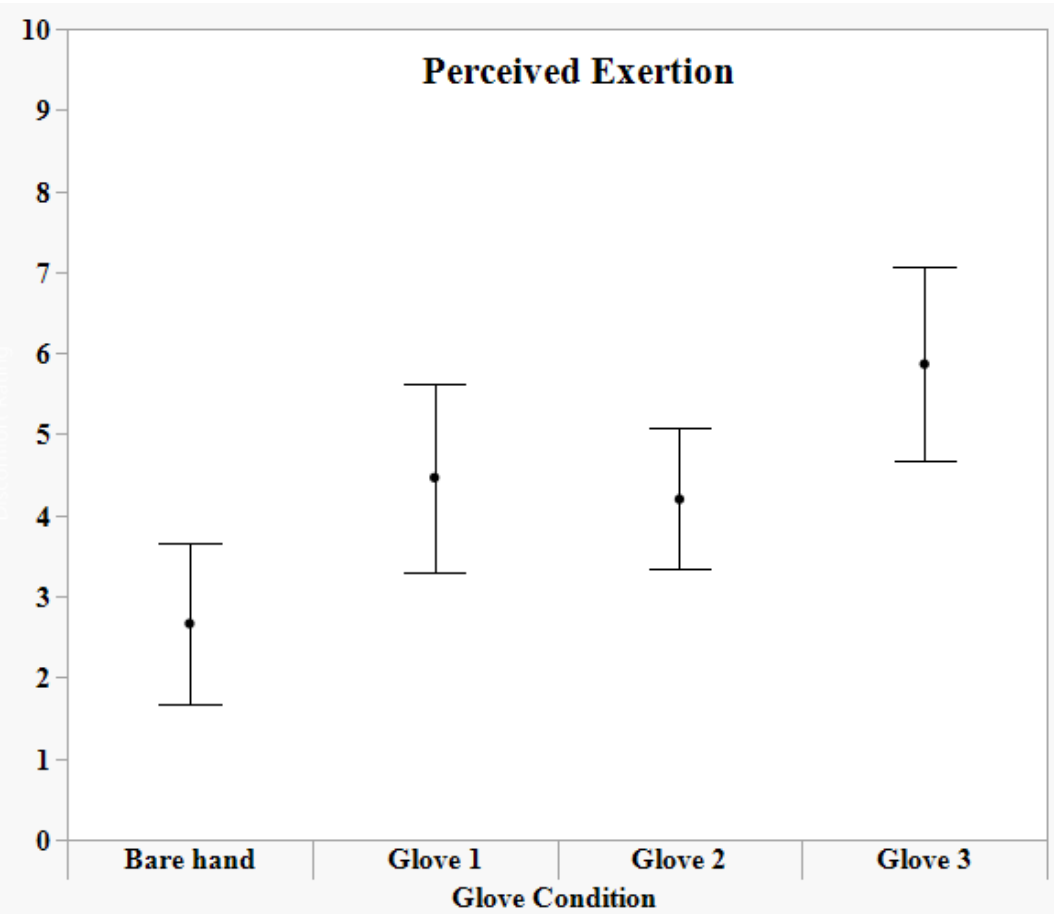

Figure 4.6: Mean and Confidence Interval of Perceived Exertion. *Error bars represent a 95\% confidence interval of the mean.

Table 4.7: ANOVA and Mean Pairwise Comparison Result of Perceived Exertion.

\begin{tabular}{crrlll}
\hline Glove Condition & Mean & SD & Significance & Comparison* \\
\hline & & & $0.0004^{*}$ \\
Bare hand & 2.7 & 1.8 & $\mathrm{~A}$ & \\
Glove 1 & 4.4 & 2.1 & $\mathrm{~A}$ & $\mathrm{~B}$ \\
Glove 2 & 4.2 & 1.6 & $\mathrm{~A}$ & $\mathrm{~B}$ \\
Glove 3 & 5.9 & 2.2 & & $\mathrm{~B}$ \\
\hline \multicolumn{6}{c}{ * Means that do not share same letter are significantly different from each other. }
\end{tabular}




\section{Chapter 5: Discussion and Conclusion}

In this study, Fitts' throughput was used to compare the performance of different metacarpal gloves in relation to bare hand. Fitts' throughput combines movement time and accuracy into one number. Regarding the process to estimate Fitts' throughput, guidance is available in the ISO 9241-9 standard. However, the guidance is mostly applicable for study designs involving virtual environments. Most of the existing studies based on throughput are in the domain of human-computer interaction. These studies dealt with the prediction and comparison of performance of human-computer interface devices such as mouse, trackball, joysticks, touchpad, and others. This study implemented for the first time using ISO 9241-9 standard was successfully used to estimate throughput in the physical environment. This is one of the main contributions of this study.

Results showed that mean throughput was the highest for bare hand (3.26 bits/s) and significantly different compared to the three metacarpal gloves tested in this study. Among the metacarpal gloves, Glove 3 had the higher throughput (2.44 bits/s). Glove 1 and Glove 2 had very similar throughputs (2.34 bits/s) and were the lowest compared other glove conditions tested in this study. The data reject our null hypothesis that the "glove condition will have no effect on the throughput". The difference between the gloves' throughput was small and statistically insignificant. Similar results were obtained in previous studies on handheld computer control devices. MacKenzie et al. (1991) [51] compared the performance of three control devices: Mouse, Tablet and Trackball during pointing. Of the devices tested, the observed throughput was $4.5,4.9$ and 3.3 respectively. The trackball was concluded to be a poor performer, whereas, the tablet was considered as the best performer.

Similarly, Epps (1986) [33] compared six cursor control devices for a target acquisition task. For a given set of devices and throughput (Trackball- 2.6, Mouse- 2.6, Touchpad 1 - 2.3, Touchpad 2-1.6, Joystick-1.2-1.1), the performance of the trackball was considered to be the best with low movement time of 2.5 secs. Herring et al. (2010) [52] provided the comparison of four control devices: Touchpad, Mouse, MiniJoystick and MicroJoystick. The measures for the throughput were 1.08, 0.91, 1.02 and 1.39 respectively. The authors in this study recommended the device with the highest throughput i.e. MicroJoystick for fast and accurate operation. On the other hand, MiniJoystick and mouse were ranked as being "difficult" to operate. 
In the aforementioned studies, although the observed difference between the throughputs of control devices was small, the device with the lowest throughput was regarded as the low performer and the device with the highest throughput as the best performer. Similar analogy could be used in our study while comparing glove conditions. Bare hand outperformed the gloves in terms of throughputs. This was quite expected as individuals can easily grasp, lift and place objects when bare fingers/hand are used. Their ability to maneuver objects was compromised when gloves were used, as additional layers (of material) get introduced between the bare fingers/hand and the object. These layers can influence hand performance by causing restriction to the movement by stiffening the bending capacity of fingers and by affecting the coefficient of friction between object and fingers. Poor fit and 'bunching' of material in case of thicker (apparently more protective) gloves introduces additional challenges [15]. Results of this study seem to indicate that gloves made out of goat leather (Glove 3) performed slightly better than pigskin leather (Glove 1) and synthetic fiber gloves (Glove 2). The goat leather, although much expensive, is softer, pliable compared to other glove materials. Furthermore, leather being a natural material, can easily adapt to the surrounding temperature and environment.

Regarding muscle behavior, results of the study showed that the muscles activation was lower with bare hand compared to the gloved hand. Among the gloves, the highest level of muscle activation was observed for Glove 3, followed by Glove 2 and Glove 1. However, statistically, muscle activation was not affected by glove condition. Therefore, data failed to reject the null hypothesis that the "glove condition will have no effect on physiological response of hand muscles". Similar observations were made in the previous studies, where different types of glove were tested. Mital et al. (1994) [14] compared the activation of extensor and flexor muscles between bare hand and nine different commercial gloves, which were commonly wore during maintenance and repair. The result of EMG activity for the muscles were insignificant for bare hand and gloves $(p>0.01)$. Thus, the authors recommended that the normal expectation of greater loss of muscle activity due to the gloves may not be logical.

Chang et al. (2007) [16] evaluated four-gloved conditions (bare hand, single layered gloves, double layered gloves and covered handle with two layers of cotton) by measuring muscle activation during a sustained task for $5 \mathrm{sec}$. Unlike the trend in this study, the muscle activation decreased for the gloves compared to the bare hand. The observed muscle activation for the four-gloved conditions were $26.2 \%, 23.2 \%, 20.2 \%$ and $21.3 \%$ respectively. 
The ANOVA results of the study indicated that wearing gloves did not affect the muscles activation compared to bare hand and the activation was indifferent. Similarly, in the study by Kovacs et al. (2002) [18], the normalized peak EMG activity of the forearm flexor and extensor did not show a significant difference between nine different glove types and bare hand.

Muscle fatigue was estimated using the \% drop in MF - higher drop indicates higher fatigue. In general, the highest drop was observed for Glove 3 and the lowest when bare hand were used. The \% drop in MF for Glove 1 and Glove 2 was alike. This trend was consistent for all the four hand muscles tested in this study and analogous to muscle activation. Moreover, statistical significance was observed for FDS muscle. In a study conducted by Furr et al. (1989) [22], the muscle fatigue for two different pressurized gloves was compared with the bare hand. During the glove condition, change in MF of hand muscles was rapid and showed the greatest amount of fatigue. Whereas, no fatigue was reported for bare hand. Larivière et al. (2010) [21] conducted a similar study, as the one used in this study, to examine two gloves and bare hand. Based on changes in MF, a lower fatigue was reported for bare hand relative to gloves. However, no significant difference was observed between gloves and bare hand.

In this study, Glove 3 exhibited higher muscle activation and fatigue when compared with Gloves 1 and Gove 2. The differences in the muscle activation as well as muscle fatigue can be explained to some extent by the design of these gloves. Comparatively, Glove 3 is composed of strips of thick TPR bested on the top of the fingers, metacarpal and knuckles, making it bulkier and less flexible. Such structures may have impeded the movement of fingers, making the gripping exertion difficult with this glove. For Glove 2, the TPR layer of protection on the thumb and back of fingers wasn't as thick as in Glove 3. In Glove 1, protective pad was used instead of thick ridge of protective layer. The thin layer or pad of protection layers for Glove 1 and Glove 2 might not have been as obstructive as in glove 3 . Therefore, the participants might have used less muscle force, producing lower activation and fatigue for Glove 1 and Glove 2 when compared with Glove 3. This argument is consistent with previous studies. Willms et al. (2009) [13] reported that the thickness of glove material on palm reduces maximum grip force and substantially increases muscle effort during submaximal effort. Wells et al. (2010) [53] also reported that there were substantial and significant increases in effort, and muscle activity with an increase in the thickness of gloves. Future study is required to measure the effect of thickness of protective layer. 
The results of the subjective assessment of the perceived exertion showed that Glove 3 was less favorable in terms of sustaining force for a long period. The participants rated Glove 3 as the hardest. Therefore, the participants felt a higher difficulty in maneuvering while wearing Glove 3. The participants indicated a perceived exertion between fairly light and moderate when performing the gripping task with bare hand and somewhat hard with Glove 1 and Glove 2. Overall, as expected the participants felt more comfortable with bare hand and it appeared to the best option for performing the required tasks.

In summary, two distinct relationships were observed between the throughput and the physiological response of the hand muscles. An inverse relationship was observed when bare hand was compared with gloves, i.e., higher throughput was associated with lower muscle activation, fatigue and perceived exertion. A direct relationship was observed when gloves were compared with each other, i.e., higher throughput was associated with higher muscle activation, fatigue and perceived exertion. It is difficulty to comments of the strengths of relationships observed in this study. These relationships could be a function of the gloves tested in this study. The best performing glove in terms of throughput was made out of betterquality material but it had thicker layer of protection on it. The better material improved its throughput, but thicker ridges of protection contributed to increase the stiffness of the glove, which in turn resulted into higher activation, fatigue and perceived exertion. This may suggest that improvement in one design attribute i.e. impact protection may influence or degrade other attributes. An ideal glove would be the one with high throughput and minimum padding for the highest level of protection.

\subsection{Limitations}

Several limitations should be considered while interpreting the results of this study. In this study, magnets were used to facilitate accurate recording of position data. However, due to their magnetic force, the participants often had difficulty in grasping them. This might have affected the throughput. Another factor that might have affected the throughput was the image processing system used in the study to estimate $\mathrm{ID}_{\mathrm{e}}$. The camera was placed centrally above the plate to remove the parallax error. However, due to unknown reason, a small amount of parallax error was observed while recording the image. In addition to this, the sensitivity of the image processing system caused it to detect foreign circular objects as targets. This error was rectified by using manual detection process, but it significantly increased the data processing time. For the muscle activation and fatigue study, a simplistic 
gripping task was used. This task was performed at only one contraction level (35\%) using a standard sitting posture. Past studies have found that there is a significant effect of contraction levels, posture and age on physiological response of muscles while performing gripping tasks [54-56]. Finally, the participants used in this study were relatively young and had little experience of performing manual material handling tasks.

\subsection{Future Work}

In this study, an attempt was made for the first time to determine and compare the performance of metacarpal gloves based on the concept of Fitts' throughput. The information gathered in this study can be used to continually determine and compare the throughput for other gloves as well. Future studies investigating gloves' throughput should look at improving the process to extract and record the position of the circular targets. One such improvement would be using a system, such as the Microscribe [57], that digitize the targets and positions into 3-D coordinates. This would help to determine the exact position of the targets with reduced parallax error and complexity. Secondly, future work can look at relationship between throughput and industrially relevant hand exertions. Future work should also consider different submaximal forces and postures to better understand relationship between throughput and physiological response. Future studies can also be performed using participants with experience in performing manual material handling tasks. 


\section{References}

1. Occupational Safety and Health Administration. (2010). Estimated costs of occupational injuries and illnesses and estimated impact on a company's profitability Worksheet. Washington, DC.

2. Bureau of Labor Statistics, US department of labor. (2017). Washington, DC. Retrieved from: https://www.bls.gov/iif/oshsum.htm\#17Summary_News_Release.

3. Bureau of Labor Statistics, US Department of Labor (2016). Nonfatal occupational injuries and illnesses involving days away from work by part of body and nature of injury or illness. Washington, DC. Retrieved from: https:// www.bls.gov/spotlight/2019/25-years-of-worker-injury-illness-and-fatality-casedata/home.htm.

4. The National Institute of Occupational Safety and Health (NIOSH). (2017). Mining facts-2015. National Institute of Occupational Safety and Health, Mining Program. Available online from URL: https:// ttps://www.cdc.gov/niosh/mining/works/statistics-/factsheets/miningfacts2015.html

5. Sosa, E. M., Dean, J. M., \& Brady, J. R. (2019). Performance under impact loads of metacarpal gloves used in the mining industry. Proceedings of the XXXIst Annual Internal Occupational Ergonomics and Safety Conference, LA, June 12-13, 2019

6. West Chester. (2019). West chester 1555RF/XL premium grade reinforced double split leather palm gloves. Fairmount Supply. Retrieved from: https://www.fairmontsupply.com /1121352/Product/West-Chester-1555RF/XL.

7. Ringer. (2019). R-169 super Hero. Ringer Gloves USA. Retrieved from: http://shop.ringersgloves.com/All-Gloves/R-169-Super.

8. Sport Bike Track Gear. (2019). Five RFX3 leather gloves. Motorcycle Apparel and Parts Specialists. USA. Retrieved from: https://www.sportbiketrackgear.com/fiverfx3-leather-gloves/

9. Fonner, A. (2019). Effect of metacarpal gloves on pinch and grip strength. the research repository. West Virginia University, Morgantown.

10. Dianat, I., Haslegrave, C. M., \& Stedmon, A. W. (2012). Using pliers in assembly work: short and long task duration effects of gloves on hand performance capabilities and subjective assessments of discomforts and ease of tool manipulation. Applied Ergonomics, 43(2), 413-423. 
11. Dianat, I., Haslegrave, C. M., \& Stedmon, A. W. (2010). Short and longer duration effects of protective gloves on hand performance capabilities and subjective assessments in a screw-driving task. Ergonomics, 53(12), 1468-1483.

12. Dianat, I., Haslegrave, C. M., \& Stedmon, A. W. (2014). Design options for improving protective gloves for industrial assembly work. Applied ergonomics, 45(4), 1208-1217.

13. Willms, K., Wells, R., \& Carnahan, H. (2009). Glove attributes and their contribution to force decrement and increased effort in power grip. Human Factors, 51(6), 797812.

14. Mital, A., Kuo, T. S. U. A. N. G., \& FAARD, H. F. (1994). A quantitative evaluation of gloves used with non-powered hand tools in routine maintenance tasks. Ergonomics, 37(2), 333-343.

15. Hägg, G. M., Luttmann, A., \& Jäger, M. (2000). Methodologies for evaluating electromyographic field data in ergonomics. Journal of electromyography and kinesiology, 10(5), 301-312.

16. Chang, C. H., \& Shih, Y. C. (2007). The effects of glove thickness and work load on female hand performance and fatigue during an infrequent high-intensity gripping task. Applied Ergonomics, 38(3), 317-324.

17. Claudon, L. (2006). Influence on grip of knife handle surface characteristics and wearing protective gloves. Applied ergonomics, 37(6), 729-735.

18. Kovacs, K., Splittstoesser, R., Maronitis, A., \& Marras, W. S. (2002). Grip force and muscle activity differences due to glove type. AIHA Journal, 63(3), 269-274.

19. Stanton, N. A., Hedge, A., Brookhuis, K., Salas, E., \& Hendrick, H. W. (Eds.). (2004). Handbook of human factors and ergonomics methods. CRC press.

20. Rybczynski, I. C., \& , F. A. (2002). Effects of glove use in a coating removal task. Human factors and ergonomics society annual meeting. Sage CA: Los Angeles, CA: SAGE Publications, 46(13), 1191-1195

21. Larivière, C., Tremblay, G., Nadeau, S., Harrabi, L., Dolez, P., Vu-Khanh, T., \& Lara, J. (2010). Do mechanical tests of glove stiffness provide relevant information relative to their effects on the musculoskeletal system? A comparison with surface electromyography and psychophysical methods. Applied Ergonomics, 41(2), 326-334.

22. Furr, P. A., Roy, S., O'Hara, J. M., \& Briganti, M. (1989). Use of quantitative electromyography (EMG) in the evaluation of fatigue associated with pressure glove work. SAE Technical Paper. 
23. Fitts, P. M. (1954). The information capacity of the human motor system in controlling the amplitude of movement. Journal of Experimental Psychology, 47(6), 381.

24. Shannon, C. E., \& Weaver, W. (1949). The mathematical theory of communication. Urbana, IL.

25. ISO, I. S. O. (2012). 9241--411 Ergonomics of human-system interaction--Part 411: Evaluation methods for the design of physical input devices. International Organization for Standardization.

26. Kabbash, P., \& Buxton, W. A. (1995). The "prince" technique: Fitts' law and selection using area cursors. Human factors in computing systems. ACM Press/Addison-Wesley Publishing Co.

27. Accot, J., \& Zhai, S. (1997, March). Beyond fitts' law: models for trajectory-based hci tasks.

28. Jagacinski, R. J., \& Monk, D. L. (1985). Fitts' law in two dimensions with hand and head movements. Journal of Motor Behavior, 17(1), 77-95.

29. Thumser, Z. C., Slifkin, A. B., Beckler, D. T., \& Marasco, P. D. (2018). Fitts' law in the control of isometric grip force with naturalistic targets. Frontiers in Psychology.

30. MacKenzie, I. S. (1992). Fitts' law as a research and design tool in human-computer interaction. Human-Computer Interaction, 7(1), 91-139.

31. Ware, C., \& Mikaelian, H. H. (1987). An evaluation of an eye tracker as a device for computer input. Acm Sigchi Bulletin, 18(4), 183-188.

32. Radwin, R. G., Vanderheiden, G. C., \& Lin, M. L. (1990). A method for evaluating head-controlled computer input devices using Fitts' law. Human factors, 32(4), 423438.

33. Epps, B. W. (1986). Comparison of six cursor control devices based on Fitts' law models. Human Factors Society Annual Meeting. Sage CA: Los Angeles, CA: SAGE Publications, 30(4), 327-331.

34. MacKenzie, I. S., Kauppinen, T., \& Silfverberg, M. (2001). Accuracy measures for evaluating computer pointing devices. Human factors in computing systems.

35. Johnsgard, T. (1994). Fitts' Law with a virtual reality glove and a mouse: Effects of gain. In Graphics interface. Canadian Information Processing Society.

36. Velloso, E., Alexander, J., Bulling, A., \& Gellersen, H. (2015). Interactions under the desk: A Characterication of Foot Movements for Input in a Seated Position. In Human-Computer Interaction (pp. 384-401). Springer, Cham. 
37. Andres, R. O., \& Hartung, K. J. (1989). Prediction of Head Movement Time using Fitts' law. Human Factors, 31(6), 703-713.

38. Drury, C. G. (1975). Application of fitts' law to foot-pedal design. Human Factors, 17(4), 368-3.

39. Drury, C. G. (1993). A note on fitts' law and assembly order. Ergonomics, 36(7), 801806.

40. West Chester Protective Gear (2019). West chester 1555RF. West Chester Protective Gear, New York.

41. Illinois Glove (2019). Meta-Miner smooth palm 499-B. Illinois Glove Company, Illinois. Retrieved from: https://www.illinoisglove.com/p/product/a4e679fb-3f384841-a22a-e0548d69ac2a/meta-miner-smooth-palm

42. Superior Glove (2019). Endura oilbloc goatskin kevlar-lined impact-resistant driver gloves. Superior Glove, New York. Retrieved from:

https://www.superiorglove.com/en/endura-oilbloc-goatskin-kevlar-lined-anti-impactdriver-gloves

43. ANSI/ISEA 138-2019. (2019). American national standard for performance and classification for impact-resistant gloves. American National Standard Institute.

44. Soukoreff, R. W., \& MacKenzie, I. S. (2004). Towards a standard for pointing device evaluation, perspectives on 27 years of Fitts' law research in HCI. International Journal of Human-Computer Studies, 61(6), 751-789.

45. Fess, E., \& Moran, C. (1981). Clinical assessment recommendations. American Society of Hand Therapists. Grip Strength.

46. de Luca, C. J., Foley, P. J., \& Erim, Z. E. Y. N. E. P. (1996). Motor unit control properties in constant-force isometric contractions. Journal of Neurophysiology, 76(3), 1503-1516.

47. Zipp, P. (1982). Recommendations for the standardization of lead positions in surface electromyography. European Journal of Applied Physiology and Occupational Physiology, 50(1), 41-5.

48. Criswell, E. (2010). Cram's introduction to surface electromyography. Jones \& Bartlett Publishers.

49. Borg, G. (1998). Borg's perceived exertion and pain scales. Human kinetics.

50. MacKenzie, I. S. (2018). Fitts' law. Handbook of Human-Computer Interaction, Hoboken, NJ: Wiley. 
51. MacKenzie, I. S., Sellen, A., \& Buxton, W. A. (1991). A comparison of input devices in element pointing and dragging tasks. Human Factors in Computing Systems.

52. Herring, S. R., Trejo, A. E., \& Hallbeck, M. S. (2010). Evaluation of four cursor control devices during a target acquisition task for laparoscopic tool control. Applied ergonomics, 41(1), 47-57.

53. Wells, R., Hunt, S., Hurley, K., \& Rosati, P. (2010). Laboratory assessment of the effect of heavy rubber glove thickness and sizing on effort, performance and comfort. International Journal of Industrial Ergonomics, 40(4), 386-391.

54. Parvatikar, V. B., \& Mukkannavar, P. B. (2009). Comparative study of grip strength in different positions of shoulder and elbow with wrist in neutral and extension positions. Journal of Exercise Science and Physiotherapy, 5(2), 67.

55. Motabar, H., Nimbarte, A. D., \& Raub, E. (2019). Strength, endurance and fatigue response of rotator cuff muscles during isometric exertions. International Journal of Industrial Ergonomics, 71, 128-135.

56. Shaffer, S. W., \& Harrison, A. L. (2007). Aging of the somatosensory system: a translational perspective. Physical therapy, 87(2), 193-207.

57. Microscribe. (2019). Microscribe Portable CMMS Combining Functionality with Affordability. GoMeasure3D, Virginia. 


\section{Appendix I: Anthropometric Measurement of Participant}

\begin{tabular}{|c|c|c|c|c|c|}
\hline Participant & Age (years) & Weight (pounds) & Height (feet) & Knuckles Width (inches) & Palm Size (inches) \\
\hline 1 & 27 & 138.6 & 5.2 & 3 & 6.5 \\
\hline 2 & 23 & 155 & 5.7 & 3.5 & 7 \\
\hline 3 & 33 & 175 & 6.1 & 3.25 & 7.75 \\
\hline 4 & 22 & 149.6 & 5.5 & 3.5 & 6 \\
\hline 5 & 31 & 125 & 5.6 & 3.5 & 7.5 \\
\hline 6 & 26 & 137 & 5.4 & 3.25 & 7 \\
\hline 7 & 24 & 136.4 & 5.7 & 3.5 & 7 \\
\hline 8 & 24 & 178 & 5.9 & 3.75 & 7 \\
\hline 9 & 24 & 178 & 5.3 & 3.25 & 7.25 \\
\hline 10 & 30 & 132 & 5.4 & 3.25 & 7 \\
\hline 11 & 27 & 63 & 5.2 & 3.25 & 6.75 \\
\hline 12 & 27 & 141 & 5.2 & 3 & 6 \\
\hline 13 & 23 & 140 & 5.7 & 3.5 & 7 \\
\hline 14 & 34 & 200 & 5.6 & 3.75 & 7.5 \\
\hline 15 & 29 & 120 & 5.4 & 3.5 & 7.25 \\
\hline
\end{tabular}




\title{
APPENDIX II: IRB CONSENT FORM
}

\section{W- WestliriginiaUniversity.}

Human Research Protocol

Only Minimal Risk Consent Form

Without HIPAA

\author{
Only Minimal Risk \\ Consent Information Form (without HIPAA) \\ Principal Investigator Dr. Ashish Nimbarte \\ Department Engineering-Industrial and Management Systems Engineering \\ Protocol Number $\quad 1907641707$ \\ Study Title Can Fitts' Throughput Be A Predictor of Muscle Fatigue- A Study Based on \\ Metacarpal Gloves? \\ Co-Investigator(s) Sachin Sah \\ Sponsor (if any) N/A \\ Contact Persons \\ Click here to enter text.
}

In the event you experience any side effects or injury related to this research, you should contact Dr. Ashish Nimbarte at (304) 293-9473. If you have any questions, concerns, or complaints about this research, you can contact Dr. Ashish Nimbarte at (304) 293-9473.

For information regarding your rights as a research subject, to discuss problems, concerns, or suggestions related to the research, to obtain information or offer input about the research, contact the Office of Research Integrity and Compliance at (304) 293-7073.

In addition if you would like to discuss problems, concerns, have suggestions related to research, or would like to offer input about the research, contact the Office of Research Integrity and Compliance at 304-293-7073.

\section{Introduction}

You, have been asked to participate in this research study, which has been explained to you by Mr. Sachin Sah. This study is being conducted by Dr. Ashish Nimbarte in the Department of Industrial and Management Systems Engineering at West Virginia University.

\section{Purpose(s) of the Study}

The purpose of this study to evaluate a new method of hand-glove performance. This new method is based on the concept of Throughput, developed by Fitt's Law. The effect of the glove on the hand performance measure using Throughput will be further validated by conducting a fatigue study. In the fatigue study, activation of four-hand muscles will be recorded using surface electromyography (SEMG). In this study, six glove condition will be tested-five metacarpal gloves and no glove/bare hand.

\author{
Chestnut Ridge Research Building \\ 886 Chestnut Ridge Road \\ Phone: $304-293-7073$ \\ Fax: 304-293-3098 \\ http://oric. research.wvu.edu \\ PO Box 6845 \\ Morgantown, WV 26506-6845
}

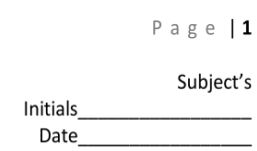




\section{W- WestlirginiaUniversity.}

Human Research Protocol Only Minimal Risk Consent Form

Without HIPAA

\section{Description of Procedures}

1) Upon arrival, the data collection procedure will be explained to the participants and their signature will be obtained on informed consent. 2) Basic anthropocentric measurements including age, body weight, height, and hand measurement will be recorded. 3) Participants will be introduced with the glove condition (five Metacarpal gloves and no-glove), Target Transfer Task and Fatigue Test. 4) Next, the participants will perform simple transfer tasks. Each task will consist of transferring a circular target from the starting position to the target position. The target transfer tasks consists of 6 different layout combination attached on steel plates of a different dimension. In each trial, a rest period of 2 minutes will be provided. A total of 36 trial will be performed and image of trial will be recorded. 5) The participants will then be prepared for muscle fatigue study. Surface Electromyography will be placed on four-hand muscles- Extensor Digitorum, Extensor Carpi Radialis, Flexor Carpi Radialis, and Flexor Digitorum Superficialis. 6) Participants will be seated on standardized hang grip position and three to five maximum grip strength will be recorded using a hand dynamometer. The duration of exertion while measuring maximal handgrip will be between 3 to 5 seconds. Rest periods of 2 minutes will be provided between the trials. 7) Next, the participants will exert $35 \%$ of their maximum grip strength under the glove condition using the dynamometer for a duration of 60 seconds. Surface electromyography data will be recorded continuously during the fatigue test. Rest periods of 5 minutes will be provided between the trials.

\section{Discomforts}

There are no known or expected risks from participating in this study, except for the mild frustration associated with answering the questions.

\section{Alternatives}

You do not have to participate in this study.

\section{Benefits}

You may not receive any direct benefit from this study. The knowledge gained from this study may eventually benefit others.

\section{Financial Considerations}

There are no special fees for participating in this study.

\section{Confidentiality}

Any information about you that is obtained as a result of your participation in this research will be kept as confidential as legally possible. Your research records and test results, just like hospital records, may be subpoenaed by court order or federal regulatory authorities (including the FDA if applicable) without your additional consent.

In addition, there are certain instances where the researcher is legally required to give information to the appropriate

\begin{tabular}{r|lr} 
& Chestnut Ridge Research Building & P a g e | 2 \\
Phone: 304-293-7073 & 886 Chestnut Ridge Road & Subject's \\
Fax: 304-293-3098 & PO Box 6845 & Initials__ \\
http://oric.research.wvu.edu & Morgantown, WV 26506-6845 & Date_te
\end{tabular}




\section{W- WestVriginiaUniversity.}

Human Research Protocol Only Minimal Risk Consent Form

Without HIPAA

authorities. These would include mandatory reporting of infectious diseases, mandatory reporting of information about behavior that is imminently dangerous to your child or to others, such as suicide, child abuse, etc.

Audiotapes or videotapes will be kept locked up and will be destroyed as soon as possible after the research is finished. In any publications that result from this research, neither your name nor any information from which you might be identified will be published without your consent.

\section{Voluntary Participation}

Participation in this study is voluntary. You are free to withdraw your consent to participate in this study at any time.

Refusal to participate or withdrawal will not affect [your class standing or grades, as appropriate] and will involve no penalty to you. Refusal to participate or withdrawal will not affect your future care, or [your employee status, as appropriate] at West Virginia University.

In the event new information becomes available that may affect your willingness to participate in this study, this information will be given to you so that you can make an informed decision about whether or not to continue your participation.

You have been given the opportunity to ask questions about the research, and you have received answers concerning areas you did not understand.

Upon signing this form, you will receive a copy.

I willingly consent to participate in this research.

Signatures

Signature of Subject

$\begin{array}{lll}\text { Printed Name Time } & \text { Date }\end{array}$

The participant has had the opportunity to have questions addressed. The participant willingly agrees to be in the study.

Signature of Investigator or Co-Investigator

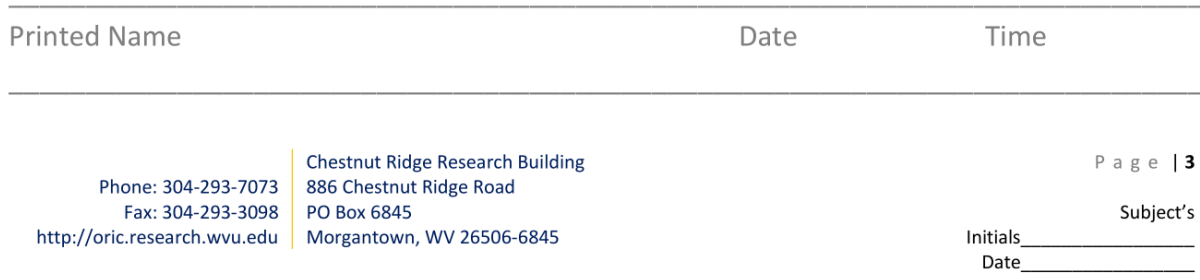

Approved:11-Sep-2019Expires:10-Sep-2021Number:1907641707 


\section{APPENDIX III: Glove Sizing Chart}

1. GLOVE SIZING CHART FOR GLOVE 1

\section{GLOVE SIZING CHART}

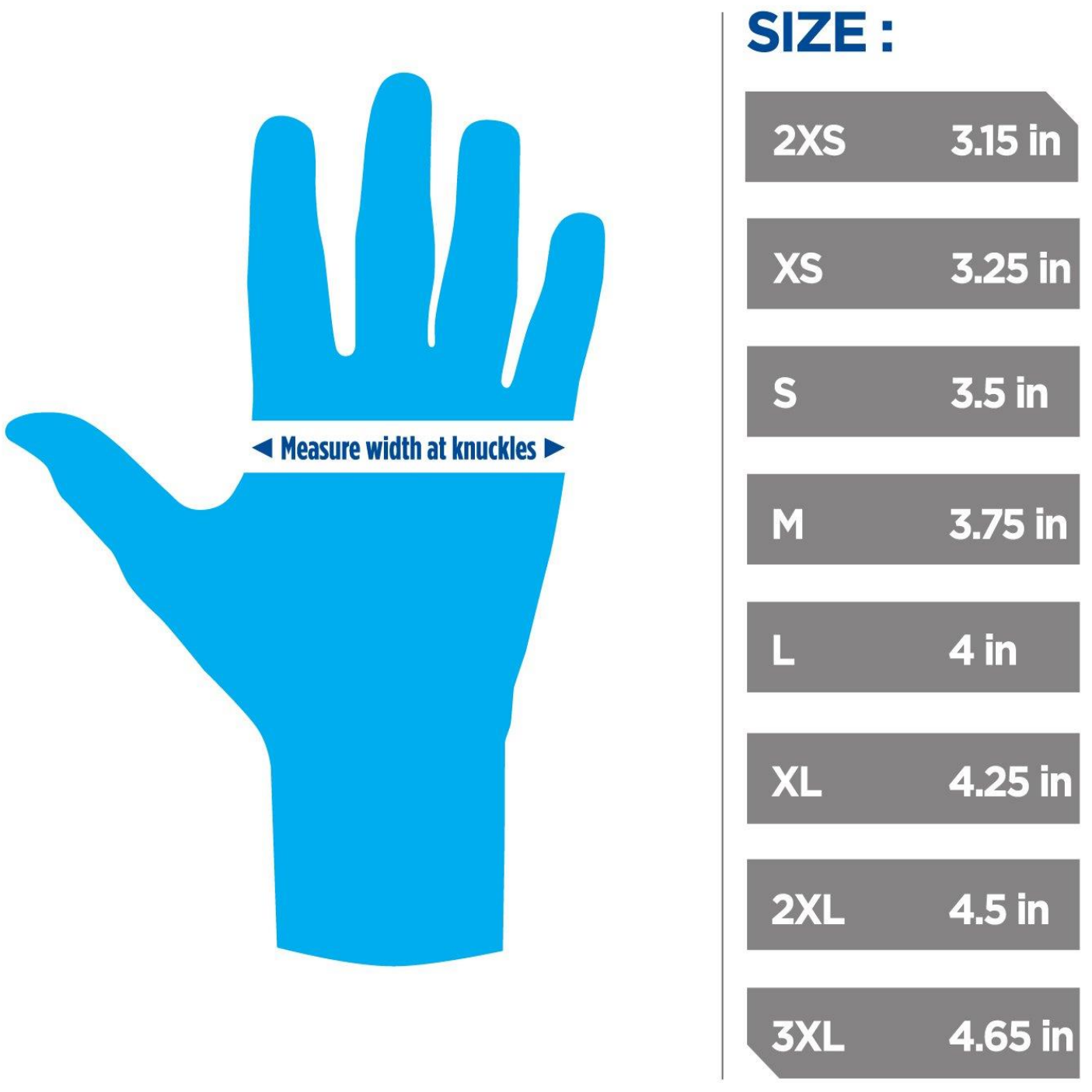




\section{GLOVE SIZING CHART FOR GLOVE 2}



\begin{tabular}{|c|c|c|c|}
\hline \multirow{2}{*}{$\begin{array}{l}\text { Glove Size } \\
\text { if you're between sizes, } \\
\text { we reccommend sizing } 00 \text { ww } \\
\text { for a snug fit. }\end{array}$} & \multicolumn{3}{|c|}{$\begin{array}{l}\text { PALM WIDTH } \\
\begin{array}{c}\text { Measure your palm width } \\
\text { from position A to B. }\end{array}\end{array}$} \\
\hline & MEN'S & WOMEN'S & KID'S \\
\hline Small & $3 \mathrm{in} / 76 \mathrm{~mm}$ & 2.75 in $/ 70 \mathrm{~mm}$ & \\
\hline Medium & $3.5 \mathrm{in} / 88 \mathrm{~mm}$ & $3 \mathrm{in} / 76 \mathrm{~mm}$ & 2.75 in $/ 70 \mathrm{~mm}$ \\
\hline Large & $4 \mathrm{in} / 101 \mathrm{~mm}$ & & \\
\hline $\mathrm{XL}$ & $4.5 \mathrm{in} / 114 \mathrm{~mm}$ & & \\
\hline $\mathbf{X X L}$ & $5 \mathrm{in} / 126 \mathrm{~mm}$ & & \\
\hline$X X X L$ & $5.5 \mathrm{in} / 139.7 \mathrm{~mm}$ & & \\
\hline
\end{tabular}




\section{GLOVE SIZING CHART FOR GLOVE 3}

\section{Glove Sizes: Measure Your Hand}

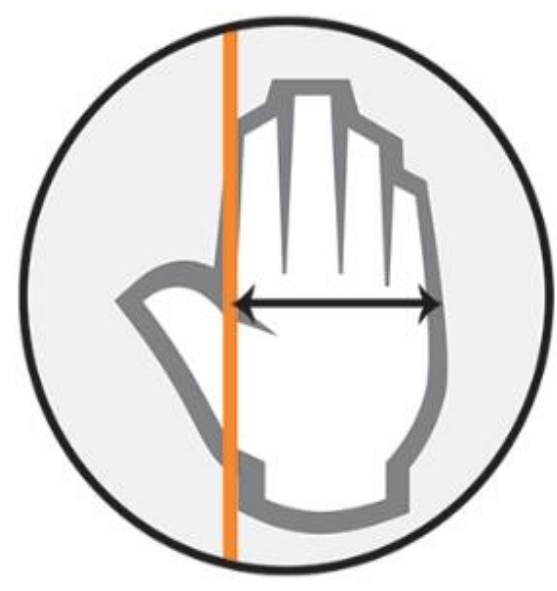

$5 / 2 \times S 50 \mathrm{~mm} / 2$ inches

6/XS $63 \mathrm{~mm} / 2.5$ inches

$7 / \mathrm{S} 75 \mathrm{~mm} / 3$ inches

$8 / \mathbf{M} 88 \mathrm{~mm} / 3.5$ inches

$\mathbf{9} / \mathbf{L} 101 \mathrm{~mm} / 4$ inches

$10 / \mathrm{XL} 113 \mathrm{~mm} / 4.5$ inches

$\mathbf{1 1 / 2 X \mathbf { L }} 126 \mathrm{~mm} / 5$ inches

$12 / 3 X L 140 \mathrm{~mm} / 5.5$ inches

Measure the width of your hand from the base of your first finger and across your knuckles.

$5 / 2 X S 50 \mathrm{~mm} / 2$ inches

6/XS $63 \mathrm{~mm} / 2.5$ inches

$7 / \mathrm{S} 75 \mathrm{~mm} / 3$ inches

$8 / \mathrm{M} 88 \mathrm{~mm} / 3.5$ inches

9/L $101 \mathrm{~mm} / 4$ inches

10/XL $113 \mathrm{~mm} / 4.5$ inches

11/2XL $126 \mathrm{~mm} / 5$ inches

12/3XL $140 \mathrm{~mm} / 5.5$ inches 


\section{APPENDIX IV: MATLAB Code for Image Processing}

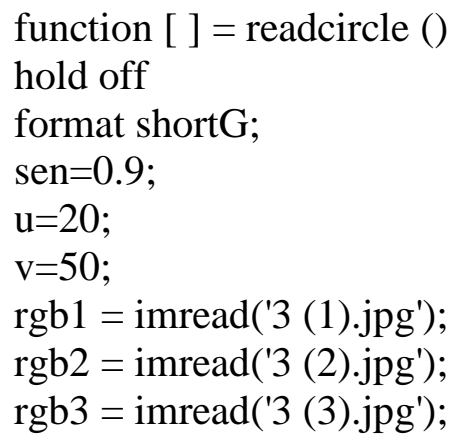

\%read first image

gray_image $1=$ rgb2gray $($ rgb1 $)$;

figure(1)

imshow(gray_image1)

$\% \mathrm{~d}=$ imdistline;

[centers1,radii1] = imfindcircles(rgb1,[u v],'ObjectPolarity','dark','Sensitivity',sen);

h1 = viscircles $($ centers 1, radii1 $)$;

$\mathrm{r} 1=\operatorname{radii} 1(:, 1)$

$\mathrm{x} 1=$ centers $1(:, 1)$

$\mathrm{y} 1=\operatorname{centers} 1(:, 2)$

pl_image = imgca;

hold(pl_image,'on')

plot(pl_image,x1(:,1),y1(:,1),'r*','Linestyle','none')

hold(pl_image,'off')

\%read figure 2

gray_image $2=$ rgb2gray $(\operatorname{rgb} 2)$;

figure(2)

imshow(gray_image2)

[centers2,radii2] = imfindcircles(rgb2,[u v],'ObjectPolarity','dark','Sensitivity',sen); h2 = viscircles (centers2,radii2);

$\mathrm{r} 2=\operatorname{radii} 2(:, 1)$;

$\mathrm{x} 2=\operatorname{centers} 2(:, 1)$

$\mathrm{y} 2=\operatorname{centers} 2(:, 2)$

pl_image =imgca;

hold(pl_image,'on')

plot(pl_image,x2(:,1),y2(:,1),'r*','Linestyle','none')

hold(pl_image,'off')

\%read figure 3

gray_image $3=$ rgb2gray $($ rgb3 $)$;

figure(3)

imshow(gray_image3)

[centers3,radii3] = imfindcircles(rgb3,[u v],'ObjectPolarity','dark','Sensitivity',sen);

$\mathrm{h} 3=$ viscircles $($ centers 3 ,radii3 $)$;

r3 = radii3 $(:, 1)$

$\mathrm{x} 3=\operatorname{centers} 3(:, 1)$ 
$\mathrm{y} 3=$ centers $3(:, 2)$

pl_image = imgca;

hold(pl_image,'on')

plot(pl_image,x3(:,1),y3(:,1),'r*','Linestyle','none')

hold(pl_image,'off')

axis on;

end 


\section{APPENDIX V: MATLAB Code for MF Calculation}

clear all;

clc

close all

rootPath = 'C: IUsers\ss0191\Desktop\EMG Data Pointl';

patientDirectory1 = 'Subject';

\%patientDirectory2 = ' Data Analysisl';

numberOfPatients $=15$; \%last patient \#

numberOfFiles = [ $\left[\begin{array}{llll}1 & 2 & 3 & 4\end{array}\right]$;

for patient $=1$ : numberOfPatients

patientPath $=[$ patientDirectory1, ' ' , num2str(patient),''l'];

for fileLooper $=1$ : numberOfFiles

fileName = strcat('\#',num2str(patient),'-',num2str(fileLooper));

completePath $=$ strcat(rootPath, patientPath,fileName,'.txt');

Raw $=$ load(completePath)

divisions $=10$;

window_size $=1000$;

fs $=1000 ; \%$ Sampling frequency

numberOfMuscles = 5;

for $\mathrm{j}=1$ :divisions

EMG_cut_Beg_Time $=(($ length $($ Raw $) /$ divisions $)) *(j-1)+1$;

EMG_cut_End_Time $=($ length $($ Raw $) /$ divisions $) *(j-1)+$ window_size;

for $\mathrm{i}=1$ :numberOfMuscles

EMG_R = Raw(EMG_cut_Beg_Time:EMG_cut_End_Time,i);\% extract each muscle data

[m,z]=size(EMG_R); \% Size of the raw signal

EMG_R = EMG_R - mean(EMG_R); \%Demeaned

$\mathrm{n}=$ floor $(\mathrm{m} / \mathrm{fs}) ; \%$ duration in \# of full seconds

$\mathrm{sn}=\mathrm{n} * \mathrm{fs} ; \%$ to get only integer \# of data

$\mathrm{EMG}=\mathrm{EMG} \mathrm{R}(1: \mathrm{sn},:) ; \%$ data length

$\mathrm{N}=\mathrm{n} * \mathrm{fs} / 2 ; \%$ number of samples in half of FFT

$\mathrm{f}=\mathrm{fs} *(0: \mathrm{N}-1) / 2 / \mathrm{N} ; \%$ frequency scaling use for median frequency computation

$\mathrm{X}=\mathrm{fft}(\mathrm{EMG})$;

$\%$ Filters $0-12 \mathrm{~Hz}$

$\mathrm{X}((\mathrm{n} * 0+1):(\mathrm{n} *(12)+1))=0$;

$\mathrm{X}($ length $(\mathrm{X})-(\mathrm{n} *(12)-1):$ length $(\mathrm{X})-(\mathrm{n} * 1-1))=0 ; \%$ high pass filtering

$\%$ Filters 59-61 Hz

$\mathrm{X}((\mathrm{n} * 59+1):(\mathrm{n} *(61)+1))=0$;

$\mathrm{X}($ length $(\mathrm{X})-(\mathrm{n} *(61)-1)$ :length $(\mathrm{X})-(\mathrm{n} * 59-1))=0 ; \%$ Attenuating line interference \%Filters $119-121 \mathrm{~Hz}$

$\mathrm{X}((\mathrm{n} * 119+1):(\mathrm{n} *(121)+1))=0$; 
$\mathrm{X}($ length $(\mathrm{X})-(\mathrm{n} *(121)-1):$ length $(\mathrm{X})-(\mathrm{n} * 119-1))=0 ; \%$ Attenuating line interference

\%Filters $179-181 \mathrm{~Hz}$

$\mathrm{X}((\mathrm{n} * 179+1):(\mathrm{n} *(181)+1))=0$;

$\mathrm{X}($ length $(\mathrm{X})-(\mathrm{n} *(181)-1):$ length $(\mathrm{X})-(\mathrm{n} * 179-1))=0 ; \%$ Attenuating line interference

\%Filters $239-241 \mathrm{~Hz}$

$\mathrm{X}((\mathrm{n} * 239+1):(\mathrm{n} *(241)+1))=0$;

$\mathrm{X}($ length $(\mathrm{X})-(\mathrm{n} *(241)-1):$ length $(\mathrm{X})-(\mathrm{n} * 239-1))=0 ; \%$ Attenuating line interference

\%Filters 299-301 Hz

$\mathrm{X}((\mathrm{n} * 299+1):(\mathrm{n} *(301)+1))=0$;

$\mathrm{X}($ length $(\mathrm{X})-(\mathrm{n} *(301)-1)$ :length $(\mathrm{X})-(\mathrm{n} * 299-1))=0 ; \%$ Attenuating line interference

\%Filters $359-361 \mathrm{~Hz}$

$\mathrm{X}((\mathrm{n} * 359+1):(\mathrm{n} *(361)+1))=0$;

$\mathrm{X}($ length $(\mathrm{X})-(\mathrm{n} *(361)-1)$ :length $(\mathrm{X})-(\mathrm{n} * 359-1))=0 ; \%$ Attenuating line interference

$\%$ Filters $400-1000 \mathrm{~Hz}$

$\mathrm{X}((\mathrm{n} * 400+1):(\mathrm{n} *(500)+1))=0$;

$\mathrm{X}($ length$(\mathrm{X})-(\mathrm{n} *(500)-1):$ length $(\mathrm{X})-(\mathrm{n} * 400-1))=0 ; \%$ low pass filtering

power $=\operatorname{abs}(\mathrm{X}(1: \mathrm{N}+1)) .^{\wedge} 2$;

area $=$ cumsum (power);

areaMax $=$ area (length (area)); \%return the last value in AREA

areaTarget $=.5 *$ areaMax; \% half of the area (cumsum)

areaHalf $=0$;

index $=1$;

while (areaHalf < areaTarget) \%run until areaHalf is bigger than areaTarget index $=$ index +1 ;

areaHalf $=$ area (index);

end

$\mathrm{MF}=\mathrm{f}($ index $) ; \%$ find the median frequency of muscel $\mathrm{k}$ from the new frequency index "f"

MFall(j,i)=MF;

end;

end;

openvar('MFall');

save(strcat('MFall',num2str(patient),fileName),'MFall');

\%end

end

end 


\section{APPENDIX VI: JMP Result for Normal Quantile Plot of Throughput}

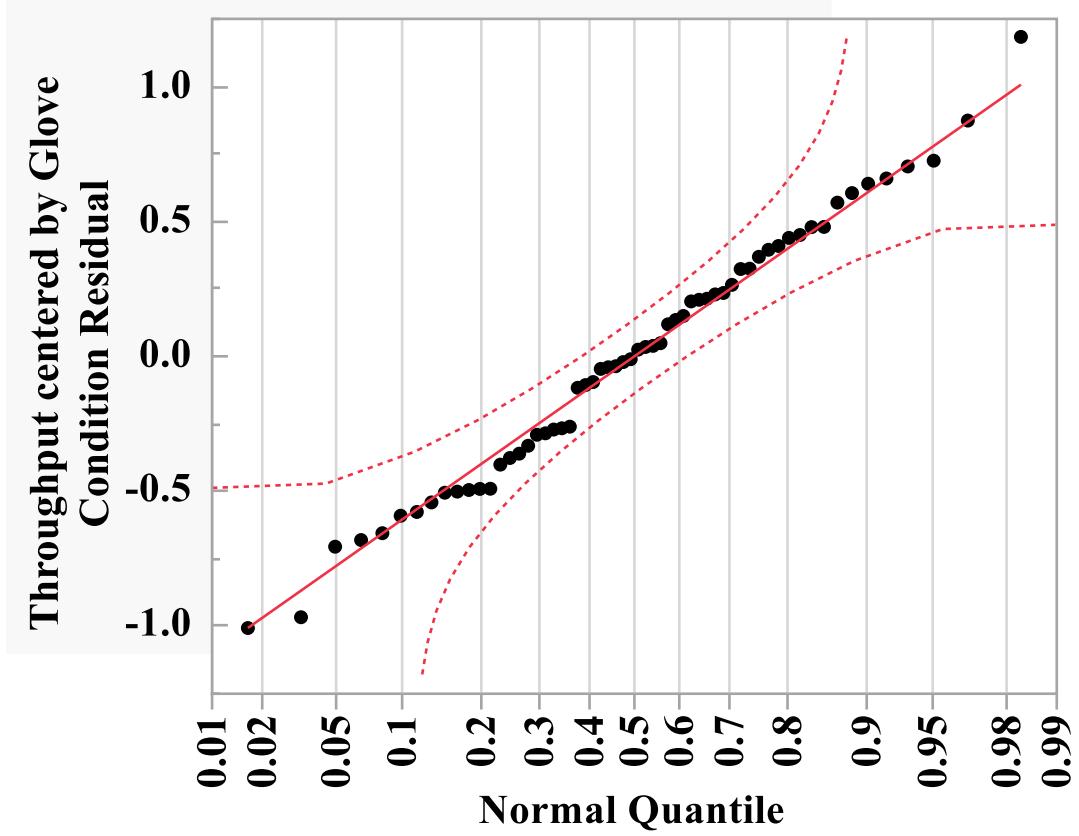

Figure: Residual Normality Plot

Tests that the Variances are Equal

$\begin{array}{lrrrr}\text { Test } & \text { F Ratio } & \text { DFNum } & \text { DFDen } & \text { Prob > F } \\ \text { O'Brien[.5] } & 1.7396 & 3 & 56 & 0.1694 \\ \text { Brown-Forsythe } & 0.5477 & 3 & 56 & 0.6518 \\ \text { Levene } & 0.6414 & 3 & 56 & 0.5916 \\ \text { Bartlett } & 1.0608 & 3 & . & 0.3643\end{array}$




\section{APPENDIX VII: JMP Result for Normal Quantile Plot of Total NMAV Normality}

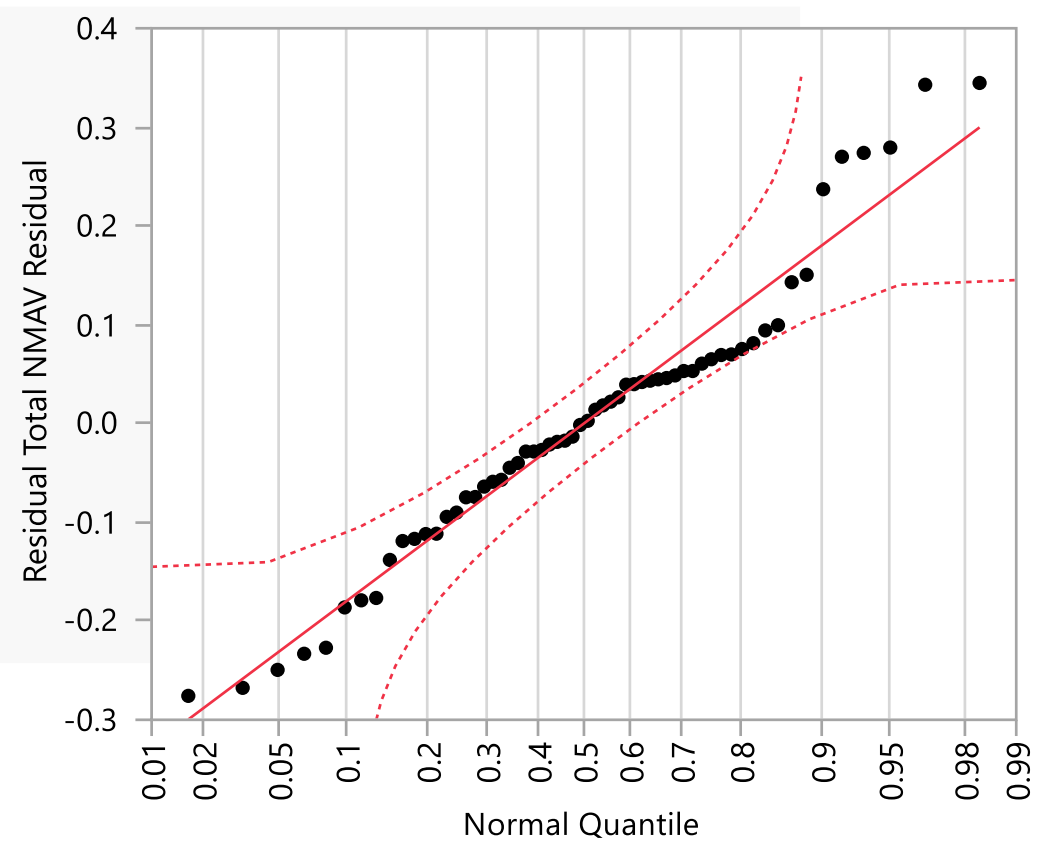

Figure: Residual Normal Quantile Plot

Tests that the Variances are Equal

\begin{tabular}{lrrrr} 
Test & F Ratio & DFNum & DFDen & Prob > F \\
\hline O'Brien[.5] & 0.1370 & 3 & 56 & 0.9375 \\
Brown-Forsythe & 0.0183 & 3 & 56 & 0.9966 \\
Levene & 0.0150 & 3 & 56 & 0.9975 \\
Bartlett & 0.1682 & 3 &. & 0.9179
\end{tabular}




\section{APPENDIX VIII: JMP Result for Normal Quantile Plot of}

Average \% drop in MF

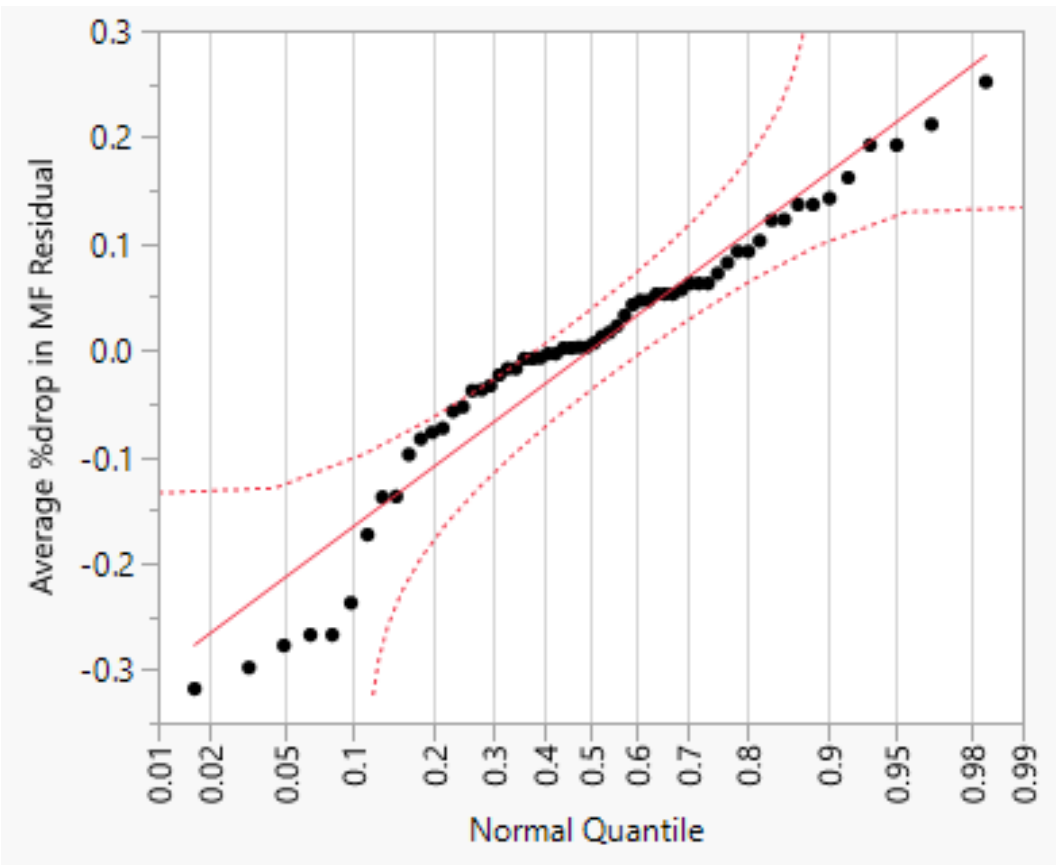

Figure: Residual Normal Quantile Plot

Tests that the Variances are Equal

$\begin{array}{lrrrr}\text { Test } & \text { F Ratio } & \text { DFNum } & \text { DFDen } & \text { Prob > F } \\ \text { O'Brien[.5] } & 1.4576 & 3 & 56 & 0.2360 \\ \text { Brown-Forsythe } & 1.1741 & 3 & 56 & 0.3278 \\ \text { Levene } & 1.3027 & 3 & 56 & 0.2826 \\ \text { Bartlett } & 2.1190 & 3 & . & 0.0955\end{array}$




\section{APPENDIX IX: JMP Result for Normal Quantile Plot Perceived Exertions}

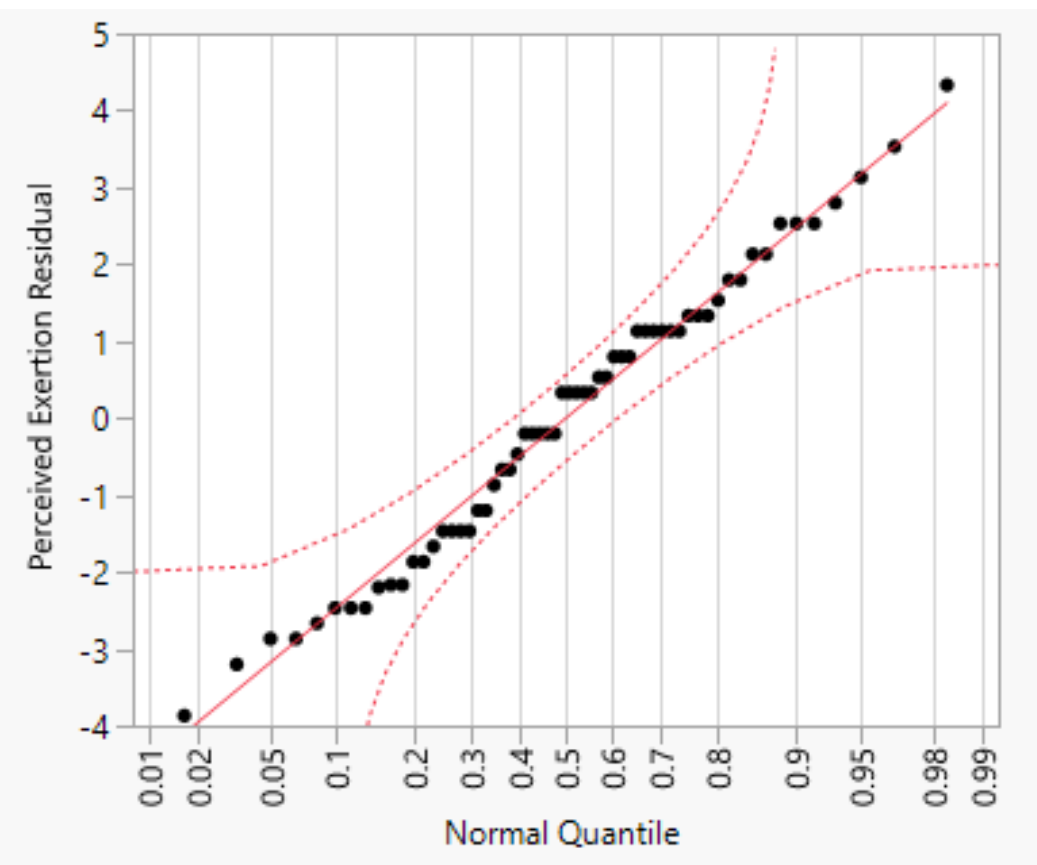

Figure: Residual Normal Quantile Plot

Tests that the Variances are Equal

$\begin{array}{lrrrr}\text { Test } & \text { F Ratio } & \text { DFNum } & \text { DFDen } & \text { Prob > F } \\ \text { O'Brien[.5] } & 0.8524 & 3 & 56 & 0.4712 \\ \text { Brown-Forsythe } & 0.8644 & 3 & 56 & 0.4650 \\ \text { Levene } & 1.9512 & 3 & 56 & 0.1318 \\ \text { Bartlett } & 0.5912 & 3 & . & 0.6207\end{array}$




\section{APPENDIX X: Effective Index of Difficulty}

\begin{tabular}{|c|c|c|c|c|c|c|c|}
\hline Participant & Glove Condition & Plate 1 & Plate 2 & Plate 3 & Plate 4 & Plate 5 & Plate 6 \\
\hline 1 & Bare hand & 2.69 & 3.16 & 4.46 & 4.23 & 4.81 & 5.35 \\
\hline 2 & Bare hand & 2.69 & 3.16 & 3.70 & 4.23 & 4.81 & 5.35 \\
\hline 3 & Bare hand & 2.51 & 3.08 & 3.69 & 4.22 & 4.78 & 5.35 \\
\hline 4 & Bare hand & 2.48 & 3.12 & 3.67 & 4.22 & 4.78 & 5.35 \\
\hline 5 & Bare hand & 2.52 & 3.14 & 3.69 & 4.23 & 4.79 & 5.35 \\
\hline 6 & Bare hand & 2.48 & 3.07 & 3.68 & 4.23 & 4.78 & 5.35 \\
\hline 7 & Bare hand & 2.48 & 3.11 & 3.68 & 4.23 & 4.78 & 5.35 \\
\hline 8 & Bare hand & 2.51 & 3.09 & 3.70 & 4.23 & 4.78 & 5.35 \\
\hline 9 & Bare hand & 2.48 & 3.10 & 3.68 & 4.23 & 4.77 & 5.35 \\
\hline 10 & Bare hand & 2.50 & 3.07 & 3.68 & 4.23 & 4.78 & 5.35 \\
\hline 11 & Bare hand & 2.49 & 3.11 & 3.68 & 4.23 & 4.78 & 5.35 \\
\hline 12 & Bare hand & 2.48 & 3.10 & 3.68 & 4.24 & 4.78 & 5.35 \\
\hline 13 & Bare hand & 2.50 & 3.12 & 3.68 & 4.23 & 4.79 & 5.36 \\
\hline
\end{tabular}




\begin{tabular}{|c|c|c|c|c|c|c|c|}
\hline 14 & Bare hand & 2.50 & 3.13 & 3.68 & 4.23 & 4.80 & 5.36 \\
\hline 15 & Bare hand & 2.48 & 3.11 & 3.69 & 4.22 & 4.78 & 5.35 \\
\hline 1 & Glove 1 & 2.67 & 3.15 & 5.23 & 4.23 & 4.81 & 5.36 \\
\hline 2 & Glove 1 & 2.50 & 3.13 & 3.67 & 4.23 & 4.78 & 5.36 \\
\hline 3 & Glove 1 & 2.51 & 3.10 & 3.67 & 4.23 & 4.78 & 5.36 \\
\hline 4 & Glove 1 & 2.49 & 3.13 & 3.67 & 4.23 & 4.78 & 5.36 \\
\hline 5 & Glove 1 & 2.48 & 3.11 & 3.68 & 4.22 & 4.78 & 5.36 \\
\hline 6 & Glove 1 & 2.49 & 3.07 & 3.67 & 4.23 & 4.78 & 5.35 \\
\hline 7 & Glove 1 & 2.47 & 3.13 & 3.69 & 4.12 & 4.78 & 5.35 \\
\hline 8 & Glove 1 & 2.48 & 2.85 & 6.69 & 4.28 & 4.77 & 5.34 \\
\hline 9 & Glove 1 & 2.49 & 3.13 & 3.70 & 4.23 & 4.77 & 5.35 \\
\hline 10 & Glove 1 & 2.48 & 3.05 & 3.68 & 4.23 & 4.78 & 5.35 \\
\hline 11 & Glove 1 & 2.48 & 3.12 & 3.67 & 4.23 & 4.78 & 5.35 \\
\hline 12 & Glove 1 & 2.49 & 3.10 & 3.68 & 4.23 & 4.78 & 5.35 \\
\hline 13 & Glove 1 & 2.51 & 3.12 & 3.68 & 4.24 & 4.78 & 5.35 \\
\hline 14 & Glove 1 & 2.50 & 3.12 & 3.67 & 4.24 & 4.80 & 5.36 \\
\hline 15 & Glove 1 & 2.48 & 3.10 & 3.68 & 4.22 & 4.77 & 5.35 \\
\hline
\end{tabular}




\begin{tabular}{|c|c|c|c|c|c|c|c|}
\hline 1 & Glove 2 & 2.66 & 3.18 & 5.17 & 4.24 & 4.80 & 5.36 \\
\hline 2 & Glove 2 & 2.51 & 3.12 & 3.67 & 4.23 & 4.79 & 5.36 \\
\hline 3 & Glove 2 & 2.52 & 3.10 & 3.68 & 4.24 & 4.66 & 5.37 \\
\hline 4 & Glove 2 & 3.08 & 3.11 & 3.67 & 4.22 & 4.78 & 5.36 \\
\hline 5 & \begin{tabular}{|l} 
Glove 2 \\
\end{tabular} & 2.51 & 3.12 & 3.67 & 4.23 & 4.78 & 5.38 \\
\hline 6 & Glove 2 & 2.49 & 3.08 & 3.68 & 4.23 & 4.78 & 5.34 \\
\hline 7 & Glove 2 & 2.49 & 3.11 & 3.69 & 4.23 & 4.78 & 5.35 \\
\hline 8 & Glove 2 & 2.50 & 3.09 & 3.68 & 4.23 & 4.78 & 5.35 \\
\hline 9 & Glove 2 & 2.49 & 3.13 & 3.70 & 4.23 & 4.77 & 5.35 \\
\hline 10 & Glove 2 & 2.49 & 3.11 & 3.68 & 4.23 & 4.78 & 5.35 \\
\hline 11 & Glove 2 & 2.47 & 3.08 & 3.68 & 4.23 & 4.78 & 5.35 \\
\hline 12 & \begin{tabular}{|l} 
Glove 2 \\
\end{tabular} & 2.49 & 3.11 & 3.68 & 4.23 & 4.79 & 5.35 \\
\hline 13 & Glove 2 & 2.51 & 3.12 & 3.69 & 4.23 & 4.79 & 5.35 \\
\hline 14 & \begin{tabular}{|l|} 
Glove 2 \\
\end{tabular} & 2.50 & 3.13 & 3.68 & 4.23 & 4.81 & 5.36 \\
\hline 15 & Glove 2 & 2.49 & 3.09 & 3.69 & 4.22 & 4.78 & 5.35 \\
\hline 1 & \begin{tabular}{|l|} 
Glove 3 \\
\end{tabular} & 2.66 & 3.17 & 4.77 & 4.24 & 4.80 & 5.35 \\
\hline 2 & Glove 3 & 2.51 & 3.11 & 3.67 & 4.23 & 4.78 & 5.36 \\
\hline
\end{tabular}




\begin{tabular}{|c|c|c|c|c|c|c|c|}
\hline 3 & Glove 3 & 2.51 & 3.11 & 3.68 & 4.23 & 4.66 & 5.36 \\
\hline 4 & Glove 3 & 2.46 & 3.15 & 3.66 & 4.23 & 4.78 & 5.36 \\
\hline 5 & Glove 3 & 2.48 & 3.11 & 3.67 & 4.23 & 4.79 & 5.35 \\
\hline 6 & Glove 3 & 2.48 & 3.09 & 3.67 & 4.22 & 4.77 & 5.34 \\
\hline 7 & \begin{tabular}{|l} 
Glove 3 \\
\end{tabular} & 2.47 & 3.11 & 3.68 & 4.23 & 4.77 & 5.34 \\
\hline 8 & Glove 3 & 2.48 & 3.09 & 3.67 & 4.23 & 4.77 & 5.34 \\
\hline 9 & Glove 3 & 2.50 & 3.08 & 3.71 & 4.22 & 4.77 & 5.35 \\
\hline 10 & Glove 3 & 2.49 & 3.05 & 3.68 & 4.23 & 4.78 & 5.35 \\
\hline 11 & Glove 3 & 2.48 & 3.09 & 3.68 & 4.23 & 4.77 & 5.35 \\
\hline 12 & Glove 3 & 2.48 & 3.05 & 3.68 & 4.23 & 4.78 & 5.35 \\
\hline 13 & Glove 3 & 2.50 & 3.11 & 3.68 & 4.23 & 4.76 & 5.36 \\
\hline 14 & \begin{tabular}{|l} 
Glove 3 \\
\end{tabular} & 2.50 & 3.13 & 3.68 & 4.23 & 4.80 & 5.35 \\
\hline 15 & Glove 3 & 2.49 & 3.13 & 3.68 & 4.22 & 4.77 & 5.35 \\
\hline
\end{tabular}


APPENDIX XI: Throughput

\begin{tabular}{|c|c|c|c|c|c|c|c|c|c|c|c|c|c|c|c|}
\hline & \multicolumn{15}{|c|}{ Participant } \\
\hline & 1 & 2 & 3 & 4 & 5 & 6 & 7 & 8 & 9 & 10 & 11 & 12 & 13 & 14 & 15 \\
\hline Bare Hand & 3.15 & 2.81 & 4.08 & 3.41 & 3.86 & 3.18 & 3.20 & 4.24 & 2.61 & 2.36 & 3.48 & 2.29 & 3.05 & 3.13 & 2.66 \\
\hline Glove 1 & 1.81 & 2.42 & 2.95 & 2.49 & 2.91 & 2.80 & 2.45 & 2.22 & 2.37 & 2.03 & 2.49 & 1.85 & 2.20 & 2.42 & 1.65 \\
\hline Glove 2 & 1.80 & 2.53 & 2.67 & 3.01 & 2.91 & 2.72 & 2.38 & 2.70 & 2.21 & 1.89 & 2.37 & 1.54 & 2.10 & 2.43 & 1.81 \\
\hline Glove 3 & 2.13 & 2.36 & 2.88 & 2.89 & 2.91 & 2.76 & 2.49 & 2.90 & 2.22 & 2.06 & 2.61 & 1.93 & 1.96 & 2.54 & 2.01 \\
\hline
\end{tabular}


APPENDIX XII: Normalized Mean Absolute Value

\begin{tabular}{|c|c|c|c|c|c|c|}
\hline Participant & Glove Condition & $\mathrm{ED}$ & $\overline{\mathrm{ECR}}$ & FDS & FCR & Total NMAV \\
\hline 1 & Bare hand & $11.11 \%$ & $10.67 \%$ & $14.87 \%$ & $10.28 \%$ & $46.94 \%$ \\
\hline 2 & Bare hand & $19.29 \%$ & $5.83 \%$ & $6.15 \%$ & $10.65 \%$ & $41.92 \%$ \\
\hline 3 & Bare hand & $13.72 \%$ & $2.71 \%$ & $4.36 \%$ & $12.25 \%$ & $33.04 \%$ \\
\hline 4 & Bare hand & $20.56 \%$ & $12.54 \%$ & $12.33 \%$ & $20.56 \%$ & $65.99 \%$ \\
\hline 5 & Bare hand & $19.26 \%$ & $3.49 \%$ & $4.44 \%$ & $27.72 \%$ & $54.92 \%$ \\
\hline 6 & Bare hand & $11.94 \%$ & $8.75 \%$ & $12.13 \%$ & $15.99 \%$ & $48.81 \%$ \\
\hline 7 & Bare hand & $10.68 \%$ & $5.42 \%$ & $5.49 \%$ & $17.66 \%$ & $39.26 \%$ \\
\hline 8 & Bare hand & $5.49 \%$ & $4.53 \%$ & $6.55 \%$ & $11.06 \%$ & $27.63 \%$ \\
\hline 9 & Bare hand & $16.11 \%$ & $5.29 \%$ & $11.97 \%$ & $21.50 \%$ & $54.87 \%$ \\
\hline 10 & Bare hand & $21.85 \%$ & $12.36 \%$ & $8.08 \%$ & $16.78 \%$ & $59.07 \%$ \\
\hline 11 & Bare hand & $19.06 \%$ & $10.17 \%$ & $23.34 \%$ & $25.77 \%$ & $78.33 \%$ \\
\hline 12 & Bare hand & $14.34 \%$ & $4.13 \%$ & $12.28 \%$ & $22.84 \%$ & $53.59 \%$ \\
\hline 13 & Bare hand & $19.78 \%$ & $7.36 \%$ & $4.60 \%$ & $26.74 \%$ & $58.48 \%$ \\
\hline 14 & Bare hand & $21.92 \%$ & $5.74 \%$ & $11.50 \%$ & $18.71 \%$ & $57.87 \%$ \\
\hline 15 & Bare hand & $17.47 \%$ & $4.52 \%$ & $6.74 \%$ & $14.74 \%$ & $43.47 \%$ \\
\hline 1 & Glove 1 & $13.21 \%$ & $17.68 \%$ & $18.97 \%$ & $13.22 \%$ & $63.08 \%$ \\
\hline
\end{tabular}




\begin{tabular}{|c|c|c|c|c|c|c|}
\hline 2 & Glove 1 & $20.69 \%$ & $9.11 \%$ & $9.48 \%$ & $13.70 \%$ & $52.98 \%$ \\
\hline 3 & Glove 1 & $14.48 \%$ & $5.09 \%$ & $8.45 \%$ & $13.20 \%$ & $41.22 \%$ \\
\hline 4 & Glove 1 & $22.45 \%$ & $14.14 \%$ & $14.65 \%$ & $21.95 \%$ & $73.18 \%$ \\
\hline 5 & Glove 1 & $19.92 \%$ & $4.33 \%$ & $7.93 \%$ & $28.53 \%$ & $60.71 \%$ \\
\hline 6 & Glove 1 & $13.04 \%$ & $9.71 \%$ & $12.17 \%$ & $21.27 \%$ & $56.20 \%$ \\
\hline 7 & Glove 1 & $13.25 \%$ & $7.29 \%$ & $8.76 \%$ & $20.12 \%$ & $49.43 \%$ \\
\hline 8 & Glove 1 & $6.03 \%$ & $5.52 \%$ & $8.34 \%$ & $11.41 \%$ & $31.31 \%$ \\
\hline 9 & Glove 1 & $16.10 \%$ & $7.51 \%$ & $12.66 \%$ & $22.88 \%$ & $59.15 \%$ \\
\hline 10 & Glove 1 & $23.89 \%$ & $15.33 \%$ & $10.16 \%$ & $18.92 \%$ & $68.30 \%$ \\
\hline 11 & Glove 1 & $22.10 \%$ & $15.72 \%$ & $27.29 \%$ & $28.23 \%$ & $93.35 \%$ \\
\hline 12 & Glove 1 & $14.45 \%$ & $4.65 \%$ & $12.78 \%$ & $22.51 \%$ & $54.40 \%$ \\
\hline 13 & Glove 1 & $21.59 \%$ & $10.26 \%$ & $8.61 \%$ & $28.37 \%$ & $68.83 \%$ \\
\hline 14 & Glove 1 & $24.61 \%$ & $8.51 \%$ & $11.62 \%$ & $18.74 \%$ & $63.48 \%$ \\
\hline 15 & Glove 1 & $16.62 \%$ & $6.66 \%$ & $9.04 \%$ & $15.36 \%$ & $47.69 \%$ \\
\hline 1 & Glove 2 & $23.54 \%$ & $22.91 \%$ & $32.83 \%$ & $14.75 \%$ & $94.03 \%$ \\
\hline 2 & Glove 2 & $23.00 \%$ & $7.15 \%$ & $10.17 \%$ & $13.71 \%$ & $54.04 \%$ \\
\hline 3 & Glove 2 & $13.66 \%$ & $4.24 \%$ & $6.16 \%$ & $12.97 \%$ & $37.04 \%$ \\
\hline 4 & Glove 2 & $20.89 \%$ & $12.81 \%$ & $12.46 \%$ & $20.57 \%$ & $66.73 \%$ \\
\hline 5 & Glove 2 & $19.46 \%$ & $4.37 \%$ & $5.85 \%$ & $28.20 \%$ & $57.88 \%$ \\
\hline 7 & Glove 2 & $11.46 \%$ & $6.64 \%$ & $8.76 \%$ & $19.07 \%$ & $45.93 \%$ \\
\hline
\end{tabular}




\begin{tabular}{|c|c|c|c|c|c|c|}
\hline 8 & Glove 2 & $6.65 \%$ & $6.87 \%$ & $9.46 \%$ & $11.83 \%$ & $34.80 \%$ \\
\hline 9 & Glove 2 & $16.79 \%$ & $7.07 \%$ & $13.61 \%$ & $22.12 \%$ & $59.59 \%$ \\
\hline 10 & Glove 2 & $23.36 \%$ & $14.06 \%$ & $10.03 \%$ & $18.34 \%$ & $65.80 \%$ \\
\hline 11 & Glove 2 & $23.68 \%$ & $11.08 \%$ & $24.10 \%$ & $27.87 \%$ & $86.74 \%$ \\
\hline 12 & Glove 2 & $15.24 \%$ & $5.05 \%$ & $13.98 \%$ & $22.63 \%$ & $56.90 \%$ \\
\hline 13 & Glove 2 & $20.77 \%$ & $7.97 \%$ & $5.38 \%$ & $27.82 \%$ & $61.95 \%$ \\
\hline 14 & Glove 2 & $23.57 \%$ & $9.70 \%$ & $11.80 \%$ & $19.00 \%$ & $64.07 \%$ \\
\hline 15 & Glove 2 & $23.55 \%$ & $5.82 \%$ & $7.93 \%$ & $14.99 \%$ & $52.30 \%$ \\
\hline 1 & Glove 3 & $20.77 \%$ & $24.25 \%$ & $31.38 \%$ & $15.48 \%$ & $91.89 \%$ \\
\hline 2 & Glove 3 & $21.11 \%$ & $11.50 \%$ & $13.52 \%$ & $14.99 \%$ & $61.12 \%$ \\
\hline 3 & Glove 3 & $14.44 \%$ & $5.61 \%$ & $11.67 \%$ & $13.63 \%$ & $45.34 \%$ \\
\hline 4 & Glove 3 & $21.83 \%$ & $13.79 \%$ & $13.33 \%$ & $21.51 \%$ & $70.46 \%$ \\
\hline 5 & Glove 3 & $23.32 \%$ & $5.81 \%$ & $6.96 \%$ & $29.26 \%$ & $65.35 \%$ \\
\hline 6 & Glove 3 & $15.07 \%$ & $13.39 \%$ & $13.85 \%$ & $19.90 \%$ & $62.22 \%$ \\
\hline 7 & Glove 3 & $14.58 \%$ & $7.38 \%$ & $9.95 \%$ & $20.15 \%$ & $52.06 \%$ \\
\hline 8 & Glove 3 & $7.20 \%$ & $7.68 \%$ & $9.83 \%$ & $12.49 \%$ & $37.20 \%$ \\
\hline 9 & Glove 3 & $18.78 \%$ & $11.12 \%$ & $12.89 \%$ & $26.03 \%$ & $68.82 \%$ \\
\hline 10 & Glove 3 & $23.77 \%$ & $15.40 \%$ & $10.22 \%$ & $19.04 \%$ & $68.43 \%$ \\
\hline 11 & Glove 3 & $20.76 \%$ & $15.46 \%$ & $24.96 \%$ & $26.49 \%$ & $87.67 \%$ \\
\hline 12 & Glove 3 & $15.50 \%$ & $6.01 \%$ & $13.06 \%$ & $22.99 \%$ & $57.57 \%$ \\
\hline
\end{tabular}




\begin{tabular}{|l|l|l|l|l|l|l|}
\hline 13 & Glove 3 & $21.51 \%$ & $10.44 \%$ & $8.22 \%$ & $29.10 \%$ & $69.27 \%$ \\
\hline 14 & Glove 3 & $23.79 \%$ & $11.15 \%$ & $13.40 \%$ & $20.92 \%$ & $69.27 \%$ \\
\hline 15 & Glove 3 & $21.97 \%$ & $6.29 \%$ & $7.98 \%$ & $16.55 \%$ & $52.80 \%$ \\
\hline
\end{tabular}


APPENDIX XIII: Percentage Drop in Median Frequency

\begin{tabular}{|c|c|c|c|c|c|c|}
\hline Participant & Glove Condition & ED & ECR & FDS & FCR & $\begin{array}{c}\text { Average } \% \text { drop in } \\
\text { MF }\end{array}$ \\
\hline 1 & Bare hand & $-19.49 \%$ & $-8.46 \%$ & $-23.91 \%$ & $-19.42 \%$ & $-17.82 \%$ \\
\hline 2 & Bare hand & $-22.48 \%$ & $-30.48 \%$ & $-27.90 \%$ & $-26.12 \%$ & $-26.74 \%$ \\
\hline 3 & Bare hand & $8.85 \%$ & $-14.62 \%$ & $-4.26 \%$ & $-9.67 \%$ & $-4.92 \%$ \\
\hline 4 & Bare hand & $2.45 \%$ & $-7.61 \%$ & $-3.30 \%$ & $-11.11 \%$ & $-4.89 \%$ \\
\hline 5 & Bare hand & $0.10 \%$ & $-10.84 \%$ & $-22.07 \%$ & $-18.59 \%$ & $-12.85 \%$ \\
\hline 6 & Bare hand & $-14.42 \%$ & $-14.28 \%$ & $-13.87 \%$ & $-18.20 \%$ & $-15.19 \%$ \\
\hline 7 & Bare hand & $-2.42 \%$ & $-14.55 \%$ & $-16.09 \%$ & $-16.14 \%$ & $-12.30 \%$ \\
\hline 8 & Bare hand & $-12.11 \%$ & $-0.99 \%$ & $-5.48 \%$ & $2.97 \%$ & $-3.90 \%$ \\
\hline 9 & Bare hand & $-30.72 \%$ & $-18.58 \%$ & $-9.57 \%$ & $-10.89 \%$ & $-17.44 \%$ \\
\hline 10 & Bare hand & $4.83 \%$ & $23.77 \%$ & $-4.34 \%$ & $-6.92 \%$ & $4.34 \%$ \\
\hline 11 & Bare hand & $-9.5 \%$ & $-17.4 \%$ & $-1.8 \%$ & $-7.2 \%$ & $-8.97 \%$ \\
\hline 12 & Bare hand & $7.32 \%$ & $5.34 \%$ & $*$ & $0.83 \%$ & $4.49 \%$ \\
\hline 13 & Bare hand & $-17.46 \%$ & $-12.20 \%$ & $1.37 \%$ & $-11.77 \%$ & $-10.01 \%$ \\
\hline 14 & Bare hand & $-3.67 \%$ & $-2.15 \%$ & $-6.28 \%$ & $-21.11 \%$ & $-8.30 \%$ \\
\hline 15 & Bare hand & $8.16 \%$ & $-13.63 \%$ & $-10.53 \%$ & $-23.62 \%$ & $-9.90 \%$ \\
\hline
\end{tabular}




\begin{tabular}{|c|c|c|c|c|c|c|}
\hline 1 & Glove 1 & $-48.81 \%$ & $-37.96 \%$ & $-35.03 \%$ & $-58.65 \%$ & $-45.11 \%$ \\
\hline 2 & Glove 1 & $-44.13 \%$ & $-48.13 \%$ & $-33.92 \%$ & $-43.37 \%$ & $-42.39 \%$ \\
\hline 3 & Glove 1 & $8.45 \%$ & $-9.96 \%$ & $-25.35 \%$ & $-25.65 \%$ & $-13.13 \%$ \\
\hline 4 & Glove 1 & $-23.17 \%$ & $-23.52 \%$ & $-19.14 \%$ & $-61.14 \%$ & $-31.74 \%$ \\
\hline 5 & Glove 1 & $-12.14 \%$ & $-16.96 \%$ & $-18.42 \%$ & $-23.86 \%$ & $-17.84 \%$ \\
\hline 6 & Glove 1 & $-14.19 \%$ & $-18.96 \%$ & $-11.61 \%$ & $-22.78 \%$ & $-16.89 \%$ \\
\hline 7 & Glove 1 & $-10.24 \%$ & $-10.47 \%$ & $-10.19 \%$ & $-17.22 \%$ & $-12.03 \%$ \\
\hline 8 & Glove 1 & $-12.47 \%$ & $-3.28 \%$ & $0.38 \%$ & $-8.20 \%$ & $-5.89 \%$ \\
\hline 9 & Glove 1 & $-14.27 \%$ & $-20.06 \%$ & $-6.55 \%$ & $-12.14 \%$ & $-13.25 \%$ \\
\hline 10 & Glove 1 & $14.89 \%$ & $-9.14 \%$ & $8.23 \%$ & $-9.69 \%$ & $1.07 \%$ \\
\hline 11 & Glove 1 & $-19.8 \%$ & $-19.9 \%$ & $-18.3 \%$ & $0.8 \%$ & $-14.30 \%$ \\
\hline 12 & Glove 1 & $0.42 \%$ & $1.99 \%$ & $1.88 \%$ & $-19.20 \%$ & $-3.73 \%$ \\
\hline 13 & Glove 1 & $-13.13 \%$ & $-19.53 \%$ & $-9.05 \%$ & $-16.69 \%$ & $-14.60 \%$ \\
\hline 14 & Glove 1 & $-15.73 \%$ & $-22.13 \%$ & $-18.08 \%$ & $-25.36 \%$ & $-20.32 \%$ \\
\hline 15 & Glove 1 & $-11.18 \%$ & $-30.78 \%$ & $-29.43 \%$ & $-23.18 \%$ & $-23.64 \%$ \\
\hline 1 & Glove 2 & $-50.00 \%$ & $-41.64 \%$ & $-39.90 \%$ & $-45.60 \%$ & $-44.28 \%$ \\
\hline 2 & Glove 2 & $-51.62 \%$ & $-55.51 \%$ & $-35.05 \%$ & $-36.42 \%$ & $-44.65 \%$ \\
\hline 3 & Glove 2 & $-12.50 \%$ & $-22.66 \%$ & $-11.31 \%$ & $-21.12 \%$ & $-16.90 \%$ \\
\hline 4 & Glove 2 & $-11.73 \%$ & $-3.40 \%$ & $-13.14 \%$ & $-70.05 \%$ & $-24.58 \%$ \\
\hline 5 & Glove 2 & $-20.04 \%$ & $-19.61 \%$ & $-15.76 \%$ & $-17.97 \%$ & $-18.35 \%$ \\
\hline
\end{tabular}




\begin{tabular}{|c|c|c|c|c|c|c|}
\hline 6 & Glove 2 & $-31.88 \%$ & $-32.79 \%$ & $-6.18 \%$ & $-13.30 \%$ & $-21.04 \%$ \\
\hline 7 & Glove 2 & $-16.12 \%$ & $-4.71 \%$ & $-17.65 \%$ & $-7.10 \%$ & $-11.40 \%$ \\
\hline 8 & Glove 2 & $-22.79 \%$ & $-1.13 \%$ & $-10.79 \%$ & $-23.51 \%$ & $-14.55 \%$ \\
\hline 9 & Glove 2 & $-1.27 \%$ & $-17.33 \%$ & $1.08 \%$ & $-14.88 \%$ & $-8.10 \%$ \\
\hline 10 & Glove 2 & $9.56 \%$ & $-6.22 \%$ & $2.58 \%$ & $2.37 \%$ & $2.07 \%$ \\
\hline 11 & Glove 2 & $-14.3 \%$ & $-17.1 \%$ & $11.3 \%$ & $-12.7 \%$ & $-8.22 \%$ \\
\hline 12 & Glove 2 & $2.20 \%$ & $-10.88 \%$ & $-17.31 \%$ & $-3.90 \%$ & $-7.47 \%$ \\
\hline 13 & Glove 2 & $-26.41 \%$ & $-22.36 \%$ & $3.12 \%$ & $-0.42 \%$ & $-11.52 \%$ \\
\hline 14 & Glove 2 & $-11.81 \%$ & $-22.96 \%$ & $2.19 \%$ & $-12.05 \%$ & $-11.16 \%$ \\
\hline 15 & Glove 2 & $-6.52 \%$ & $-24.14 \%$ & $-24.58 \%$ & $-22.05 \%$ & $-19.32 \%$ \\
\hline 1 & Glove 3 & $-50.65 \%$ & $-54.58 \%$ & $-45.04 \%$ & $-60.07 \%$ & $-52.59 \%$ \\
\hline 2 & Glove 3 & $-48.81 \%$ & $-66.59 \%$ & $-43.70 \%$ & $-58.95 \%$ & $-54.51 \%$ \\
\hline 3 & Glove 3 & $-17.13 \%$ & $-22.50 \%$ & $-19.89 \%$ & $-0.10 \%$ & $-14.91 \%$ \\
\hline 4 & Glove 3 & $-30.33 \%$ & $-7.98 \%$ & $-18.18 \%$ & $-76.22 \%$ & $-33.18 \%$ \\
\hline 5 & Glove 3 & $-4.71 \%$ & $-27.91 \%$ & $-26.19 \%$ & $-38.39 \%$ & $-24.30 \%$ \\
\hline 6 & Glove 3 & $-28.75 \%$ & $-24.86 \%$ & $-20.81 \%$ & $-31.92 \%$ & $-26.58 \%$ \\
\hline 7 & Glove 3 & $-10.80 \%$ & $-18.26 \%$ & $-20.81 \%$ & $-15.58 \%$ & $-16.36 \%$ \\
\hline 8 & Glove 3 & $-14.08 \%$ & $-15.49 \%$ & $-13.64 \%$ & $-0.97 \%$ & $-11.04 \%$ \\
\hline 9 & Glove 3 & $-11.45 \%$ & $-30.32 \%$ & $-20.33 \%$ & $-31.58 \%$ & $-23.42 \%$ \\
\hline 10 & Glove 3 & $-1.12 \%$ & $-2.14 \%$ & $-0.44 \%$ & $-3.11 \%$ & $-1.70 \%$ \\
\hline
\end{tabular}




\begin{tabular}{|l|l|l|l|l|l|l|}
\hline 11 & Glove 3 & $-13.9 \%$ & $-11.7 \%$ & $-3.0 \%$ & $-1.0 \%$ & $-7.38 \%$ \\
\hline 12 & Glove 3 & $-4.50 \%$ & $4.91 \%$ & $*$ & $6.44 \%$ & $2.28 \%$ \\
\hline 13 & Glove 3 & $-23.28 \%$ & $-14.79 \%$ & $-54.14 \%$ & $-54.64 \%$ \\
\hline 14 & Glove 3 & $-15.62 \%$ & $-24.39 \%$ & $-27.53 \%$ & $-22.89 \%$ & $-22.61 \%$ \\
\hline 15 & Glove 3 & $-12.74 \%$ & $-30.11 \%$ & $-23.92 \%$ & $-28.57 \%$ & $-23.84 \%$ \\
\hline
\end{tabular}


APPENDIX XIV: Subjective Assessment of Perceived exertion

\begin{tabular}{|c|c|c|c|c|c|c|c|c|c|c|c|c|c|c|c|}
\hline \multirow{2}{*}{ Perceived exertion } & \multicolumn{15}{|c|}{ Participant } \\
\hline & 1 & 2 & 3 & 4 & 5 & 6 & 7 & 8 & 9 & 10 & 11 & 12 & 13 & 14 & 15 \\
\hline Bare Hand & 1 & $\overline{0}$ & 2 & 3 & 4 & 0.5 & 0.5 & 3 & 7 & 2 & 4 & 3 & 3 & 3 & 4 \\
\hline Glove 1 & 2 & 3 & 2 & 8 & 3 & 2 & 3 & 7 & 5 & 6 & 7 & 3 & 7 & 5 & 4 \\
\hline Glove 2 & 3 & 4 & 4 & 4 & 4 & 1 & 2 & 7 & 6 & 5 & 3 & 4 & 6 & 5 & 5 \\
\hline Glove 3 & 2 & 7 & 5 & 7 & 3 & 3 & 4 & 8 & 9 & 4 & 7 & 7 & 8 & 7 & 7 \\
\hline
\end{tabular}

